University of Tennessee Health Science Center UTHSC Digital Commons

\title{
Pandemic Potential of Reassortant Swine Influenza A Viruses
}

Christy Brockwell Staats

University of Tennessee Health Science Center

Follow this and additional works at: https://dc.uthsc.edu/dissertations

Part of the Animal Diseases Commons, Medical Sciences Commons, Public Health Commons, and the Virus Diseases Commons

\section{Recommended Citation}

Staats, Christy Brockwell , "Pandemic Potential of Reassortant Swine Influenza A Viruses" (2009). Theses and Dissertations (ETD). Paper 245. http://dx.doi.org/10.21007/etd.cghs.2009.0296.

This Dissertation is brought to you for free and open access by the College of Graduate Health Sciences at UTHSC Digital Commons. It has been accepted for inclusion in Theses and Dissertations (ETD) by an authorized administrator of UTHSC Digital Commons. For more information, please contact jwelch30@uthsc.edu. 


\title{
Pandemic Potential of Reassortant Swine Influenza A Viruses
}

\begin{abstract}
Influenza A viruses are capable of causing disease in several species, including birds, humans and swine. Host specificity of the viruses is not absolute, and is influenced by a range of factors. Swine play a pivotal role in the interspecies transmission of influenza A viruses, as they are susceptible to infection with both human and avian strains and have been implicated as a "mixing vessel" for the reassortment of influenza $A$ viruses from different species. The reassortment of influenza A viruses of human and avian origin led to human influenza pandemics in 1957 and 1968.
\end{abstract}

The dynamics of swine influenza viruses in North America changed drastically with the introduction of the avian-origin PA and PB2 and human-origin HA, NA, and PB1 gene segments and the creation of the triple reassortant swine virus lineage in 1998. While the previously circulating classical swine H1N1 influenza virus lineage was very stable in the swine population, triple reassortant lineage viruses have supplanted the classical $\mathrm{H} 1 \mathrm{~N} 1$ lineage and undergone repeated reassortment events, acquiring HA and NA genes from human, swine, and avian influenza viruses, while maintaining triple reassortant internal gene (TRIG) cassette. Viruses of the triple reassortant lineage have been very successful in the swine population, yet the mechanisms underlying their unique characteristics and increased fitness have not been elucidated.

Here we address the pandemic potential of triple reassortant swine influenza A viruses, their transmissibility, and their relative fitness compared to classical and double reassortant swine influenza viruses. Several triple reassortant viruses, including one with avian-origin HA and NA, were characterized in the ferret, which is a commonly used model for human influenza infection. The effect of the TRIG cassette on the reassortment potential and temperature sensitivity of swine influenza viruses was determined in cell culture, and the replication and transmission of a classical and a reassortant swine virus were compared in pigs.

We found that triple reassortant swine viruses replicated efficiently in the ferret model, although there was some variation in transmission efficiencies. An H2N3 virus with avian-origin $\mathrm{HA}$ and NA was transmissible in the ferret model, and this transmissibility could be abolished with a single amino acid change in the HA protein that altered its receptor binding specificity. Avian $\mathrm{H} 2 \mathrm{~N} 3$ viruses were also capable of replicating in ferrets without adaptation and could acquire transmissibility through a change in the receptor binding specificity of the HA protein.

Both double and triple reassortant swine viruses had an advantage over the classical H1N1 swine virus at early timepoints in cell culture. Reassortant viruses also demonstrated less temperature sensitivity than the classical $\mathrm{H} 1 \mathrm{~N} 1$ swine virus. The triple reassortant $\mathrm{H} 1 \mathrm{~N} 1$ virus had an increased reassortment potential in cell culture compared to the classical swine $\mathrm{H} 1 \mathrm{~N} 1$ virus as determined by acquisition of a human HA gene.

Triple reassortant swine viruses have an increased ability to establish infection, and an increased potential for reassortment, potentially introducing novel HA genes into a host population. This indicates that triple reassortant swine viruses may have an increased potential to cause human pandemics. In April 2009, a novel H1N1 pandemic virus containing five of the six genes of the TRIG cassette emerged in the human population, emphasizing the importance of reassortant swine influenza $A$ viruses in the generation of human pandemics.

\section{Document Type}

Dissertation 


\section{Degree Name}

Doctor of Philosophy (PhD)

\section{Program}

Biomedical Sciences

\section{Research Advisor}

Richard J. Webby, PhD

\section{Keywords}

Influenza, Pandemic, Reassortment, Swine, Zoonosis

\section{Subject Categories}

Animal Diseases | Diseases | Medical Sciences | Medicine and Health Sciences | Public Health | Virus Diseases 


\title{
PANDEMIC POTENTIAL OF REASSORTANT SWINE INFLUENZA A VIRUSES
}

\author{
A Dissertation \\ Presented for \\ The Graduate Studies Council \\ The University of Tennessee \\ Health Science Center

\begin{abstract}
In Partial Fulfillment
Of the Requirements for the Degree

Doctor of Philosophy

From The University of Tennessee
\end{abstract}

By

Christy Brockwell Staats

December 2009 
Portions of Chapter 1 (C) 2009 by Wiley-Blackwell. All other material (C) 2009 by Christy Brockwell Staats. 


\section{DEDICATION}

This dissertation is dedicated to my husband, Jason Staats, who has been my rock

through the hardest years of this process, and to my parents Beth and Bill Brockwell, who have supported and encouraged me always. 


\section{ACKNOWLEDGEMENTS}

I would like to thank my advisor, Dr. Richard Webby, for giving me the opportunity to work in his lab and for the excellent training I have received. I would also like to thank my committee members, Dr. Kelli Boyd, Dr. Jon McCullers, Dr. Lawrence Pfeffer, and Dr. Patrick Ryan for their guidance and support during my studies.

Thanks also to all of the members of the Flu Group at St. Jude Children's Research Hospital, but especially Mariette Ducatez, Stephanie Sonnberg, Ashley Webb, Yolanda Griffin, Jennifer DeBeauchamp, Evelyn Stigger-Rosser, Jacco Boon, and John Franks, not only for excellent help and advice, but for your friendship as well.

This work was funded by the National Institute of Allergy and Infectious Diseases, the National Institutes of Health, under contract number HHSN266200700005C, and the American Lebanese Syrian Associated Charities (ALSAC). 


\begin{abstract}
Influenza A viruses are capable of causing disease in several species, including birds, humans and swine. Host specificity of the viruses is not absolute, and is influenced by a range of factors. Swine play a pivotal role in the interspecies transmission of influenza A viruses, as they are susceptible to infection with both human and avian strains and have been implicated as a "mixing vessel" for the reassortment of influenza A viruses from different species. The reassortment of influenza A viruses of human and avian origin led to human influenza pandemics in 1957 and 1968.
\end{abstract}

The dynamics of swine influenza viruses in North America changed drastically with the introduction of the avian-origin PA and PB2 and human-origin HA, NA, and PB1 gene segments and the creation of the triple reassortant swine virus lineage in 1998. While the previously circulating classical swine H1N1 influenza virus lineage was very stable in the swine population, triple reassortant lineage viruses have supplanted the classical H1N1 lineage and undergone repeated reassortment events, acquiring HA and NA genes from human, swine, and avian influenza viruses, while maintaining triple reassortant internal gene (TRIG) cassette. Viruses of the triple reassortant lineage have been very successful in the swine population, yet the mechanisms underlying their unique characteristics and increased fitness have not been elucidated.

Here we address the pandemic potential of triple reassortant swine influenza A viruses, their transmissibility, and their relative fitness compared to classical and double reassortant swine influenza viruses. Several triple reassortant viruses, including one with avian-origin HA and NA, were characterized in the ferret, which is a commonly used model for human influenza infection. The effect of the TRIG cassette on the reassortment potential and temperature sensitivity of swine influenza viruses was determined in cell culture, and the replication and transmission of a classical and a reassortant swine virus were compared in pigs.

We found that triple reassortant swine viruses replicated efficiently in the ferret model, although there was some variation in transmission efficiencies. An H2N3 virus with avian-origin HA and NA was transmissible in the ferret model, and this transmissibility could be abolished with a single amino acid change in the HA protein that altered its receptor binding specificity. Avian $\mathrm{H} 2 \mathrm{~N} 3$ viruses were also capable of replicating in ferrets without adaptation and could acquire transmissibility through a change in the receptor binding specificity of the HA protein.

Both double and triple reassortant swine viruses had an advantage over the classical H1N1 swine virus at early timepoints in cell culture. Reassortant viruses also demonstrated less temperature sensitivity than the classical H1N1 swine virus. The triple reassortant $\mathrm{H} 1 \mathrm{~N} 1$ virus had an increased reassortment potential in cell culture compared to the classical swine H1N1 virus as determined by acquisition of a human HA gene. 
Triple reassortant swine viruses have an increased ability to establish infection, and an increased potential for reassortment, potentially introducing novel HA genes into a host population. This indicates that triple reassortant swine viruses may have an increased potential to cause human pandemics. In April 2009, a novel H1N1 pandemic virus containing five of the six genes of the TRIG cassette emerged in the human population, emphasizing the importance of reassortant swine influenza A viruses in the generation of human pandemics. 


\section{TABLE OF CONTENTS}

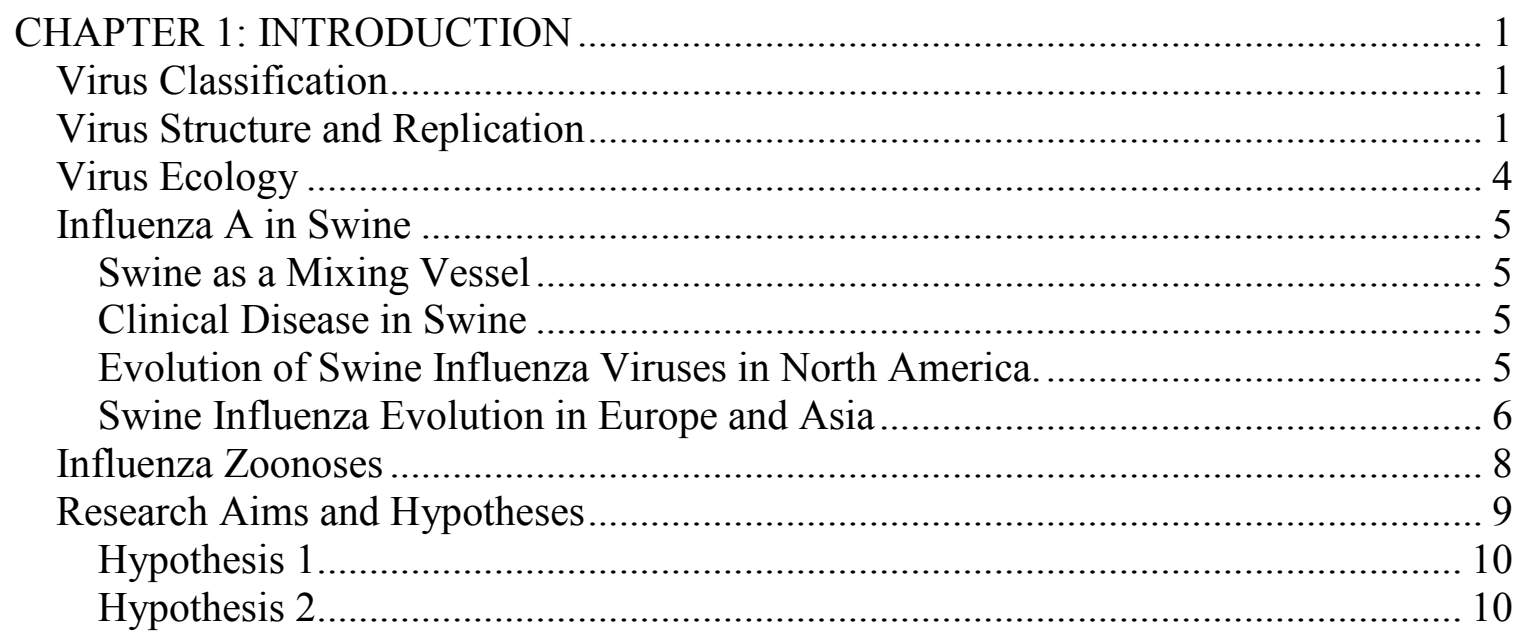

\section{CHAPTER 2: TRANSMISSIBILITY OF A NOVEL H2N3 SWINE INFLUENZA}

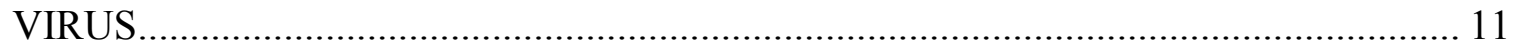

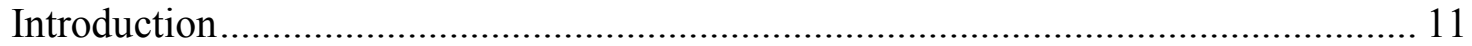

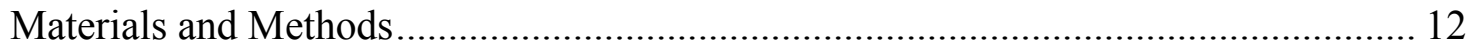

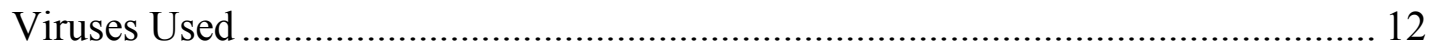

Generation of Reverse Genetics Viruses .............................................................. 13

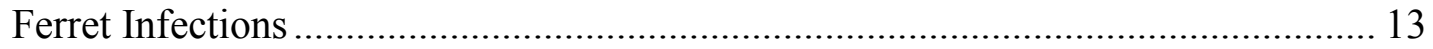

Hemagglutination Inhibition (HI) Assays............................................................ 13

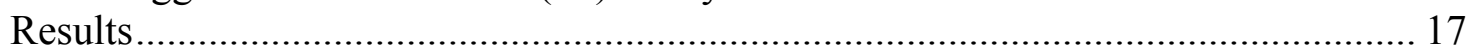

Swine H2N3 Viruses Are Transmissible in Ferrets................................................. 17

Avian H2N3 Viruses Replicate in Ferrets but Do Not Transmit Efficiently............ 17

A Single Amino Acid Change in the HA Abolishes the Ability of a Swine

H2N3 Virus to Transmit in Ferrets................................................................. 22

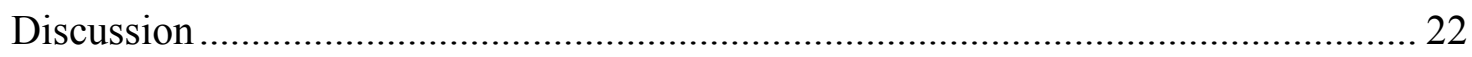

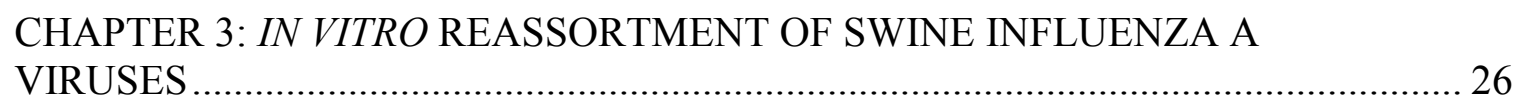

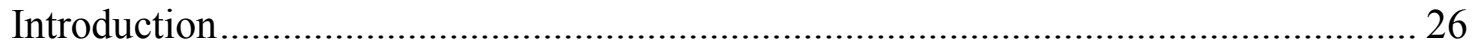

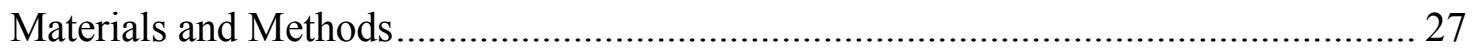

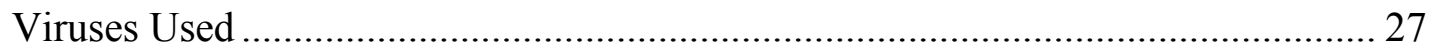

Co-infection of MDCK Cells................................................................................ 29

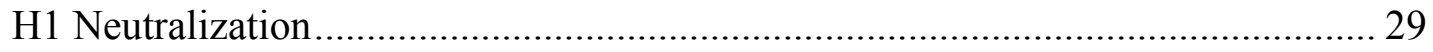

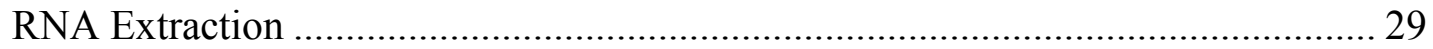

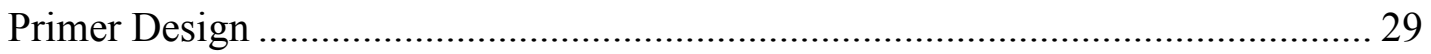

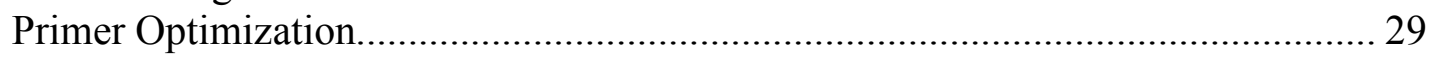

Detection of Reassortant Viruses...................................................................... 32

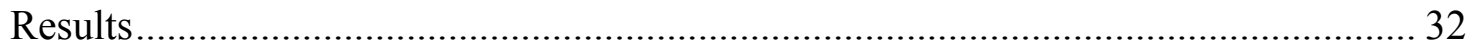

No Detectable Reassortment of a Classical Swine H1N1 Virus................................. 32

High Frequency of Reassortment of a Reassortant Swine H1N1 Virus .................... 32

Optimal Conditions for Human/Swine Virus Reassortment....................................... 38 
Discussion

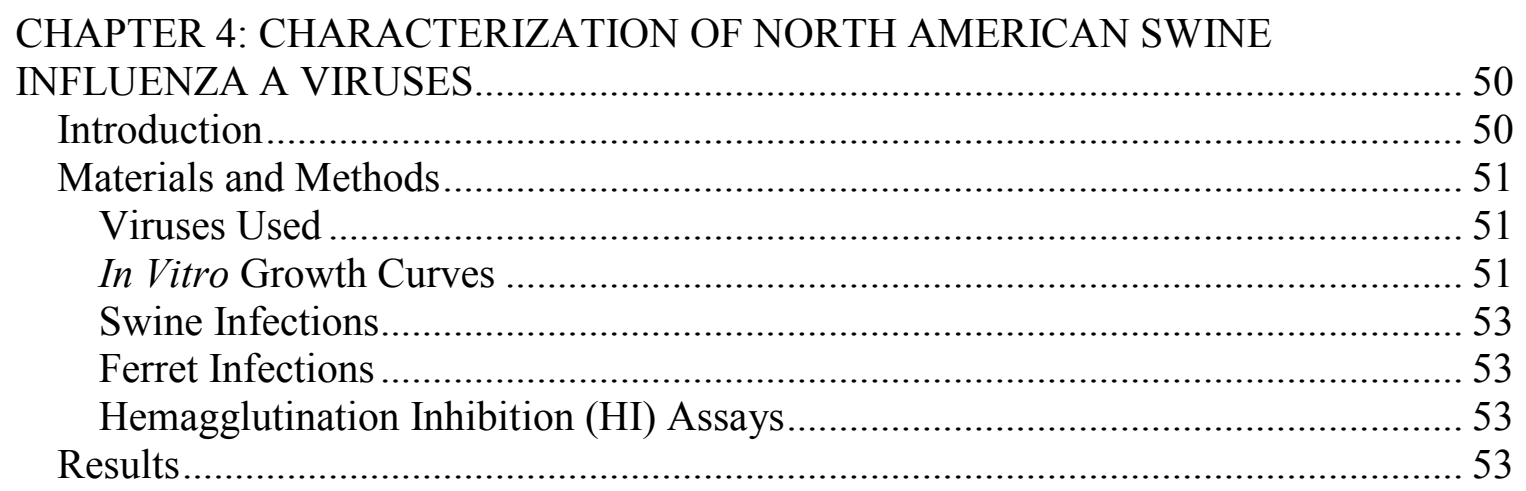

Reassortant Swine Viruses Have Improved Growth Kinetics at Early

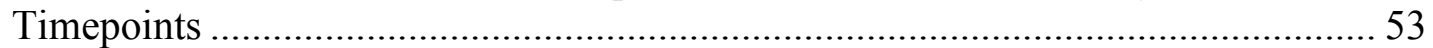

Swine Viruses Differ in Temperature Sensitivity In Vitro ..................................... 54

A Human H3N2 Influenza A Virus Inefficiently Infects Swine............................. 57

A Reassortant H1N1 Swine Virus Does Not Have an Advantage over a

Classical H1N1 Swine Virus in the Nasal Cavity of Swine .................................. 60

Triple Reassortant Lineage Swine Influenza Viruses Can Replicate and

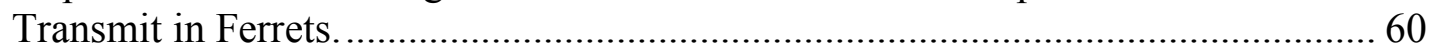

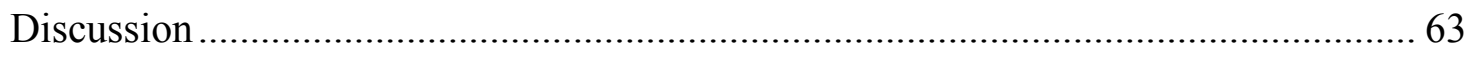

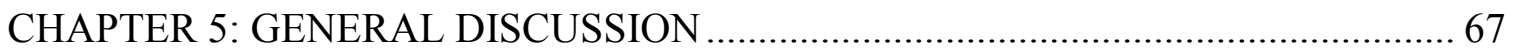

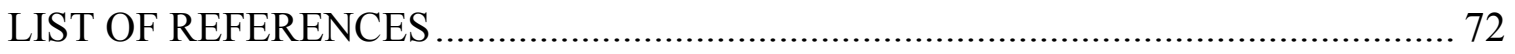

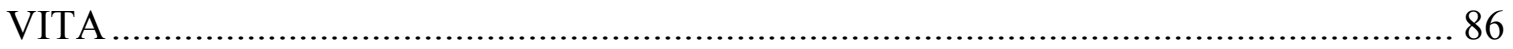




\section{LIST OF TABLES}

Table 1-1. Influenza A Viruses Isolated from North American Swine since 1998...... 7

Table 2-1. $\quad$ H2N3 Viruses Rescued Using Reverse Genetics.................................. 16

Table 2-2. Weight Loss, Peak Viral Titers, and Serum HI Titers of Inoculated Ferrets .................................................................................................... 19

Table 2-3. Weight Loss, Peak Viral Titers, and Serum HI Titers of Contact Ferrets 19

Table 3-1. Primer Sequences and PCR Conditions Used to Detect Reassortant Viruses 


\section{LIST OF FIGURES}

Figure 1-1. Schematic of the Influenza A Virus Particle.............................................. 2

Figure 2-1. Eight Plasmid Reverse Genetics System ............................................... 14

Figure 2-2. Swine H2N3 Viruses Replicate and Transmit in Ferrets ......................... 18

Figure 2-3. Avian H2N3 Viruses Replicate but Do Not Transmit Efficiently in Ferrets

Figure 2-4. A Receptor Binding Mutant Swine H2N3 Virus Replicates but Does Not Efficiently Transmit in Ferrets.......................................................... 23

Figure 2-5. Amino Acid Differences in the Amino Acid Sequences of Avian, Swine, and Human $\mathrm{H} 2$ Viruses.

Figure 3-1. Swine Viruses Used for Reassortment Studies ......................................... 28

Figure 3-2. Combinations of Human and Swine Virus Inoculums Used to Infect

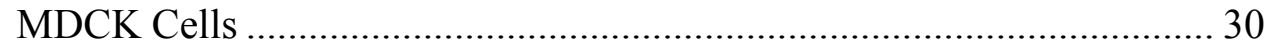

Figure 3-3. M Gene PCR on TX/96 + SW/MN/99 Co-infection Supernatants........... 33

Figure 3-4. H1 Gene PCR on TX/96 + SW/MN/99 Co-infection Supernatants ......... 34

Figure 3-5. H3 Gene PCR on TX/96 + SW/MN/99 Co-infection Supernatants ......... 35

Figure 3-6. PA Gene PCR on TX/96 + SW/MN/99 Co-infection Supernatants ......... 36

Figure 3-7. PB2 Gene PCR on TX/96 + SW/MN/99 Co-infection Supernatants ....... 37

Figure 3-8. M Gene PCR on TX/96 + SW/NC/02 Co-infection Supernatants............ 39

Figure 3-9. H1 Gene PCR on TX/96 + SW/NC/02 Co-infection Supernatants .......... 40

Figure 3-10. H3 Gene PCR on TX/96 + SW/NC/02 Co-infection Supernatants .......... 41

Figure 3-11. PA Gene PCR on TX/96 + SW/NC/02 Co-infection Supernatants .......... 42

Figure 3-12. PB2 Gene PCR on TX/96 + SW/NC/02 Co-infection Supernatants ........ 43

Figure 3-13. Conditions under Which Reassortant Viruses Were Detected .................. 44

Figure 4-1. Swine Viruses Characterized In Vitro..................................................... 52 


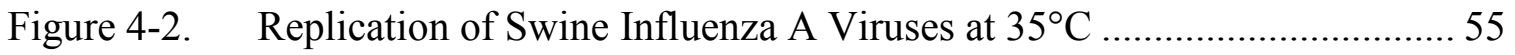

Figure 4-3. Replication of Swine Influenza A Viruses at $33^{\circ} \mathrm{C}$ and $39^{\circ} \mathrm{C} \ldots \ldots \ldots \ldots \ldots \ldots . . . .56$

Figure 4-4. Effect of Temperature on Growth of Swine Influenza A Viruses ............ 58

Figure 4-5. Growth and Transmission of a Human H3N2 Virus in Pigs ................... 59

Figure 4-6. Growth and Transmission of Classical and Reassortant Swine H1N1

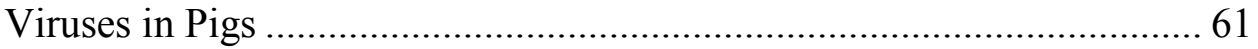

Figure 4-7. Growth and Transmission of a Triple Reassortant Swine H3N2 Virus

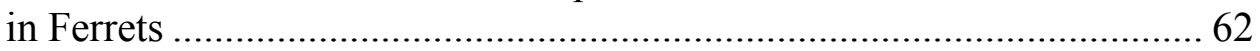

Figure 4-8. Growth and Transmission of Triple Reassortant H1N1 Swine Viruses in

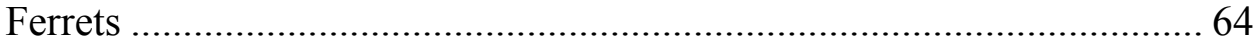




\section{LIST OF ABBREVIATIONS}

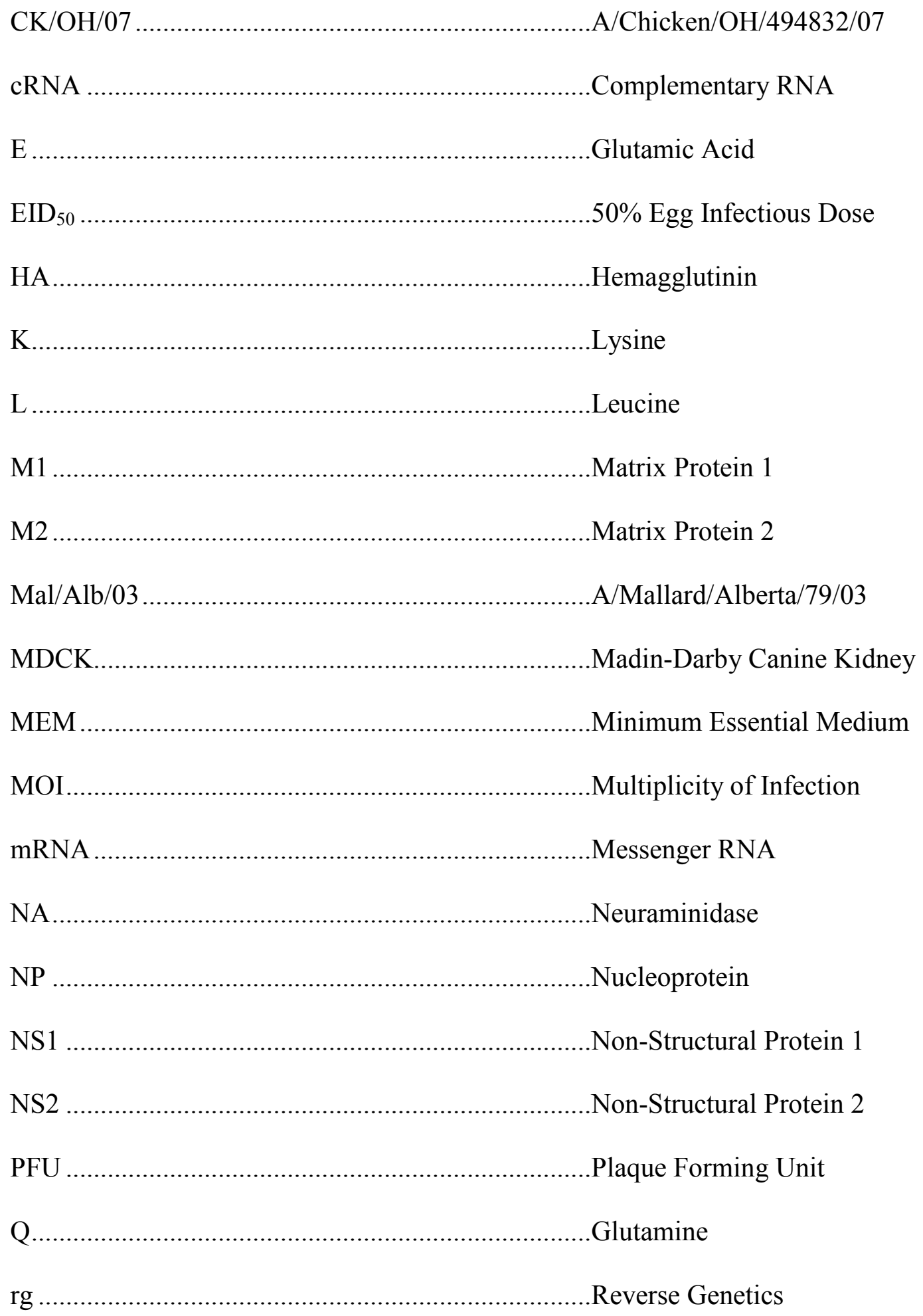




SW/MN/99




\section{CHAPTER 1: INTRODUCTION}

\section{Virus Classification}

Influenza A viruses are a genus of the family Orthomyxoviridae, along with Influenza $\mathrm{B}$ virus, Influenza $\mathrm{C}$ virus, Isavirus, and Thogotovirus (62). Influenza A, B, and $C$ viruses are differentiated from each other based on antigenic differences in their nucleoprotein (NP) and matrix (M1) proteins (150), and influenza A viruses are further classified into subtypes based on their two surface glycoproteins, hemagglutinin (HA) and neuraminidase (NA). There have been $16 \mathrm{HA}$ and 9 NA subtypes identified based on the antigenic properties of these proteins $(39,151)$.

\section{Virus Structure and Replication}

Influenza A viruses are enveloped viruses with a segmented genome that is comprised of eight negative-sense, single-stranded RNA molecules (Figure 1-1). These 8 segments encode 11 proteins. The polymerase complex is comprised of three proteins, PB2, PB1, and PA (7), that along with a viral RNA (vRNA) segment and the NP protein form the viral ribonucleoprotein (vRNP) complex (27). In the viral particle, the vRNPs are associated with the M1 protein, which is the main structural protein of influenza A viruses and lies just below the lipid envelope. There are two surface glycoproteins anchored in the envelope, HA and NA. HA serves as the receptor binding and fusion protein for influenza A viruses, as well as being its major antigenic protein. NA is a sialidase and acts to cleave cell surface sialic acids to allow for viral release. Also contained within the viral envelope is the matrix protein 2 (M2). This protein forms an envelope-spanning proton channel (109) which allows for acidification of the viral particle and the dissociation of the VRNPs from M1 for release into the cell cytoplasm (72). The genome also encodes two non-structural proteins (NS1 and NS2) as well as an alternate reading frame protein from PB1 known as PB1-F2 (22). NS1 has several functions in the infected cell, including binding double-stranded RNA (102), and suppressing an infected cell's type I interferon response (43) and protein kinase R response (6). NS2 is involved in the nuclear export of newly-synthesized vRNP complexes (103), while PB1-F2 induces cell apoptosis as well as enhancing the development of secondary bacterial pneumonia (93).

Viral infection of a cell begins when the HA proteins on the surface of an influenza A virus particle bind with $\alpha-2,3$ or $\alpha-2,6$ linked terminal sialyloligosaccharides on the surface of an epithelial cell. This causes the virus to be endocytosed (91) and acidification of the endosome leads to a conformational change in the HA protein that exposes the fusion peptide. The insertion of the fusion peptides of several HA molecules into the endocytic membrane forms a pore that allows for the release of the vRNPs from the virus particle into the cytoplasm of the cell (32). The vRNPs are transported into the nucleus of the cell where the vRNA serves as a template for the synthesis of both 


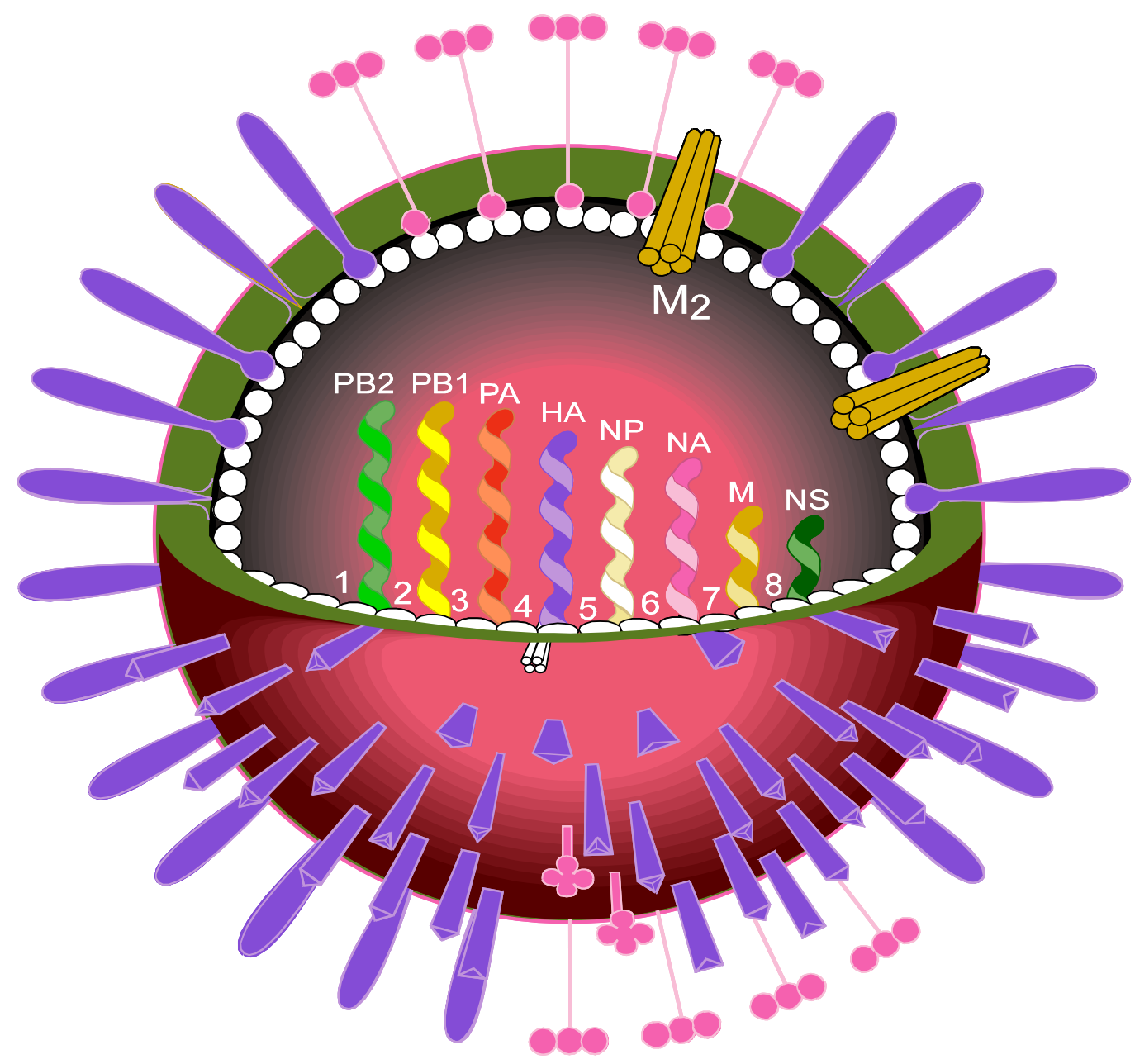

Figure 1-1. Schematic of the Influenza A Virus Particle. Influenza A virus particles contain eight single-stranded RNA gene segments and have two surface glycoproteins HA, shown in purple, and NA, shown in pink. Reprinted with permission from R.G. Webster. 
messenger RNA (mRNA) and full-length complementary RNA (cRNA) molecules. The mRNA molecules are translated into new viral proteins, and the cRNA molecules are used as templates for the synthesis of new vRNA molecules.

The three subunits of the influenza A polymerase complex (PB2, PB1, and PA) catalyze the synthesis of all viral RNA products. The initiation of mRNA synthesis requires a 5 ' capped primer, which the virus obtains from host cell pre-mRNA transcripts (68). PB1 binds to the 5' end of the vRNA, which allows the capped primer to be bound by PB2 and cleaved by PB1 (77). Elongation is catalyzed by PB1 and continues until the polymerase complex reaches a stretch of uridine residues near the 5' end of the vRNA. These nucleotides, along with the secondary structure of the vRNA, cause the polymerase to stutter, adding a poly-adenosine tail to the transcript (111). Following the transcription and translation of the mRNAs, the viral polymerase complex switches from transcription to replication. There are several theories as to the mechanism responsible for the switch from transcription to replication. The presence of newly-synthesized NP proteins has been shown to be necessary (123), but it is not known if these proteins induce a conformational change in the polymerase complex, thereby changing its activity, or if they associate with cRNA molecules to prevent their degradation and allow transcription to vRNA (110). It has also been suggested that the viral polymerase complex is synthesizes mRNA and cRNA simultaneously, but that the cRNA molecules are degraded in the absence of newly-synthesized polymerase complexes (144).

During replication, a positive-sense cRNA molecule is first synthesized for each gene segment and then used as a template for the negative-sense viral genome. Unlike mRNA synthesis, cRNA and vRNA synthesis do not require 5' capped primers and result in full-length transcripts (69). Following the replication of the viral genome, vRNP complexes are formed in the nucleus and exported to the cytoplasm through interactions with M1, NS2 and cellular chaperones $(37,103,12)$. After nuclear export, the vRNPs are transported to areas of the lipid membrane with high concentrations of HA and NA. There are two proposed models for the packaging of vRNPs into virus particles, random incorporation and selective incorporation. The random incorporation model assumes that a common feature present on al vRNPs causes them to be incorporated into newly forming virions (3). The selective incorporation model proposes that each gene segment has a unique packaging signal that allows for the selective packaging of one of each vRNP that comprises the influenza A genome (35). Conserved sequences at the 3' and 5' coding regions of PB2, PB1, PA (79), HA (146), NA (41), and NS (40) have all been demonstrated to be necessary for efficient incorporation of vRNPs into viral particles. While there is increasing evidence to support the selective incorporation model, the exact mechanism controlling segment specific packaging is not understood. However, it most likely involves interactions between the packaging sequences of each vRNA or interactions between the packaging signals and viral proteins.

Following genome packaging, new virus particles are formed by budding of the lipid membrane. NA is responsible for cleaving cell surface sialic acids to allow the newly-budded virus to be released (81). Once released, HA molecules, which are synthesized as an HA0 precursor molecule, are cleaved by extra-cellular trypsin-like 
proteases into HA1 and HA2 (4). One of the factors that contributes to the increased pathogenicity of some influenza A viruses is the presence of a poly-basic amino acid cleavage site in the HA0 that can be cleaved by intracellular proteases or proteases found outside of the respiratory tract (20).

\section{Virus Ecology}

While their natural reservoir is aquatic birds, in which they cause an asymptomatic infection of the intestinal tract, influenza A viruses have the ability to infect a number of host species, most significantly swine, humans, poultry, and other terrestrial birds, but also horses, cats, dogs, and aquatic mammals such as seals and whales (151). Influenza A viruses do exhibit host specificity, but this restriction is not absolute. Several factors influence the host specificity of influenza viruses, including receptor binding. Avian and equine influenza viruses have HA proteins that preferentially bind $\alpha-2,3$ linked sialyloligosaccharides, which are widespread on the epithelium of the avian intestinal tract and equine trachea $(52,53)$. In contrast, human and swine influenza viruses contain HA proteins that preferentially bind $\alpha-2,6$ linked sialyloligosaccharides, which are common on the epithelium of the mammalian respiratory tract $(29,30)$. Influenza A viruses in different species evolve along separate paths, but viruses of different lineages are able to exchange genetic information (151).

The segmented nature of the influenza A virus genome enables these viruses to undergo reassortment if a single cell is concurrently infected with more than one virus (34). These reassortment events can dramatically change the evolution of influenza A viruses in a host through the introduction of new gene segments (63). Recent human pandemic influenza A viruses were created through the reassortment of human and avian viruses $(127,121)$, causing an antigenic shift, which is the introduction of a novel HA into a naïve population. In February 1957, a novel human-avian H2N2 reassortant virus emerged in the human population in southern China. This virus contained the HA, NA, and PB1 from an avian influenza virus, while the remaining gene segments were from the circulating human H1N1. The United States was affected in two waves, the first in October 1957 and the second in January 1958. The first two waves of this virus caused about 70,000 deaths in the United States and about 1 million deaths worldwide (155). In the summer of 1968, a reassortant H3N2 virus that had a novel HA and PB1 from an avian virus and the remaining gene segments from the previously circulating human H2N2 virus emerged in humans (151). This virus caused about 34,000 deaths in the United States during the first two years it circulated (101). The currently circulating H1N1 pandemic virus is the result of a reassortment between a human-avian-swine reassortant virus from the United States and an avian-like swine virus from Europe (33). From the time of its emergence in April 2009 through August 2009, it has been responsible for approximately 9,000 hospitalizations and almost 600 deaths in the United States (17) 


\section{Influenza A in Swine}

Swine as a Mixing Vessel. Swine play an important role in the ecology of influenza A viruses because they are susceptible to viruses of both the avian and mammalian lineages. The cells of the swine respiratory tract contain receptor sialyloligosaccharides possessing both $\mathrm{N}$-acetylneuraminic acid- $\alpha 2,3$-galactose, which is the preferred receptor for avian influenza viruses and $\mathrm{N}$-acetylneuraminic acid- $\alpha 2,6$ galactose, which is the preferred receptor for mammalian influenza viruses $(52,116)$. While only the $\mathrm{H} 1$ and $\mathrm{H} 3$ subtypes are endemic in swine, they are susceptible to infection with avian viruses of the H4-H13 subtypes (64). This has led to the proposal that swine serve as a "mixing vessel" for influenza viruses of different lineages, providing a host in which reassortment and interspecies adaptation can take place (120).

Clinical Disease in Swine. Influenza was first described as a disease of swine in 1918 (66) and the first influenza A virus was isolated from a pig in 1930 (125). Influenza A in swine has an incubation period of 12-48 hours and causes an acute respiratory tract infection characterized by high fever, loss of appetite, labored breathing, coughing, sneezing, nasal discharge, lethargy, and weight loss (105). The virus replicates in the bronchial, bronchiolar, and alveolar epithelium, but is rarely found in the serum or other tissues $(138,54)$. Swine influenza is usually introduced into a herd through the movement of infected pigs, generally resulting in herd morbidity close to $100 \%$, but very low mortality of less than $1 \%(143,105)$. The virus is transmitted between pigs through nasopharyngeal secretions. Once introduced into a herd, influenza will continue to circulate until there are no susceptible pigs remaining. A vaccine which protects against the H1N1 and H3N2 swine influenza subtypes is commercially available for pigs over three weeks of age and is most commonly used to vaccinate sows in order to provide maternal antibodies to newborn piglets (105).

Evolution of Swine Influenza Viruses in North America. Reassortment has played a pivotal role in the evolution of influenza A viruses in North American swine. The first influenza A virus isolated from swine in 1930 was of the H1N1 subtype and was from the same lineage as the 1918 pandemic virus. These viruses entered the human and swine populations at around the same time but evolved independently in each host $(125,127)$. This "classical" swine H1N1 virus continued to circulate as the dominant influenza virus in the North American swine population until 1998. It caused predictable seasonal peaks of disease, similar to those seen in humans, and was not of great economic concern (36). While classical H1N1 was the dominant virus, human H3N2 viruses were detected by serology at very low levels, but these viruses never became established in the swine population $(18,50,106)$.

In late 1998, two distinct H3N2 influenza viruses were isolated from swine with unusually severe influenza-like illness in North Carolina, Minnesota, Iowa, and Texas. The isolate from North Carolina was classified as a double reassortant virus and 
contained HA, NA and PB1 genes similar to those of contemporary human H3N2 influenza viruses and M, NP, NS, PA, and PB2 genes similar to those of the classical H1N1 swine influenza lineage. This virus caused spontaneous abortion in $7 \%$ of breeding sows in the herd it was first isolated from and had about a $2 \%$ mortality rate (160), compared to a less than $1 \%$ mortality rate normally seen with swine influenza infection (105). The isolates from Minnesota, Iowa, and Texas were classified as triple reassortant viruses and had even more complex genomes. Like the North Carolina isolate, these viruses contained HA, NA, and PB1 genes from a contemporary human virus lineage and $M, N P$, and NS genes from the classical swine H1N1 lineage. However, these isolates contained PA and PB2 genes from an avian influenza virus lineage. Disease caused by these triple reassortant viruses was less severe than that caused by the double reassortant virus, with lower morbidity and mortality rates, but the virus was able to spread throughout more swine herds in a larger geographical area $(160,159)$. After the emergence of these two reassortant viruses, the double reassortant virus did not continue to circulate, but the triple reassortant lineage became established in the swine population and continued to circulate and evolve. By early 2000 , over $20 \%$ of sampled pigs were seropositive for the triple reassortant H3N2 (149). Further studies identified triple reassortant viruses in samples collected from pigs as early as March 1998 (60).

Variants of the original $\mathrm{H} 3 \mathrm{~N} 2$ triple reassortant virus continue to be isolated from the North American swine population along with several other lineages of influenza A viruses (Table 1-1). Not all of the isolated viruses successfully become established in the swine population, but all of the currently circulating viruses contain a genetically similar constellation of internal genes with different surface glycoproteins. This constellation of internal genes is referred to as the triple reassortant internal gene (TRIG) cassette, and is comprised of the avian-origin PB2 and PA gene segments, the human-origin PB1 gene segment, and the classical swine-origin NP, M, and NS gene segments (143). This TRIG cassette is thought to provide a competitive advantage in swine compared to other internal gene constellations. Influenza A viruses isolated from swine since 1998 include 3 distinct H3N2 viruses, each with a human-like HA from a different year (149), an H1N2 virus with a human-like HA (57), an H1N2 virus with a classical swine-like HA (58), an H1N1 virus with a human-like HA and NA (142), and an H1N1 virus with a classical swine-like HA and NA (148). Other reassortant virus subtypes that have sporadically been isolated from pigs since 1998, but have not become established in the swine population include an $\mathrm{H} 3 \mathrm{~N} 1$ and an $\mathrm{H} 2 \mathrm{~N} 3(83,84)$. Several wholly-avian viruses, including an H4N6, H3N3, and H1N1 have been isolated from swine herds in Canada, but none have spread beyond the initially infected herds $(56,104,61)$.

Swine Influenza Evolution in Europe and Asia. The evolution of swine influenza A viruses in Europe and Asia has been distinct from their evolution in North America. Swine influenza was not reported in Europe until 1976, when the classical swine H1N1 virus was detected in pigs in Italy (100). Around the same time, a whollyhuman H3N2 virus was also introduced into the European swine population (15), and in 1979, a wholly avian-like influenza A virus was isolated from swine in Italy (108). This 
Table 1-1. Influenza A Viruses Isolated from North American Swine since 1998.

\begin{tabular}{|c|c|c|c|c|}
\hline Subtype & Origin & $\begin{array}{c}\text { Year } \\
\text { Initially } \\
\text { Isolated }\end{array}$ & $\begin{array}{l}\text { Country } \\
\text { Isolated }\end{array}$ & Reference \\
\hline H3N2 & Swine/Human & 1998 & U.S. & $(160)$ \\
\hline $\mathrm{H} 3 \mathrm{~N} 2$ & Swine/Human/Avian & 1998 & U.S. & $(160)$ \\
\hline $\mathrm{H} 1 \mathrm{~N} 2$ & Reassortant Swine/Swine & 1999 & U.S. & $(58)$ \\
\hline H4N6 & Avian & 1999 & Canada & (59) \\
\hline H1N1 & Reassortant Swine/Swine & 2001 & U.S. & $(148)$ \\
\hline $\mathrm{H} 3 \mathrm{~N} 3$ & Avian & 2001 & Canada & (61) \\
\hline H1N1 & Avian & 2002 & Canada & (61) \\
\hline $\mathrm{H} 1 \mathrm{~N} 2$ & Human & 2003 & Canada & $(57)$ \\
\hline $\mathrm{H} 3 \mathrm{~N} 1$ & Reassortant Swine/Reassortant Swine & 2004 & U.S. & (83) \\
\hline H1N2 & Reassortant Swine/Human & 2004 & Canada & (57) \\
\hline H1N1 & Reassortant Swine/Human & 2005 & U.S. & (142) \\
\hline $\mathrm{H} 2 \mathrm{~N} 3$ & Reassortant Swine/Avian & 2006 & U.S. & (84) \\
\hline $\mathrm{H} 1 \mathrm{~N} 1$ & Reassortant Swine/Avian & 2009 & Canada & $(153)$ \\
\hline
\end{tabular}


avian-like H1N1 virus quickly replaced the classical swine H1N1 virus as the dominant lineage and reassorted with the human $\mathrm{H} 3 \mathrm{~N} 2$ virus, resulting in a virus with human-like HA and NA genes and avian-like internal genes (16). An H1N2 virus that contained a human-like H1, swine-like N2, and avian-like internal genes was isolated from swine in Great Britain in 1994 (11), and in 2005 a novel H1N2 virus that was the result of reassortment between a swine $\mathrm{H} 1 \mathrm{~N} 2$ virus and a swine $\mathrm{H} 3 \mathrm{~N} 2$ virus was isolated in Germany (158).

Most of the European swine influenza viruses also circulate in Asia, but there are several lineages which are unique to this region. Human H3N2 viruses were first isolated from pigs in Taiwan in 1970 (70) and continue to circulate in the swine population along with several different reassortant H3N2 viruses $(107,156,126)$. Interestingly, viruses with an HA and NA most closely related to the original human pandemic $\mathrm{H} 3 \mathrm{~N} 2$ isolate from 1968 can still be isolated from pigs in China, along with more recent human H3N2 and human H1N1 viruses (157). In China and Korea, several isolates have been detected that contain gene segments that are genetically similar to those found in the North American swine population (74). In 2004, an H1N2 virus was isolated in Hong Kong that contained five of the internal genes from the North American triple reassortant swine viruses with a Eurasian lineage $\mathrm{H} 1$ and M (128). In Thailand, several reassortant viruses have been isolated from swine, including an H1N1 that contains the HA and NS from the classical swine H1N1 lineage and the remaining genes from the Eurasian avian-like swine lineage. An H1N2 reassortant virus with the HA from the classical swine H1N1 lineage and the remaining genes from the Eurasian avian-like swine lineage was also isolated $(25,132)$. These two reassortant viruses have also been isolated from humans (67). An avian H9N2 virus was isolated from pigs in Hong Kong in 1998 (107) but did not become established in the pig population of Asia. A distinct H9N2 virus reassorted with and obtained the internal genes of an $\mathrm{H} 5 \mathrm{~N} 1$ virus and both the reassortant and the original H9N2 virus still circulate in pigs $(28,156)$. Avian H5N1 viruses have been isolated sporadically from swine in China and Indonesia, but do not appear to be highly pathogenic in swine, do not efficiently transmit from pig to pig, and have not become established in the population $(24,161,131)$.

\section{Influenza Zoonoses}

The most catastrophic zoonotic influenza event was the H1N1 pandemic of 19181919. While it has long been proposed that this virus was a wholly avian virus that transmitted directly into the human and swine populations (114), new evidence suggests that the virus was actually the result of several reassortment events between human, swine, and avian influenza viruses (127). In early 1918, there was a mild wave of disease, which was followed in the fall by a highly pathogenic wave that killed more than 20 million people worldwide $(133,134,5)$. Related H1N1 viruses remained in the human and swine populations, evolving along separate paths (127). H1N1 viruses were replaced in the human population by viruses of the H2N2 subtype in 1957 but were re-introduced into the human population in 1977 (151). 
The first swine influenza virus was isolated from a human in 1974. Forty-three confirmed cases of transmission of influenza A virus from pigs to humans were reported between 1974 and 2005, including six fatalities. Because there are no unique clinical symptoms to differentiate swine influenza from seasonal influenza in humans, this number is probably only a small fraction of the actual cases (124). Serological studies on swine farm workers, meat-packers, and veterinarians showed a high frequency of exposure to several subtypes of swine influenza viruses $(46,98)$ Most of the reported cases of swine flu infections in humans were the result of direct exposure to swine or were human-to-human transmission within a family cluster (97). An exception was in early 1976, when there was an outbreak of severe respiratory disease at Fort Dix, New Jersey. Thirteen soldiers became severely ill, and one died. The causative agent of the outbreak was determined to be a classical swine H1N1 virus. Further serological studies showed that over 200 infections occurred, however, within a month, the virus had disappeared from the human population (44). From December 2005 through February 2009, 11 cases of human infection with swine influenza were reported to the CDC. These infections were all caused by triple reassortant swine influenza viruses. Ten of the infections were caused by an H1N1 virus with classical swine origin HA and NA genes, and one was caused by an H1N2 virus with human origin HA and NA genes. Four of the patients were hospitalized, but no deaths were reported (124).

In April 2009, two cases of un-subtypeable influenza A in humans with no known swine contact were reported in southern California. The viruses isolated from these cases were of swine origin, but were distinct from the influenza A viruses currently known to be circulating in the North American swine population. They appeared to be the result of reassortment between a North American triple reassortant lineage swine virus and a Eurasian H1N1 swine virus. The HA gene and the internal genes were similar to those found in circulating reassortant swine viruses, but the NA and $\mathrm{M}$ genes were more closely related to the Eurasian avian-like swine influenza A lineage (33). The origin of this virus is currently unknown, but it has spread in humans throughout the United States and around the world and was declared a pandemic virus on 11 June 2009 (19). The virus has also been detected in swine herds in Canada (153,38), Australia (14), Ireland $(115,45)$, Argentina (1), and the U.S. (26) but it remains to be seen if it will become established in the swine population worldwide and if it will replace the currently circulating strains.

\section{Research Aims and Hypotheses}

Swine influenza is a dynamic zoonotic disease. The continued rapid and as yet unpredictable evolution of swine influenza A viruses poses a threat to human health, as evidenced by the recent emergence of a novel H1N1 pandemic influenza virus of swine origin. Despite yearly human epidemics, four pandemics in the last century, and the veterinary impact of influenza A viruses, we know little about the fundamental biologic properties of these viruses. The purpose of this study was to characterize the pandemic potential of reassortant influenza A viruses of swine, assess their fitness as compared to 
other swine influenza viruses, as well as to examine the reassortment potential of these viruses.

Hypothesis 1. North American swine influenza viruses containing the TRIG cassette are able to acquire surface glycoproteins from an avian influenza virus through reassortment, and the adaptation of these viruses in pigs can lead to a virus that is transmissible in mammals through minor changes in the HA which alter receptor specificity.

Hypothesis 2. The avian-origin polymerase genes of reassortant swine influenza A viruses give these viruses a replicative advantage over classical swine influenza viruses both in vitro and in vivo and confer the ability to acquire human HA gene segments. 


\section{CHAPTER 2: TRANSMISSIBILITY OF A NOVEL H2N3 SWINE INFLUENZA VIRUS}

\section{Introduction}

Influenza A viruses are classified into subtypes based on the antigenic properties of their two surface glycoproteins, HA and NA. HA is the receptor binding protein of the virus and as well as its main antigenic determinant. It binds with terminal sialic acid residues on the surface of host cells and allows for viral entry into the cell. There are 16 HA and 9 NA subtypes that have been identified $(39,151)$. Viruses of all these subtypes can be isolated from wild aquatic birds, the natural reservoir of influenza A viruses, however, only three subtypes have caused human pandemics - H1, H2, and H3 (151).

The host specificity of influenza A viruses is largely due to the receptor binding specificity of the HA. The HA of avian-origin influenza A viruses binds preferentially to $\alpha-2,3$ linked sialyloligosaccharides on the surface of avian intestinal epithelial cells (52), while the HA of mammalian-origin influenza A viruses binds preferentially to $\alpha-2,6$ linked sialyloligosaccharides on epithelial cells in the respiratory tract (116). A single amino acid substitution at position 226 (H3 numbering) of the HA1 protein has been shown to be responsible for the receptor preference in $\mathrm{H} 2$ and $\mathrm{H} 3$ subtypes. An HA with a glutamine (Q) at position 226 will preferentially bind $\alpha-2,3$ linked sialyloligosaccharides, while an HA with leucine (L) at position 226 will preferentially bind $\alpha-2,6$ linked sialyloligosaccharides. An additional substitution from glycine to serine at position 228 has also been observed as $\mathrm{H} 2$ viruses adapt from avian hosts to mammalian hosts (29), but the effect of this mutation on receptor specificity and viral transmission is unknown.

Swine have been proposed as an intermediate host between birds and mammals for influenza A viruses because the cells of the swine respiratory tract contain both $\alpha-2,3$ and $\alpha-2,6$ linked sialyloligosaccharide receptors $(120,52)$. This makes swine susceptible to both avian and human influenza A viruses. Replication of an avian influenza virus in a pig can lead to its adaptation to a mammalian host through mutation or reassortment with a co-infecting influenza A virus (120). Pigs are also able to transmit influenza A viruses to humans (97). The Fort Dix outbreak of 1976 was caused by a classical swine H1N1 virus and there have been eleven reported cases of triple reassortant swine influenza infection in humans since $2005(44,97)$.

Influenza A viruses of the $\mathrm{H} 2 \mathrm{~N} 2$ subtype were first detected in the human population in 1957 , causing the second pandemic of the $20^{\text {th }}$ century. The pandemic virus was the result of reassortment between the H1N1 virus that had circulated in the human population since the 1918 pandemic and an avian $\mathrm{H} 2 \mathrm{~N} 2$ virus. This reassortment produced a virus with avian-origin HA, NA, and PB1 genes and human-origin PB2, PA, $\mathrm{NP}, \mathrm{M}$, and NS genes (121). H2N2 influenza viruses circulated in the human population until 1968, when an H3N2 virus emerged and replaced the H2N2 subtype. H2 influenza 
viruses continued to circulate in birds, but were not isolated from humans or other mammals, including pigs, after 1968 (151).

In 2006, two H2N3 viruses were isolated from separate swine herds in Missouri. Analysis of these viruses showed that they contained HA, NA, and PA genes from avian influenza viruses and the remaining genes from the North American triple reassortant swine influenza lineage. These viruses were the first swine viruses isolated in North America which contained the TRIG cassette along with avian surface glycoproteins, demonstrating the ability of this gene constellation to acquire a wide range of novel HA genes and bring them into a naïve population. Sequencing of the two isolates showed that both isolates contained a leucine (mammalian-like) at position 226 and a glycine (avian-like) at position 228 of the HA1. This novel H2N3 virus was found to be pathogenic and transmissible in pigs and also pathogenic in mice without adaptation (84).

Because H2N3 viruses have not been isolated from humans since 1968, and pigs can transmit influenza A viruses to humans, a mammalian-adapted $\mathrm{H} 2 \mathrm{~N} 3$ virus in the swine population would have a high pandemic potential. The mechanisms controlling interspecies transmission of influenza A viruses are not well defined. Receptor specificity has been shown to play a role in the ability of a virus to infect a host, though it has not previously been linked to transmissibility in $\mathrm{H} 2$ subtype viruses. Transmission studies in ferrets showed that receptor specificity was responsible for direct contact transmission of the virus, and that this transmissibility was attenuated by changing the leucine at position 226 of the HA1 back to the avian consensus glutamine. While there are several animal models that can be used to characterize influenza A viruses, ferrets are highly suitable for infection and transmission studies of influenza A viruses because they are naturally susceptible to the virus, exhibit symptoms of disease similar to those seen in humans (129), and have receptor distribution in the airway that is similar to humans $(75,85)$.

\section{Materials and Methods}

Viruses Used. Three wild-type viruses were used to characterize the transmission of $\mathrm{H} 2 \mathrm{~N} 3$ viruses in ferrets. SW/MO/2124514/06 $(\mathrm{SW} / \mathrm{MO} / 06)$ is one of the original swine $\mathrm{H} 2 \mathrm{~N} 3$ isolates. A/Mallard/Alberta/79/03 (Mal/Alb/03) is an $\mathrm{H} 2 \mathrm{~N} 3$ virus that contains an HA with $98.8 \%$ amino acid homology to the HA of SW/MO/06.

$\mathrm{CK} / \mathrm{OH} / 494832 / 07(\mathrm{CK} / \mathrm{OH} / 07)$ is an $\mathrm{H} 2 \mathrm{~N} 3$ virus that contains an $\mathrm{HA}$ and NA similar to those of SW/MO/06 (97.7\% and 98.5\% amino acid homology respectively). SW/MO/06 and $\mathrm{CK} / \mathrm{OH} / 07$ were obtained from Dr. Marie Gramer at the University of Minnesota Veterinary Diagnostic Laboratory, and Mal/Alb/03 was obtained from the virus repository at St. Jude Children's Research Hospital. All virus stocks were grown in embryonated hen eggs and stored at $-80^{\circ} \mathrm{C}$. 
Generation of Reverse Genetics Viruses. Three additional H2N3 viruses were generated using the eight plasmid reverse genetics system (Figure 2-1). cDNA for each gene segment was synthesized and ligated into the plasmid pHw2000. The insertion site is flanked by a human RNA polymerase I promoter sequence and a murine terminator sequence. The entire polymerase I and cDNA sequence is flanked by an RNA polymerase II promoter sequence and a poly-adenylation site. Upon transfection into a co-culture of 293T and Madin-Darby Canine Kidney (MDCK) cells, both vRNA and mRNA are synthesized from each plasmid (51). To obtain an $\mathrm{H} 2$ virus with altered receptor specificity, a t707a (L226Q) mutation was introduced into the SW/MO/06 HA plasmid through site-directed mutagenesis, the plasmid was sequenced to confirm the mutation, and the virus was rescued as described. For each of the three viruses rescued, lug of each plasmid was transfected into MDCK/293T cell co-culture and incubated for 72 hours. Supernatants were harvested and injected into eggs. Eggs were incubated for 48 hours and the allantoic fluid was collected. The genetic constellation of all viruses was confirmed by sequencing.

The viruses rescued were $\mathrm{rgSW} / \mathrm{MO} / 06$, which contained the HA, NA, and PA genes from SW/MO/06 and the remaining five genes from SW/TX/4199-2/98 (Table 21); $\mathrm{rgSW} / \mathrm{MO} / 06 \mathrm{HAmut}$, which contained the $\mathrm{HA}$ gene from $\mathrm{SW} / \mathrm{MO} / 06$ containing a t707a mutation, NA and PA genes from $\mathrm{SW} / \mathrm{MO} / 06$, and the remaining five genes from $\mathrm{SW} / \mathrm{TX} / 98$; and $\mathrm{rgCK} / \mathrm{OH} / 07$, which contained the $\mathrm{HA}$ gene from $\mathrm{CK} / \mathrm{OH} / 07$, the NA and $\mathrm{PA}$ genes from $\mathrm{SW} / \mathrm{MO} / 06$, and the remaining five genes from $\mathrm{SW} / \mathrm{TX} / 98$. $\mathrm{rgSW} / \mathrm{MO} / 06$ and $\mathrm{rgCK} / \mathrm{OH} / 07$ were rescued to compare their properties to wild-type virus. $\mathrm{rgSW} / \mathrm{MO} / 06 \mathrm{HAmut}$ was rescued to determine if the L226Q mutation would alter the virus's growth and transmissibility.

Ferret Infections. Influenza A negative ferrets were obtained from the ferret breeding program at St. Jude Children's Research Hospital or from Triple F Farms (Sayre, PA). Infectivity and transmissibility of each influenza H2 virus was tested in six 3-4 month old ferrets per virus under BSL-2 conditions. Three ferrets were anesthetized with isofluorane and inoculated intranasally with $10^{5} \mathrm{TCID}_{50}(\mathrm{Mal} / \mathrm{Alb} / 03$ and $\mathrm{SW} / \mathrm{MO} / 06)$ or $10^{6} \mathrm{TCID}_{50}(\mathrm{CK} / \mathrm{OH} / 07, \mathrm{rgSW} / \mathrm{MO} / 06, \mathrm{rgSW} / \mathrm{MO} / 06 \mathrm{HAmut}$, $\mathrm{rgCK} / \mathrm{OH} / 07)$ of virus diluted in PBS. Twenty-four hours post-inoculation, one naïve contact animal was housed with each infected animal. At days 1, 4, 7 and 11 postinoculation, animals were anesthetized with ketamine and nasal washes were collected. The nasal washes were titrated in embryonated hen eggs and egg 50\% infectious dose $\left(E_{50}\right)$ was calculated using the Reed-Muench method (113).

Hemagglutination Inhibition (HI) Assays. Serum samples were collected at 21 days post-infection and treated overnight at $37^{\circ} \mathrm{C}$ with Vibrio cholerae receptordestroying enzyme (Denka-Sekien, Tokyo, Japan) followed by heat inactivation at $56^{\circ} \mathrm{C}$ for 30 minutes prior to serological testing. Sera were titrated in round bottom 96-well plates and incubated for 45 minutes at room temperature with four agglutinating doses of 
Figure 2-1. Eight Plasmid Reverse Genetics System. A PCR synthesized cDNA molecule was created for each gene segment and ligated into the $\mathrm{pHw} 2000$ plasmid. The eight plasmids were then transfected into a co-culture of 293T and MDCK cells and incubated at $37^{\circ} \mathrm{C}$ for 72 hours. Modified with permission. Hoffmann E, Neumann G, Kawaoka Y, Hobom G, Webster RG. A DNA transfection system for generation of influenza A virus from eight plasmids. Proc Natl Acad Sci U S A 2000 May 23;97(11):6108-13. 


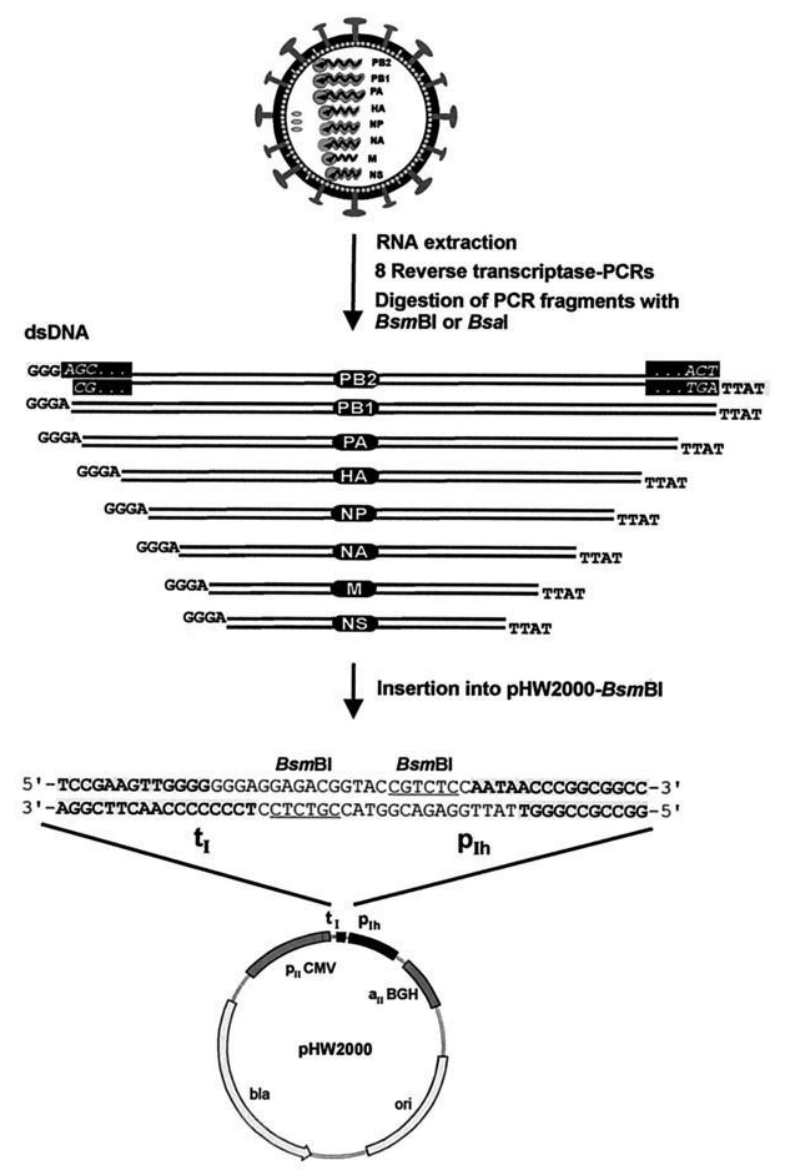

Expression plasmids

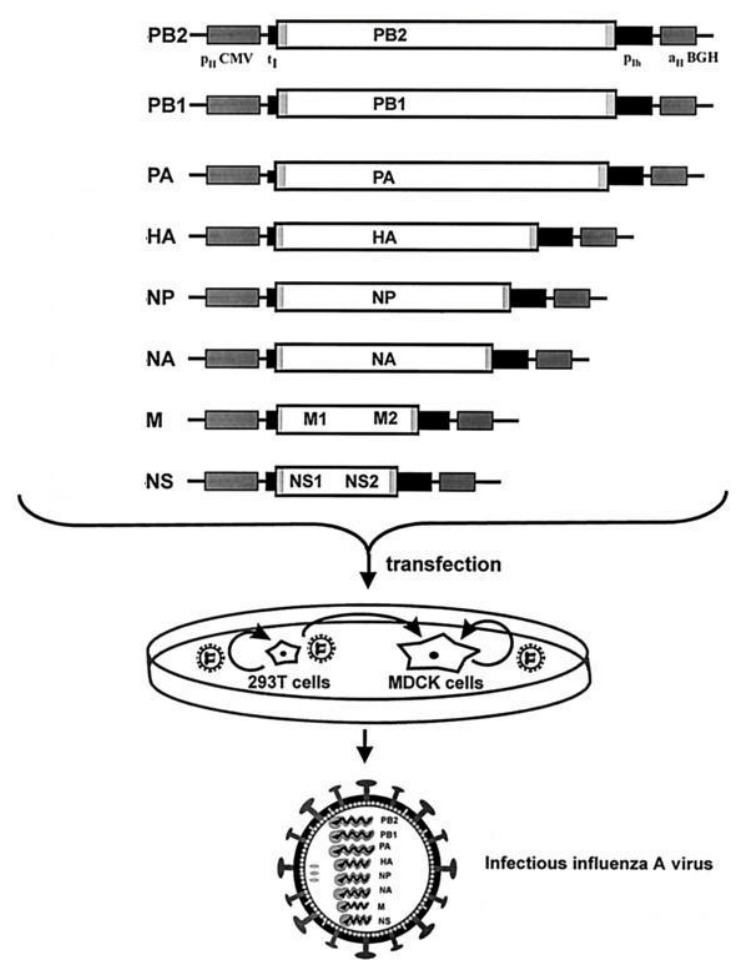


Table 2-1. H2N3 Viruses Rescued Using Reverse Genetics.

\begin{tabular}{|c|c|c|c|c|c|c|c|c|}
\hline \multirow{2}{*}{ Virus } & \multicolumn{8}{|c|}{ Gene Segment Virus of Origin } \\
\hline & PB2 & PB1 & $\mathbf{P A}$ & HA & $\mathbf{N P}$ & $\mathbf{N A}$ & $\mathbf{M}$ & $\mathbf{N S}$ \\
\hline $\mathrm{rgSW} / \mathrm{MO} / 06$ & $\mathrm{SW} / \mathrm{TX} / 98$ & SW/TX/98 & $\mathrm{SW} / \mathrm{MO} / 06$ & $\mathrm{SW} / \mathrm{MO} / 06$ & $\mathrm{SW} / \mathrm{TX} / 98$ & $\mathrm{SW} / \mathrm{MO} / 06$ & SW/TX/98 & $\mathrm{SW} / \mathrm{TX} / 98$ \\
\hline $\begin{array}{l}\mathrm{rgSW} / \mathrm{MO} / 06 \\
\text { HAmut }\end{array}$ & SW/TX/98 & SW/TX/98 & $\mathrm{SW} / \mathrm{MO} / 06$ & $\begin{array}{l}\text { SW/MO/06 } \\
\text { L226Q }\end{array}$ & SW/TX/98 & $\mathrm{SW} / \mathrm{MO} / 06$ & $\mathrm{SW} / \mathrm{TX} / 98$ & $\mathrm{SW} / \mathrm{TX} / 98$ \\
\hline $\mathrm{rgCK} / \mathrm{OH} / 06$ & SW/TX/98 & SW/TX/98 & $\mathrm{SW} / \mathrm{MO} / 06$ & $\mathrm{CK} / \mathrm{OH} / 07$ & SW/TX/98 & $\mathrm{SW} / \mathrm{MO} / 06$ & $\mathrm{SW} / \mathrm{TX} / 98$ & $\mathrm{SW} / \mathrm{TX} / 98$ \\
\hline
\end{tabular}


homologous virus. A $0.5 \%$ solution of turkey red blood cells was then added and incubated at room temperature for 30 minutes. HI titer was determined based on the highest dilution of sera which caused complete inhibition of red blood cell agglutination.

\section{Results}

Swine H2N3 Viruses Are Transmissible in Ferrets. To determine if $\mathrm{SW} / \mathrm{MO} / 06$ was transmissible in the ferret model, three ferrets were inoculated intranasally with $10^{5} \mathrm{TCID}_{50}$ of SW/MO/06 or $10^{6} \mathrm{TCID}_{50}$ of $\mathrm{rgSW} / \mathrm{MO} / 06$. One naïve contact animal was housed with each inoculated animal beginning 24 hours postinoculation. Ferrets inoculated with both wild-type and $\mathrm{rgSW} / \mathrm{MO} / 06$ shed detectable amounts of virus by day one post-inoculation with average titers of $10^{5.5} \mathrm{EID}_{50} / \mathrm{ml}$ for wild-type and $10^{6.25} \mathrm{EID}_{50} / \mathrm{ml}$ for the reverse genetics virus (Figure 2-2). Contact ferrets in both groups began to shed virus by day three post contact with average titers of $10^{6.17}$ $E I D_{50} / \mathrm{ml}$ for wild-type and $10^{5.17} \mathrm{EID}_{50} / \mathrm{ml}$ for the reverse genetics virus. All ferrets cleared the virus within seven days of infection, and none of the ferrets showed any clinical symptoms or lost a significant amount of weight (Table 2-2 and Table 2-3).

\section{Avian H2N3 Viruses Replicate in Ferrets but Do Not Transmit Efficiently.} To determine if avian $\mathrm{H} 2 \mathrm{~N} 3$ viruses were transmissible in ferrets, three ferrets were inoculated with $10^{5} \mathrm{TCID}_{50}$ of Mal/Alb/03, $10^{6} \mathrm{TCID}_{50}$ of CK/OH/07, or $10^{6} \mathrm{TCID}_{50}$ of $\mathrm{rgCK} / \mathrm{OH} / 07$. Twenty-four hours post-inoculation, one contact ferret was housed with each inoculated ferret. Ferrets infected with $\mathrm{Mal} / \mathrm{Alb} / 03$ shed detectable levels of virus by one day post-inoculation, although the average titer of $10^{4.4} \mathrm{EID}_{50} / \mathrm{ml}$ was lower than that observed in ferrets infected with $\mathrm{SW} / \mathrm{MO} / 06$. Only one of the three contact ferrets shed detectable levels of virus at days 7 and 11 post-infection, $10^{6.75} \mathrm{EID}_{50} / \mathrm{ml}$ and $10^{5.5}$ $\mathrm{EID}_{50} / \mathrm{ml}$, respectively (Figure 2-3A). This contact ferret shed higher titers of virus than the infected ferrets, and when the HA of the isolated virus was sequenced, it was shown that the HA gene coded for a leucine at position 226 of the HA1 instead of the wild-type glutamine. This Q226L mutation alters the receptor specificity of the HA from avian-like to mammalian-like. The two contact ferrets that did not shed virus also did not have detectable HI titers (Table 2-3). Following intranasal infection with wild-type or reverse genetics $\mathrm{CK} / \mathrm{OH} / 07$, ferrets began to shed virus by day one post-infection to similar titers as Mal/Alb $/ 03$, with an average titer of $10^{4.08} \mathrm{EID}_{50} / \mathrm{ml}$ for wild-type and $10^{3.58} \mathrm{EID}_{50} / \mathrm{ml}$ for the reverse genetics virus (Figures 2-3B and 2-3C). Wild-type CK/OH/07 was not detectable in the nasal washes of the contact ferrets although one contact animal did seroconvert. $\mathrm{rgCK} / \mathrm{OH} / 07$ was not detected in the nasal washes of any of the contact ferrets and none of the contact animals seroconverted. No clinical symptoms were observed in any of the infected or contact ferrets (Table 2-2 and Table 2-3). 
A

SW/MO/06

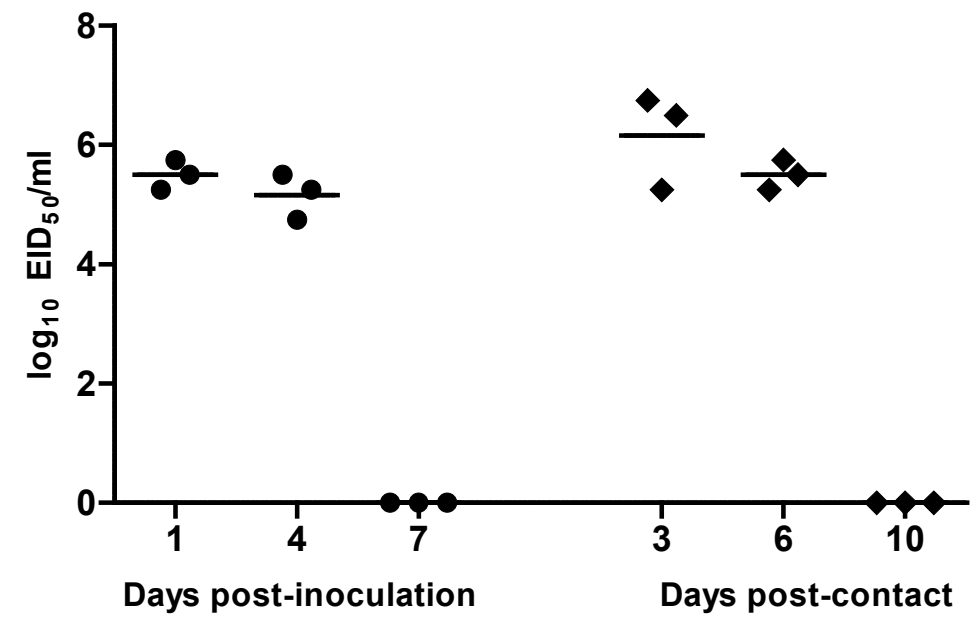

B

$\mathrm{rgSW} / \mathrm{MO} / 06$

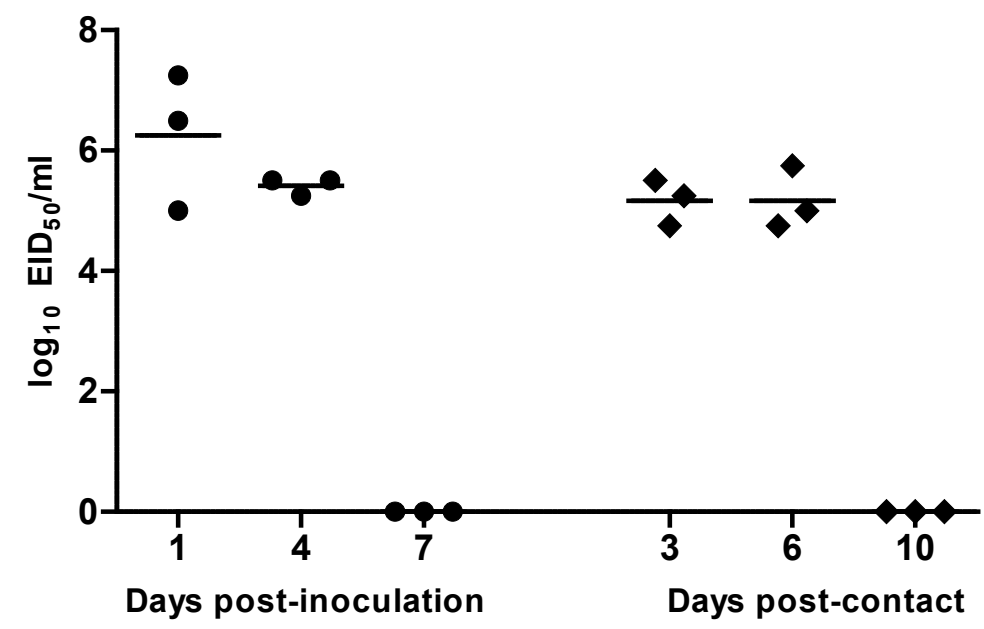

Figure 2-2. Swine H2N3 Viruses Replicate and Transmit in Ferrets. Three ferrets were inoculated intranasally with $10^{5} \mathrm{TCID}_{50}$ of SW/MO/06 (A) or $10^{6} \mathrm{TCID}_{50}$ of $\mathrm{rgSW} / \mathrm{MO} / 06$ (B). Twenty-four hours post-inoculation, one naïve contact ferret was placed in the cage with each inoculated ferret. Nasal washes were collected 1, 4, 7, and 11 days post-inoculation and viral titers were determined by ID $_{50}$. 
Table 2-2. Weight Loss, Peak Viral Titers, and Serum HI Titers of Inoculated Ferrets.

\begin{tabular}{|c|c|c|c|}
\hline \multirow[b]{2}{*}{ Virus } & \multicolumn{3}{|c|}{ Inoculated Ferrets } \\
\hline & $\begin{array}{l}\text { Weight Loss } \\
(\%)\end{array}$ & $\begin{array}{l}\text { Peak Titer } \\
\text { (day) }\end{array}$ & Serum HI Titer $^{b}$ \\
\hline $\mathrm{SW} / \mathrm{MO} / 06$ & $4.67 \pm 1.24$ & $5.75(1)$ & $160,320,320$ \\
\hline $\mathrm{rgSW} / \mathrm{MO} / 06$ & $5.17 \pm 3.57$ & $7.25(1)$ & $1280,1280,>5120$ \\
\hline rgSW/MO/06 HAmut & $7 \pm 3.56$ & $6.5(4)$ & $80,160,320$ \\
\hline $\mathrm{CK} / \mathrm{OH} / 07$ & $0.70 \pm 0.57$ & $4.75(1)$ & $80,80,160$ \\
\hline $\mathrm{rgCK} / \mathrm{OH} / 07$ & $0^{c}$ & $3.75(1)$ & $20,80,80$ \\
\hline $\mathrm{Mal} / \mathrm{Alb} / 03$ & $8.33 \pm 2.87$ & $4.75(4)$ & $80,80,160$ \\
\hline
\end{tabular}

${ }^{\mathrm{a}}$ Titers are shown as the $\log _{10} \mathrm{EID}_{50} / \mathrm{ml}$.

${ }^{\mathrm{b}}$ Homologous virus was used in HI assays.

${ }^{c}$ None of the ferrets lost weight.

Table 2-3. Weight Loss, Peak Viral Titers, and Serum HI Titers of Contact Ferrets.

\begin{tabular}{|c|c|c|c|}
\hline \multirow[b]{2}{*}{ Virus } & \multicolumn{3}{|c|}{ Contact Ferrets } \\
\hline & $\begin{array}{l}\text { Weight Loss } \\
(\%)\end{array}$ & $\begin{array}{l}\text { Peak Titer } \\
\text { (day) }\end{array}$ & Serum HI Titer \\
\hline $\mathrm{SW} / \mathrm{MO} / 06$ & $3^{c}$ & $6.75(6)$ & $160,320,320$ \\
\hline $\mathrm{rgSW} / \mathrm{MO} / 06$ & $3.87 \pm 3.67$ & $5.5(6)$ & $640,640,2560$ \\
\hline $\mathrm{rgSW} / \mathrm{MO} / 06 \mathrm{HAmut}$ & $1.6^{\mathrm{c}}$ & $6.5(6)$ & $<10,<10,160$ \\
\hline $\mathrm{CK} / \mathrm{OH} / 07$ & $2.5^{\mathrm{c}}$ & $\mathrm{NT}^{\mathrm{d}}$ & $<10,<10,320$ \\
\hline $\mathrm{rgCK} / \mathrm{OH} / 07$ & $1.5^{\mathrm{c}}$ & $\mathrm{NT}^{\mathrm{d}}$ & $<10,<10,<10$ \\
\hline $\mathrm{Mal} / \mathrm{Alb} / 03$ & $7.67 \pm 1.86$ & $6.75(6)$ & $<10,<10,160$ \\
\hline
\end{tabular}

${ }^{\mathrm{a}}$ Titers are shown as the $\log _{10} \mathrm{EID}_{50} / \mathrm{ml}$.

${ }^{\mathrm{b}}$ Homologous virus was used in HI assays.

${ }^{\mathrm{c}}$ Only one of the ferrets lost weight.

${ }^{\mathrm{d}}$ No detectable titer. 
Figure 2-3. Avian H2N3 Viruses Replicate but Do Not Transmit Efficiently in

Ferrets. Three ferrets were inoculated intranasally with $10^{5} \mathrm{TCID}_{50}$ of Mal/Alb/03 (A), $10^{6} \mathrm{TCID}_{50}$ of CK/OH/07 (B), or $10^{6} \mathrm{TCID}_{50}$ of $\mathrm{rgCK} / \mathrm{OH} / 07$ (C). Twenty-four hours post-inoculation, one naïve contact ferret was housed with each inoculated ferret. Nasal washes were collected 1, 4, 7, and 11 days post-inoculation and viral titers were determined by EID $_{50}$. 
A Mal/Alb/03

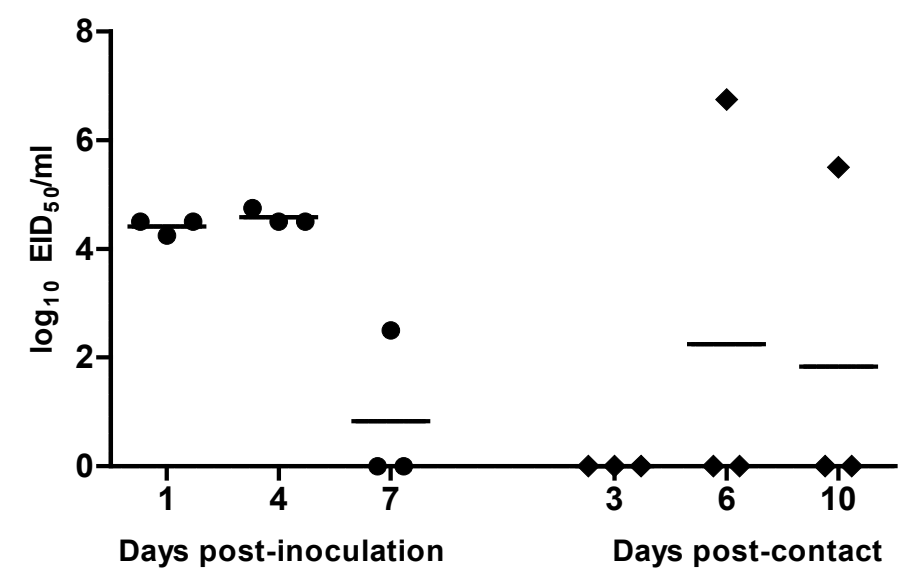

B CK/OH/07

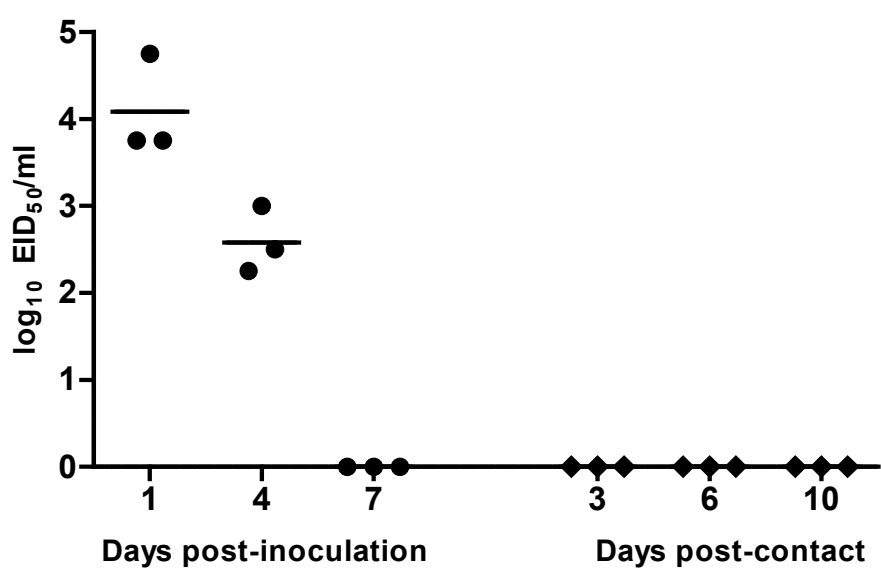

C

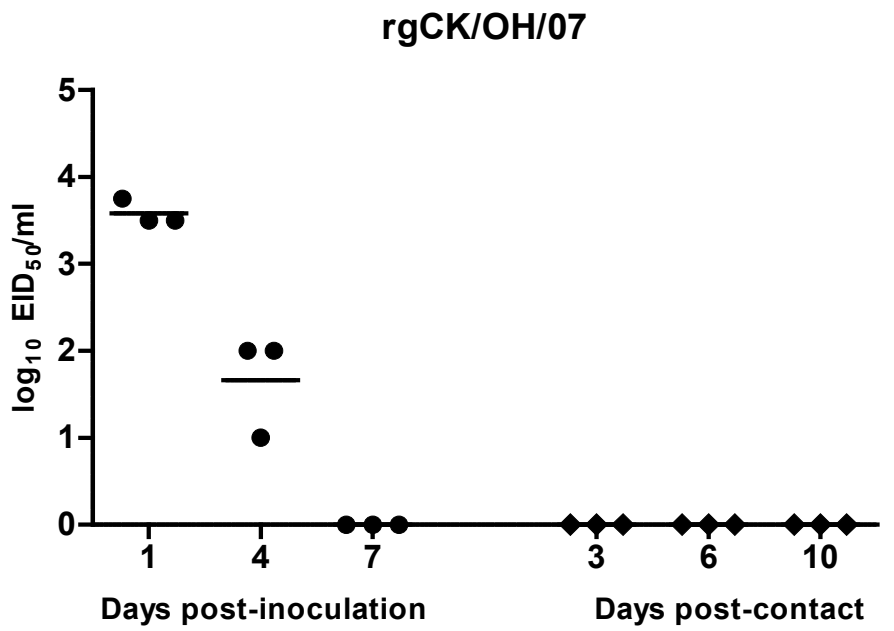




\section{A Single Amino Acid Change in the HA Abolishes the Ability of a Swine}

H2N3 Virus to Transmit in Ferrets. Because the presence of a leucine at position 226 of the HA1 has been shown to play a significant role in host receptor binding specificity, we used site-directed mutagenesis to change the position 226 leucine of SW/MO/06 HA to a glutamine and used reverse genetics to rescue a virus containing this mutation. Three ferrets were infected with $10^{6} \mathrm{TCID}_{50}$ of $\mathrm{rgSW} / \mathrm{MO} / 06$ HAmut and three contact animals were housed with the infected animals beginning 24 hours post-inoculation. Following infection with $\mathrm{rgSW} / \mathrm{MO} / 06$ HAmut, ferrets shed detectable levels of virus by day one post-infection and had titers similar to those of ferrets infected with $\mathrm{rgSW} / \mathrm{MO} / 06$, with an average titer of $10^{5.92} \mathrm{EID}_{50} / \mathrm{ml}$ (Figure 2-4). Virus was isolated from the nasal wash of one contact ferret at day three and day six post contact with titers of $10^{2} \mathrm{EID}_{50} / \mathrm{ml}$ and $10^{6.5} \mathrm{EID}_{50} / \mathrm{ml}$, respectively. When virus isolated from the infected contact ferret on day six post-contact was sequenced, it was found that position 226 of the HA had reverted back to a leucine.

\section{Discussion}

For an influenza pandemic to occur, several criteria must be met, including the introduction of a virus that contains an HA to which the host population has little or no pre-existing immunity (65). The emergence in swine of an $\mathrm{H} 2 \mathrm{~N} 3$ virus that has the ability to transmit between mammals is of great concern because $\mathrm{H} 2$ influenza viruses have not circulated in the human population since 1968 (151). Another criteria for an influenza pandemic virus is the ability to transmit between humans, a trait that is most often modeled in ferrets (85). The swine H2N3 virus examined here transmitted very efficiently in the ferret direct contact model, and a single amino acid change in the HA abolished the virus's transmissibility. Two avian H2N3 viruses could also replicate in ferrets and one was capable of gaining transmissibility.

Although $\mathrm{rgCK} / \mathrm{OH} / 07$ contains the same internal genes and NA gene as $\mathrm{rgSW} / \mathrm{MO} / 06$ and $\mathrm{rgSW} / \mathrm{MO} / 06$ HAmut, it replicated to lower titers, indicating that further changes in the HA may be necessary for optimal replication efficiency. Other than the Q226L change in the receptor binding site, there is only one other amino acid difference between the HA proteins of $\mathrm{CK} / \mathrm{OH} / 07$ and $\mathrm{SW} / \mathrm{MO} / 06$ that is also observed in human $\mathrm{H} 2$ viruses. $\mathrm{CK} / \mathrm{OH} / 07$ has a phenylalanine residue at position 142, while $\mathrm{SW} / \mathrm{MO} / 06$ and other human $\mathrm{H} 2$ isolates have a serine at this position. This change has not been previously described and its impact on replication and transmissibility is unknown. Because the NA from SW/MO/06 was used, it is also possible that an HA/NA mismatch was responsible for the lower replication seen, as balanced HA and NA activity has been shown to be important for efficient viral replication (95).

Examination of the amino acid sequences of the HAs of CK/OH/07, SW/MO/06, an early human $\mathrm{H} 2 \mathrm{~N} 2$ virus (A/Singapore/1/57), and a late human $\mathrm{H} 2 \mathrm{~N} 2$ virus (A/Berkley/1/68), showed nine amino acid residues where the swine sequence matched the avian sequence but differed from both early and late human viruses (Figure 2-5A). An additional 13 residues were conserved among the avian, swine, and early human HAs, 


\section{rgSW/MO/06 HAmut}

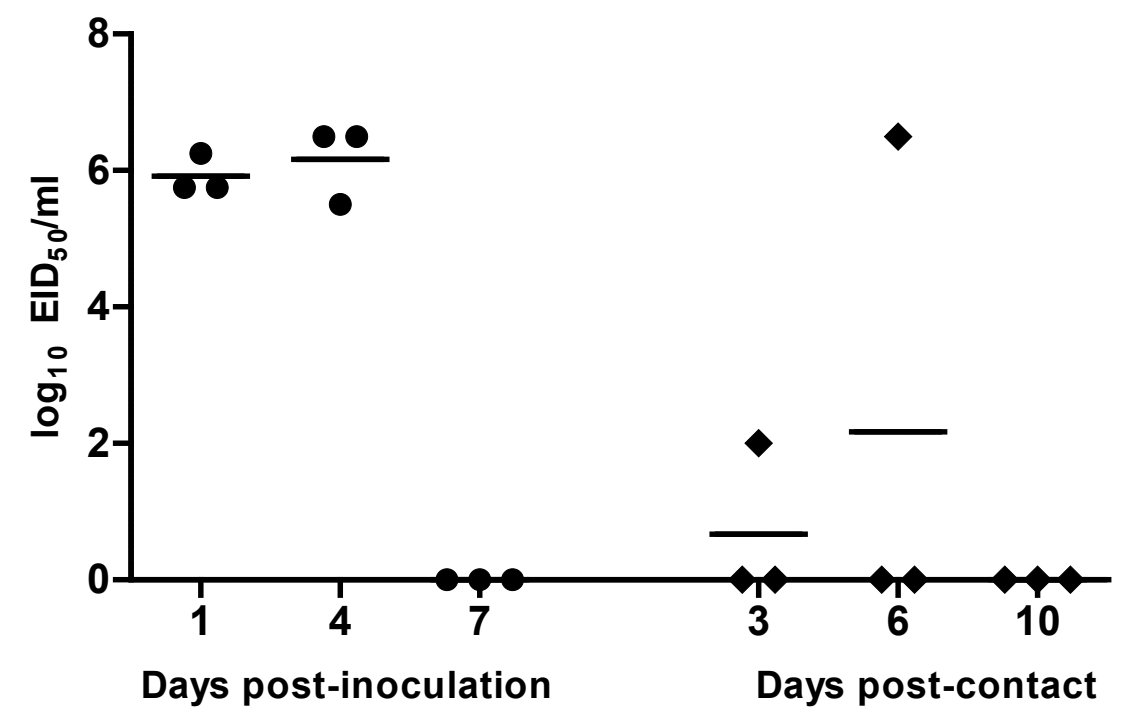

Figure 2-4. A Receptor Binding Mutant Swine H2N3 Virus Replicates but Does Not Efficiently Transmit in Ferrets. Three ferrets were inoculated intranasally with $10^{6}$ $\mathrm{TCID}_{50}$ of $\mathrm{rgSW} / \mathrm{MO} / 06 \mathrm{HAmut}$. Twenty-four hours post-inoculation, one naïve contact ferret was housed with each infected ferret. Nasal washes were collected 1, 4, 7, and 11 days post-inoculation and viral titers were determined by $\operatorname{EID}_{50}$. 
A

\begin{tabular}{lccccccccc} 
& \multicolumn{10}{c}{ HA Amino Acid Position } \\
& 4 & 114 & 214 & 228 & 242 & 314 & 375 & 401 & 460 \\
\cline { 2 - 9 } CK/OH/07 & $\mathrm{K}$ & $\mathrm{T}$ & $\mathrm{I}$ & $\mathrm{G}$ & $\mathrm{V}$ & $\mathrm{R}$ & $\mathrm{I}$ & $\mathrm{N}$ & $\mathrm{A}$ \\
SW/MO/06 & $\mathrm{K}$ & $\mathrm{T}$ & $\mathrm{I}$ & $\mathrm{G}$ & $\mathrm{V}$ & $\mathrm{R}$ & $\mathrm{I}$ & $\mathrm{N}$ & $\mathrm{A}$ \\
A/Singapore/1/57 & $\mathrm{R}$ & $\mathrm{K}$ & $\mathrm{T}$ & $\mathrm{S}$ & $\mathrm{T}$ & $\mathrm{K}$ & $\mathrm{F}$ & $\mathrm{S}$ & $\mathrm{V}$ \\
A/Berkley/1/68 & $\mathrm{R}$ & $\mathrm{K}$ & $\mathrm{T}$ & $\mathrm{S}$ & $\mathrm{T}$ & $\mathrm{K}$ & $\mathrm{F}$ & $\mathrm{S}$ & $\mathrm{V}$
\end{tabular}

B

HA Amino Acid Position

$\mathrm{CK} / \mathrm{OH} / 07$

$\mathrm{SW} / \mathrm{MO} / 06$

\begin{tabular}{ccccccccccccc}
93 & 131 & 144 & 159 & 193 & 197 & 204 & 205 & 219 & 244 & 252 & 499 & 507 \\
\hline G & T & N & S & T & N & V & G & T & N & I & N & K \\
G & T & N & S & T & N & V & G & T & N & I & N & K \\
G & T & N & S & T & N & V & G & T & N & I & N & K \\
S & E & K & P & A & E & E & A & A & S & V & K & E
\end{tabular}

Figure 2-5. Amino Acid Differences in the Amino Acid Sequences of Avian, Swine, and Human $\mathbf{H 2}$ Viruses. (A) There are nine amino acid residues which are conserved between the avian and swine viruses but differ from early and late human $\mathrm{H} 2$ viruses. (B) There are 13 amino acid residues which are conserved between the avian, swine, and early human $\mathrm{H} 2$ viruses but differ from the late human $\mathrm{H} 2$ virus. 
but differed from the late human virus sequence (Figure 2-5B). These residues are likely involved in the adaptation of the virus for optimal replication and transmission in humans.

Position 226 of the HA1 has been shown to be associated with receptor binding specificity in several subtypes of influenza A viruses, including H5 and H9 (47). It has been shown that the Q226L mutation in avian H9N2 viruses allowed for direct contact transmission among ferrets, but not aerosol transmission. In contrast to our results however, introducing an L226Q mutation into the HA of an H9 virus decreased replication efficiency of the virus in ferrets, along with abolishing direct transmission (145), while the H2N3 virus containing the L226Q mutation showed no replication defect. Although the amino acids responsible for receptor binding in $\mathrm{H} 1$ viruses differ from those in $\mathrm{H} 2$ viruses, it has been shown that a two amino acid change in the HA of a $1918 \mathrm{H} 1 \mathrm{~N} 1$ virus which changes the receptor specificity from $\alpha-2,6$ to $\alpha-2-3$ linkages abolishes aerosol transmission, and a virus with a single amino acid change that results in dual receptor binding transmits inefficiently (136). However, receptor binding had not previously been associated with transmissibility in the H2 subtype. The Q226L mutation was noted early in the $1957 \mathrm{H} 2 \mathrm{~N} 2$ pandemic, along with a later G228S mutation. This G228S mutation has not been observed in swine $\mathrm{H} 2 \mathrm{~N} 3$ viruses and its contribution to the receptor binding specificity of the virus is unclear (84). Because both the $\mathrm{H} 2$ and $\mathrm{H} 9$ viruses tested retained the avian residue at position 228 and were able to transmit only by direct contact, it is possible that this amino acid may have a role in the aerosol transmission of the virus. When ferrets were infected with viruses containing glutamine at HA position 226, two of the three viruses quickly mutated to leucine at this position and were able to transmit to contacts. The ease with which these viruses can adapt to a mammalian host greatly increases their pandemic potential.

Because $\mathrm{rgCK} / \mathrm{OH} / 07$, which contains the avian HA on the TRIG backbone, does not replicate more efficiently in ferrets than the wild-type wholly-avian $\mathrm{CK} / \mathrm{OH} / 07$, it does not appear that the presence of the TRIG cassette provides a replicative advantage for these viruses in the ferret model. It also does not appear that the TRIG cassette is necessary for the adaptation of the HA, as wild-type Mal/Alb/03 was able to gain transmissibility through the Q226L mutation. However, in pigs, the reassortant virus was isolated, while wholly-avian viruses were not, indicating that the TRIG may confer an advantage in pigs. The main contribution of the TRIG cassette appears to be acquiring new HA and NA genes and bringing them into the swine population. While direct transmission of influenza viruses from birds to humans does occur, it is not a common event and is usually only seen with highly pathogenic avian influenza viruses (55). However, the transmission of influenza viruses from pigs to humans is much more frequent (97). Although at this time $\mathrm{H} 2 \mathrm{~N} 3$ viruses do not appear to have become established in the swine population, the isolation of this virus along with the emergence of the novel pandemic H1N1 influenza A virus, which also contains elements of the TRIG cassette (33), highlights the importance of swine in the evolution of influenza A viruses and their introduction into the human population. 


\section{CHAPTER 3: IN VITRO REASSORTMENT OF SWINE INFLUENZA A VIRUSES}

\section{Introduction}

The segmented nature of the influenza A virus genome allows these viruses to rapidly evolve through the process of reassortment (34). Reassortment occurs when a single host cell is concurrently infected with two different influenza A viruses. As the genomes of these viruses are replicated and packaged, gene segments from the two separate viruses can be packaged into a single virion, creating a genetically novel virus (151). Successful reassortment depends on several factors.

1) A single cell must be infected with at least two different viruses.

2) The genomes of both viruses must be packaged together in progeny virions.

3) The resulting reassortant viruses must be as least as fit as the parental viruses.

Reassortment of influenza A viruses has played a role in the generation of the last four influenza pandemics in humans through antigenic shift $(33,127,121)$. Antigenic shift occurs when the result of a reassortment event is a virus with an HA that is novel to the host population. In 1957, an avian virus and a human virus reassorted to create an H2N2 virus that contained the HA, NA, and PB1 genes from an avian virus and the remaining gene segments from the previously circulating human virus. This new H2N2 virus replaced the circulating $\mathrm{H} 1 \mathrm{~N} 1$ virus and remained in the human population until the next pandemic virus emerged in 1968. In 1968, the H2N2 virus underwent another reassortment event with an avian virus and acquired an avian $\mathrm{H} 3$ and a novel avian PB1 (151). Descendents of this virus still circulate in the human population. In 2009, an influenza A virus that was the product of a reassortment between a North American triple reassortant swine virus and a Eurasian H1N1 swine virus caused the first influenza pandemic of the $21^{\text {st }}$ century $(33,154)$. Swine have long been proposed as a mixing vessel for influenza A viruses from different host species due to the presence of both avian-like and mammalian-like sialic acid receptors in their respiratory tracts and, in many countries, their close proximity to both birds and humans $(52,120)$.

Prior to 1998, swine influenza in North America was caused by a stable lineage of H1N1 viruses related to the pandemic strain of 1918 (18,50,106). However, in 1998, two groups of novel H3N2 viruses were isolated from swine in the U.S. These viruses were genetically and antigenically distinct both from each other and from previously isolated swine influenza viruses and both were reassortants (160). While the double reassortant virus, containing gene segments of human and classical swine origin, did not become established in the swine population, the triple reassortant lineage, which contained gene segments of human, classical swine, and avian origin, quickly became established and spread throughout North America (149). 
As the triple reassortant viruses spread through the pig population, they continued to reassort with other circulating viruses, maintaining their internal gene constellation, which has been designated the triple reassortant internal gene (TRIG) cassette, but acquiring novel HA and NA genes from both human and swine viruses. Between 1998 and 2008, three distinct H3N2 viruses, two distinct $\mathrm{H} 1 \mathrm{~N} 1$ viruses, and two distinct H1N2 viruses were isolated from North American swine $(148,143)$. The TRIG cassette has also shown the ability to acquire avian-origin HA and NA genes and introduce them into the swine population, as occurred with the H2N3 viruses isolated from pigs in 2006 (84). This frequent introduction of HA and NA genes of different subtypes into the swine population is in marked contrast to the situation prior to the introduction of the TRIG cassette, when $\mathrm{H} 3$ viruses were rarely detected in pigs $(18,50,106)$.

Although reassortment plays an important role in the evolution of influenza A viruses, little is known about the mechanisms controlling the frequency of successful reassortment events and the impact of viral replication, genome packaging, and genome compatibility. Several different subtypes of swine influenza viruses containing the TRIG cassette have been isolated since 1998. In contrast, the classical swine lineage remained unchanged for close to 80 years. This epidemiological data suggest that there is some intrinsic property of the TRIG cassette that allows it to easily acquire different HA genes. Three internal genes differ between triple reassortant swine viruses and classical swine viruses, PA, PB1, and PB2. Therefore these genes are the most likely to be responsible for the observed increase in reassortment frequency. To characterize the reassortment of swine influenza viruses in vitro, and determine if a swine virus containing the TRIG cassette was better able to acquire a human HA than a classical swine virus, a PCR assay was developed to determine the frequency with which a classical or reassortant swine $\mathrm{H} 1 \mathrm{~N} 1$ influenza virus was able to acquire a human $\mathrm{H} 3$ gene.

\section{Materials and Methods}

Viruses Used. Three influenza A viruses were used in the analysis of the reassortment of swine influenza A viruses. A/TX/6/96 (TX/96) is a human H3N2 virus which has HA and NA genes similar to those found in early swine H3N2 reassortant viruses. SW/MN/37866/99 (SW/MN/99) is an H1N1 virus of the classical swine lineage (Figure 3-1A), and SW/NC/18161/02 (SW/NC/02) is a triple reassortant $\mathrm{H} 1 \mathrm{~N} 1$ virus with 5 genes (HA, NA, M, NP, and NS) from the classical swine lineage, 1 gene (PB1) from the human H3N2 lineage, and two genes (PA and PB2) from an avian lineage (Figure 31B). TX/96 was obtained from the Centers for Disease Control and Prevention, SW/MN/99 was obtained from Dr. Marie Gramer at the University of Minnesota Veterinary Diagnostic Laboratory, and SW/NC/02 was obtained from Dr. Gene Erickson at the Rollins Animal Disease Laboratory. Stocks of all viruses were grown in MDCK cells for 72 hours at $35^{\circ} \mathrm{C}$ and stored until use at $-80^{\circ} \mathrm{C}$. Viral titers were determined by TCID $_{50}$. 
A

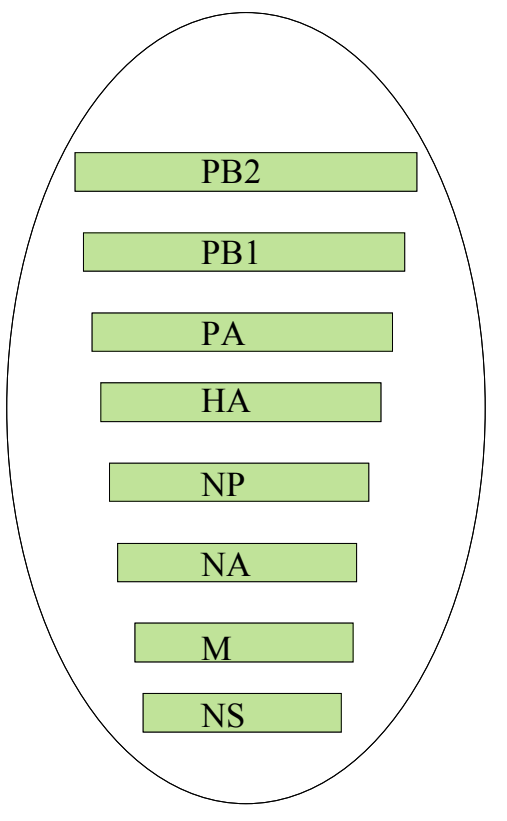

B

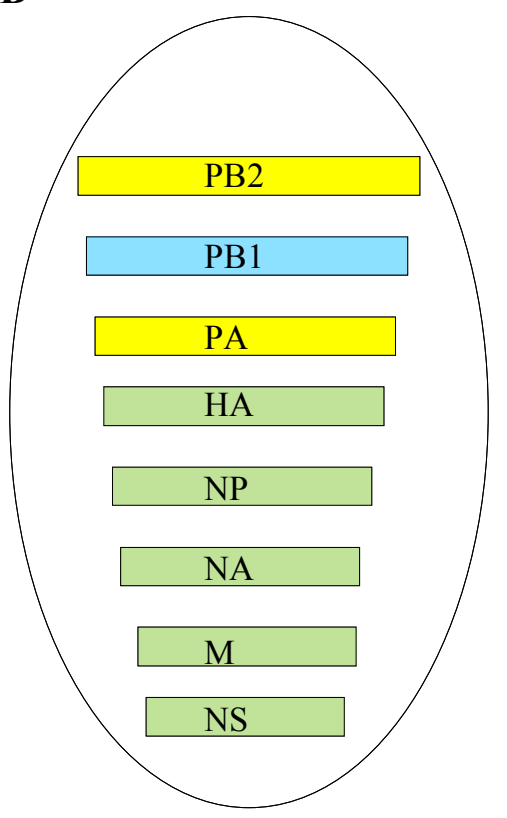

Figure 3-1. Swine Viruses Used for Reassortment Studies. Gene segments from the classical swine lineage are in green. Gene segments from the human H3N2 lineage are in blue. Gene segments from the avian lineage are in yellow. (A) SW/MN/99 is a classical swine $\mathrm{H} 1 \mathrm{~N} 1$ virus. (B) $\mathrm{SW} / \mathrm{NC} / 02$ is a triple reassortant swine $\mathrm{H} 1 \mathrm{~N} 1$ virus. 
Co-infection of MDCK Cells. Twenty-four well tissue culture plates were seeded with MDCK cells and the cells were allowed to reach $90 \%$ confluency. Dilutions of the stock viruses were made in MDCK infection media (1X MEM supplemented with antibiotic/antimycotic solution, vitamin solution, and bovine serum albumin). To determine if optimal conditions existed for the reassortment of swine and human influenza viruses, virus dilutions of 5, 1, 0.1, and 0.01 multiplicities of infection (MOI) were made for each virus (TX/96, SW/MN/99, and SW/NC/02). Cells were infected simultaneously with TX/96 and either $\mathrm{SW} / \mathrm{MN} / 99$ or $\mathrm{SW} / \mathrm{NC} / 02$ or cells were singly infected with SW/MN/99 or SW/NC/02 and then infected with TX/96 following a 24 hour incubation (Figure 3-2). Because polymerase genes influence the ability of viruses to replicate at different temperatures (8), cells were incubated at either $37^{\circ} \mathrm{C}$ or $39^{\circ} \mathrm{C}$ for 48 hours post-infection. Cell supernatants were harvested and stored at $4^{\circ} \mathrm{C}$ until selection for $\mathrm{H} 3$ viruses and then were stored at $-80^{\circ} \mathrm{C}$.

H1 Neutralization. In order to select for viruses which contained the human H3, after cell supernatants were harvested, 30ul of the supernatant was combined with $30 \mathrm{ul}$ of swine serum raised against SW/MN/99 or SW/NC/02 and incubated at $4{ }^{\circ} \mathrm{C}$ for 1 hour. 240ul MDCK infection media was added and 250ul of this mixture was added to MDCK cells in a 24 well plate. Cells were incubated for 48 hours at either $37^{\circ} \mathrm{C}$ or $39^{\circ} \mathrm{C}$ and supernatants were collected. Supernatants were stored at $4^{\circ} \mathrm{C}$ until RNA extraction and then were stored at $-80^{\circ} \mathrm{C}$.

RNA Extraction. RNA was extracted from cell supernatants using the MagMax AI/ND RNA extraction kit from Ambion on a KingFisher machine. Control RNA was extracted from stored supernatants of TX/96, SW/MN/99, and SW/NC/02 using the RNeasy Mini-Kit from Qiagen. Control RNA was diluted to 5ng/ul. RNA was stored at $4^{\circ} \mathrm{C}$ and analyzed within four days of extraction.

Primer Design. Primers were designed based on the sequences of the PA and $\mathrm{PB} 2$ genes of SW/MN/99 and SW/NC/02 in order to determine if these gene segments were present in the isolated $\mathrm{H} 3$ viruses. Primers chosen for testing had at least five nucleotide differences between the swine virus and TX/96, and amplified a 200-500 base pair segment. H3 specific primers were designed based on the sequence of TX/96. Previously designed $\mathrm{H} 1$ and $\mathrm{M}$ specific primers were used for the amplification of these segments (Table 3-1).

Primer Optimization. One-step reverse-transcriptase PCR (RT-PCR) (Qiagen) was performed under a variety of conditions to determine conditions under which each primer set was discriminatory. All reactions had a constant reverse transcriptase step of 30 minutes at $55^{\circ} \mathrm{C}$ and a Taq activation step of 15 minutes at $95^{\circ} \mathrm{C}$. Reactions were run with 35 or 40 cycles and annealing temperatures ranging from $50^{\circ} \mathrm{C}$ to $59^{\circ} \mathrm{C}$, using $10 \mathrm{ng}$ $\mathrm{TX} / 96, \mathrm{SW} / \mathrm{MN} / 99$, or SW/NC/02 as templates. All PCR products were visualized on a 
A

\begin{tabular}{|c|c|c|c|}
\hline $\begin{array}{c}\text { TX/96 MOI=5 } \\
\text { SW/MN/99 MOI=5 }\end{array}$ & $\begin{array}{c}\text { TX/96 MOI=5 } \\
\text { SW/MN/99 MOI=1 }\end{array}$ & $\begin{array}{c}\text { TX/96 MOI }=5 \\
\text { SW/MN/99 MOI }=0.1\end{array}$ & $\begin{array}{c}\text { TX/96 MOI }=5 \\
\text { SW/MN/99 MOI }=0.01\end{array}$ \\
\hline $\begin{array}{c}\text { TX/96 MOI=1 } \\
\text { SW/MN/99 MOI=5 }\end{array}$ & $\begin{array}{c}\text { TX/96 MOI=1 } \\
\text { SW/MN/99 MOI=1 }\end{array}$ & $\begin{array}{c}\text { TX/96 MOI=1 } \\
\text { SW/MN/99 MOI=0.1 }\end{array}$ & $\begin{array}{c}\text { TX/96 MOI=1 } \\
\text { SW/MN/99 MOI=0.01 }\end{array}$ \\
\hline $\begin{array}{c}\mathrm{TX} / 96 \mathrm{MOI}=0.1 \\
\mathrm{SW} / \mathrm{MN} / 99 \mathrm{MOI}=5\end{array}$ & $\begin{array}{c}\mathrm{TX} / 96 \mathrm{MOI}=0.1 \\
\mathrm{SW} / \mathrm{MN} / 99 \mathrm{MOI}=1\end{array}$ & $\begin{array}{c}\text { TX/96 MOI }=0.1 \\
\text { SW/MN/99 MOI }=0.1\end{array}$ & $\begin{array}{c}\text { TX/96 MOI }=0.1 \\
\text { SW/MN/99 MOI }=0.01\end{array}$ \\
\hline $\begin{array}{c}\mathrm{TX} / 96 \mathrm{MOI}=0.01 \\
\mathrm{SW} / \mathrm{MN} / 99 \mathrm{MOI}=5\end{array}$ & $\begin{array}{c}\text { TX/96 MOI }=0.01 \\
\text { SW/MN/99 MOI=1 }\end{array}$ & $\begin{array}{c}\text { TX/96 MOI }=0.01 \\
\text { SW/MN/99 MOI }=0.1\end{array}$ & $\begin{array}{c}\text { TX/96 MOI }=0.01 \\
\text { SW/MN/99 MOI }=0.01\end{array}$ \\
\hline
\end{tabular}

B

\begin{tabular}{|c|c|c|c|}
\hline $\begin{array}{c}\mathrm{TX} / 96 \mathrm{MOI}=5 \\
\mathrm{SW} / \mathrm{NC} / 02 \mathrm{MOI}=5\end{array}$ & $\begin{array}{c}\mathrm{TX} / 96 \mathrm{MOI}=5 \\
\mathrm{SW} / \mathrm{NC} / 02 \mathrm{MOI}=1\end{array}$ & $\begin{array}{c}\mathrm{TX} / 96 \mathrm{MOI}=5 \\
\mathrm{SW} / \mathrm{NC} / 02 \mathrm{MOI}=0.1\end{array}$ & $\begin{array}{c}\mathrm{TX} / 96 \mathrm{MOI}=5 \\
\mathrm{SW} / \mathrm{NC} / 02 \mathrm{MOI}=0.01\end{array}$ \\
\hline $\begin{array}{c}\mathrm{TX} / 96 \mathrm{MOI}=1 \\
\mathrm{SW} / \mathrm{NC} / 02 \mathrm{MOI}=5\end{array}$ & $\begin{array}{c}\mathrm{TX} / 96 \mathrm{MOI}=1 \\
\mathrm{SW} / \mathrm{NC} / 02 \mathrm{MOI}=1\end{array}$ & $\begin{array}{c}\mathrm{TX} / 96 \mathrm{MOI}=1 \\
\mathrm{SW} / \mathrm{NC} / 02 \mathrm{MOI}=0.1\end{array}$ & $\begin{array}{c}\mathrm{TX} / 96 \mathrm{MOI}=1 \\
\mathrm{SW} / \mathrm{NC} / 02 \mathrm{MOI}=0.01\end{array}$ \\
\hline $\mathrm{TX} / 96 \mathrm{MOI}=0.1$ & $\begin{array}{c}\mathrm{TX} / 96 \mathrm{MOI}=0.1 \\
\mathrm{SW} / \mathrm{NC} / 02 \mathrm{MOI}=1\end{array}$ & $\begin{array}{c}\mathrm{TX} / 96 \mathrm{MOI}=0.1 \\
\mathrm{SW} / \mathrm{NC} / 02 \mathrm{MOI}=0.1\end{array}$ & $\begin{array}{c}\mathrm{TX} / 96 \mathrm{MOI}=0.1 \\
\mathrm{SW} / \mathrm{NC} / 02 \mathrm{MOI}=0.01\end{array}$ \\
\hline $\mathrm{TX} / 96 \mathrm{MOI}=0.01$ & $\begin{array}{c}\mathrm{TX} / 96 \mathrm{MOI}=0.01 \\
\mathrm{SW} / \mathrm{NC} / 02 \mathrm{MOI}=5\end{array}$ & $\begin{array}{c}\mathrm{TX} / 96 \mathrm{MOI}=0.01 \\
\mathrm{SW} / \mathrm{NC} / 02 \mathrm{MOI}=0.1\end{array}$ & $\begin{array}{c}\mathrm{TX} / 96 \mathrm{MOI}=0.01 \\
\mathrm{SW} / \mathrm{NC} / 02 \mathrm{MOI}=0.01\end{array}$ \\
\hline
\end{tabular}

Figure 3-2. Combinations of Human and Swine Virus Inoculums Used to Infect

MDCK Cells. TX/96 was added to cells simultaneously or 24 hours after infection with $\mathrm{SW} / \mathrm{MN} / 99$ (A) or SW/NC/02 (B). 
Table 3-1. Primer Sequences and PCR Conditions Used to Detect Reassortant Viruses.

\begin{tabular}{lll}
\hline Primer Name & Sequence (5'-3') & PCR Conditions \\
\hline M-481 & ACAGATTGCTGATTCCCAGCA & $57^{\circ} \mathrm{C}$ annealing \\
M-915R & TATTCTTCCCTCATAGACTC & 35 cycles \\
SW-H1-1 & CAGGGGAAAATAAAAGCAACCAAAATG & $59^{\circ} \mathrm{C}$ annealing \\
SW-H1-970R & GACATTCTCCAATTGTGACTGGATG & 35 cycles \\
H3-1151 & TAGACGGTTGGTACGGTTTCAGG & $59^{\circ} \mathrm{C}$ annealing \\
H3-1609R & ACCGGTTGTTTAATGCTTCGTCTC & 40 cycles \\
MN-PA-206 & TTGAAGGGAGGGACCGGAAT & $57^{\circ} \mathrm{C}$ annealing \\
MN-PA-410R & ATATGGATGTGCGTACCT & 35 cycles \\
MN-PB2-1363 & TTGGGATACTCCCTGATTTA & $50^{\circ} \mathrm{C}$ annealing \\
MN-PB2-1569R & TTATCGTTAACCTTTCATTC & 40 cycles \\
NC-PA-762 & ACGTCCCCTCAGATTGCCT & $57^{\circ} \mathrm{C}$ annealing \\
NC-PA-1070R & CACTTCAATTGGCTTGTTC & 35 cycles \\
NC-PB2-1540 & GACACAAGGAACGGAGAAGT & $59^{\circ} \mathrm{C}$ annealing \\
NC-PB2-1792R & TTTGCTGGAACAGTGTCCTT & 40 cycles \\
\hline
\end{tabular}

Note: Nucleotides in bold differ from A/TX/6/96 sequence. 
$1 \%$ agarose gel containing Gel Red. The discriminatory primers chosen for SW/MN/99 were MN-PA-206F with MN-PA-410R and MN-PB2-1363F with MN-PB2-1569R. SW/MN/99 PA primers were specific after 35 cycles with an annealing temperature of $57^{\circ} \mathrm{C}$ and SW/MN/99 PB2 primers were specific after 40 cycles with an annealing temperature of $50^{\circ} \mathrm{C}$. The discriminatory primers chosen for SW/NC/02 were NC-PA$762 \mathrm{~F}$ with NC-PA-1070R, and NC-PB2-1540F with NC-PB2-1792F. SW/NC/02 PA primers were specific for $\mathrm{SW} / \mathrm{NC} / 02$ after 35 cycles with an annealing temperature of $57^{\circ} \mathrm{C}$ and $\mathrm{SW} / \mathrm{NC} / 02 \mathrm{~PB} 2$ primers were specific for $\mathrm{SW} / \mathrm{NC} / 02$ after 35 cycles with an annealing temperature of $59^{\circ} \mathrm{C}$ (Table 3-1).

Detection of Reassortant Viruses. After RNA was extracted from the cell supernatants, an RT-PCR was run with M gene specific primers to determine sample quality. The PCR was run for 35 cycles using a $57^{\circ} \mathrm{C}$ annealing temperature. RT-PCR with $\mathrm{H} 1$ specific primers was run to confirm that no $\mathrm{H} 1$ viruses were present in the samples. These reactions were run for 40 cycles with a $59^{\circ} \mathrm{C}$ annealing temperature. RTPCR with $\mathrm{H} 3$ specific primers was run to confirm the presence of $\mathrm{H} 3$ in the samples and was run for 40 cycles with a $59^{\circ} \mathrm{C}$ annealing temperature. $\mathrm{PA}$ and $\mathrm{PB} 2$ reactions were run using the optimal conditions previously described. PCR products were visualized on a $1 \%$ agarose gel containing Gel Red.

\section{Results}

No Detectable Reassortment of a Classical Swine H1N1 Virus. To determine the ability of a classical swine H1N1 influenza virus to successfully acquire a human $\mathrm{H3}$ gene, MDCK cells were co-infected with the classical swine lineage virus SW/MN/99 and the human influenza virus $\mathrm{TX} / 96$. The cells were incubated at $37^{\circ} \mathrm{C}$ or $39^{\circ} \mathrm{C}$ and supernatants were collected 48 hours post-infection. The supernatants were then incubated with swine serum raised against SW/MN/99 to neutralize any viruses containing the classical swine $\mathrm{H} 1$ and used to inoculate MDCK cells which were then incubated for 48 hours. RNA was extracted from the cell supernatants and five RT-PCR reactions were performed to detect $\mathrm{M}, \mathrm{H} 1, \mathrm{H} 3$, swine $\mathrm{PA}$, and swine $\mathrm{PB} 2$. Of the 61 samples collected, 44 were PCR positive for $\mathrm{M}$, indicating the presence of virus in the sample (Figure 3-3). One sample was PCR positive for H1 (Figure 3-4), indicating that neutralization was incomplete in that sample. 38 of the M positive samples were PCR positive for $\mathrm{H} 3$ (Figure 3-5), and an additional 10 samples in which $\mathrm{M}$ was not detected were also positive for $\mathrm{H} 3$. Of the 48 samples that were positive for $\mathrm{H} 3$, none were positive for SW/MN/99 PA or PB2 (Figures 3-6 and 3-7), indicating that SW/MN/99 was not able to successfully acquire the human $\mathrm{H} 3$ gene under any of the tested conditions and that the $\mathrm{H} 3$ viruses detected were likely wholly TX/96.

High Frequency of Reassortment of a Reassortant Swine H1N1 Virus. To determine the ability of a triple reassortant swine H1N1 influenza virus to successfully 


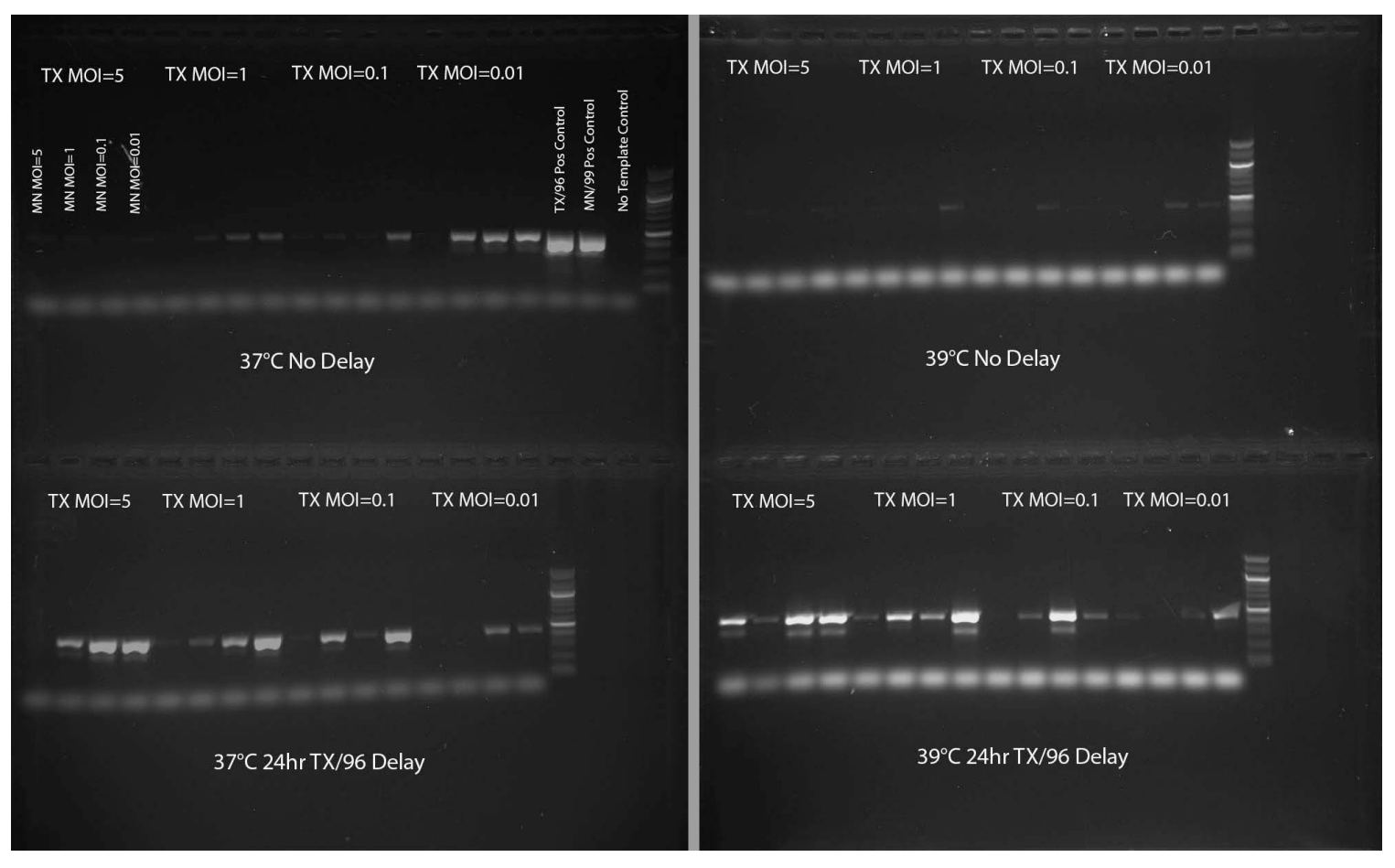

Figure 3-3. M Gene PCR on TX/96 + SW/MN/99 Co-infection Supernatants. MDCK cells were co-infected with TX/96 and SW/MN/99. Forty-eight hours postinfection, the tissue culture media was collected and incubated with swine sera raised against $\mathrm{SW} / \mathrm{MN} / 99$. The neutralized supernatants were then used to infect MDCK cells and the cells were incubated for 48 hours. RNA was extracted from the cell supernatants and one-step RT-PCR was performed using M gene specific primers. All products were run on a $1 \%$ agarose gel containing Gel Red. 


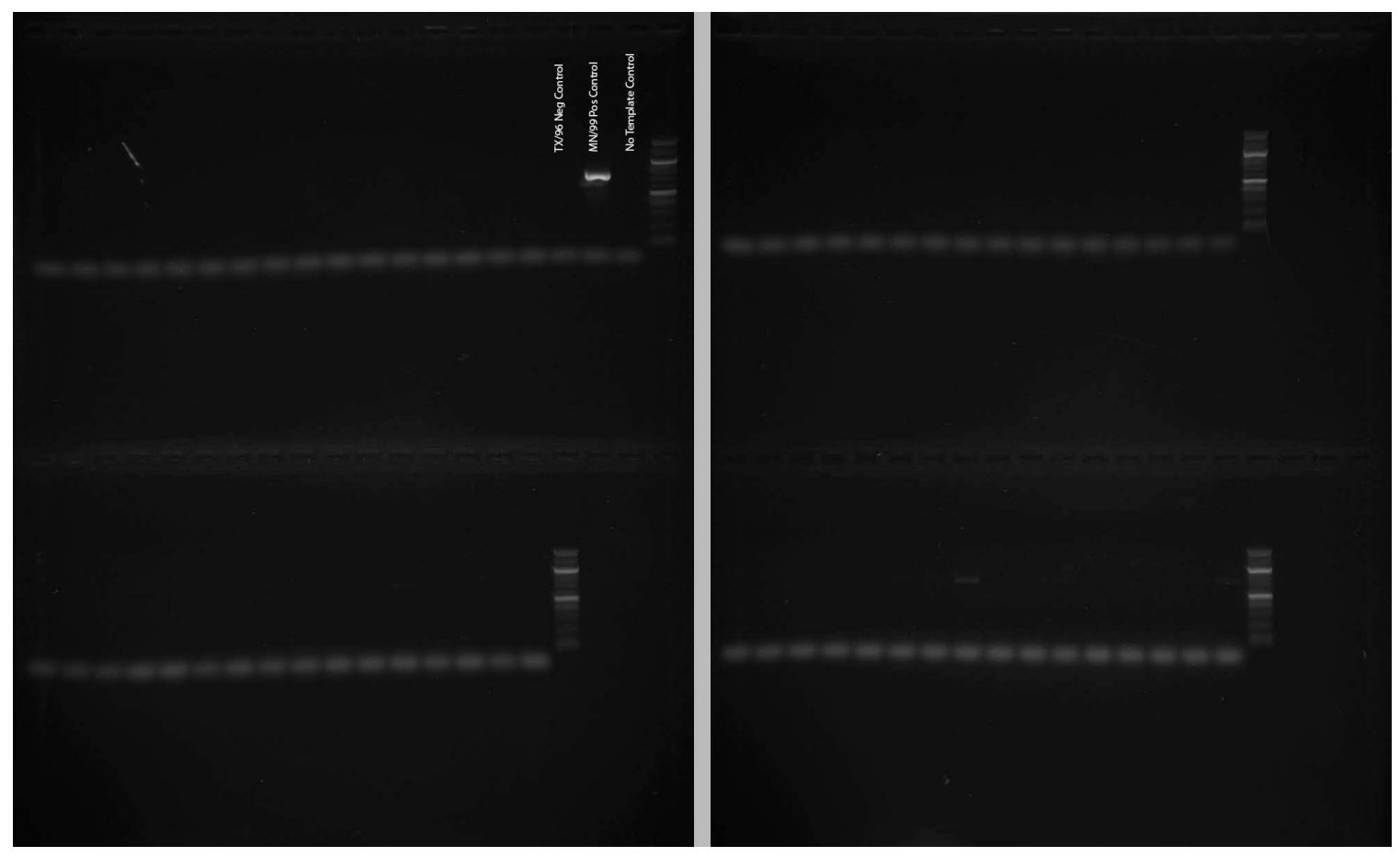

Figure 3-4. H1 Gene PCR on TX/96 + SW/MN/99 Co-infection Supernatants. RNA was extracted from the cell supernatants of co-infected MDCK cells. One-step RT-PCR was performed using $\mathrm{H} 1$ specific primers and products were visualized on a $1 \%$ agarose gel containing Gel Red. 

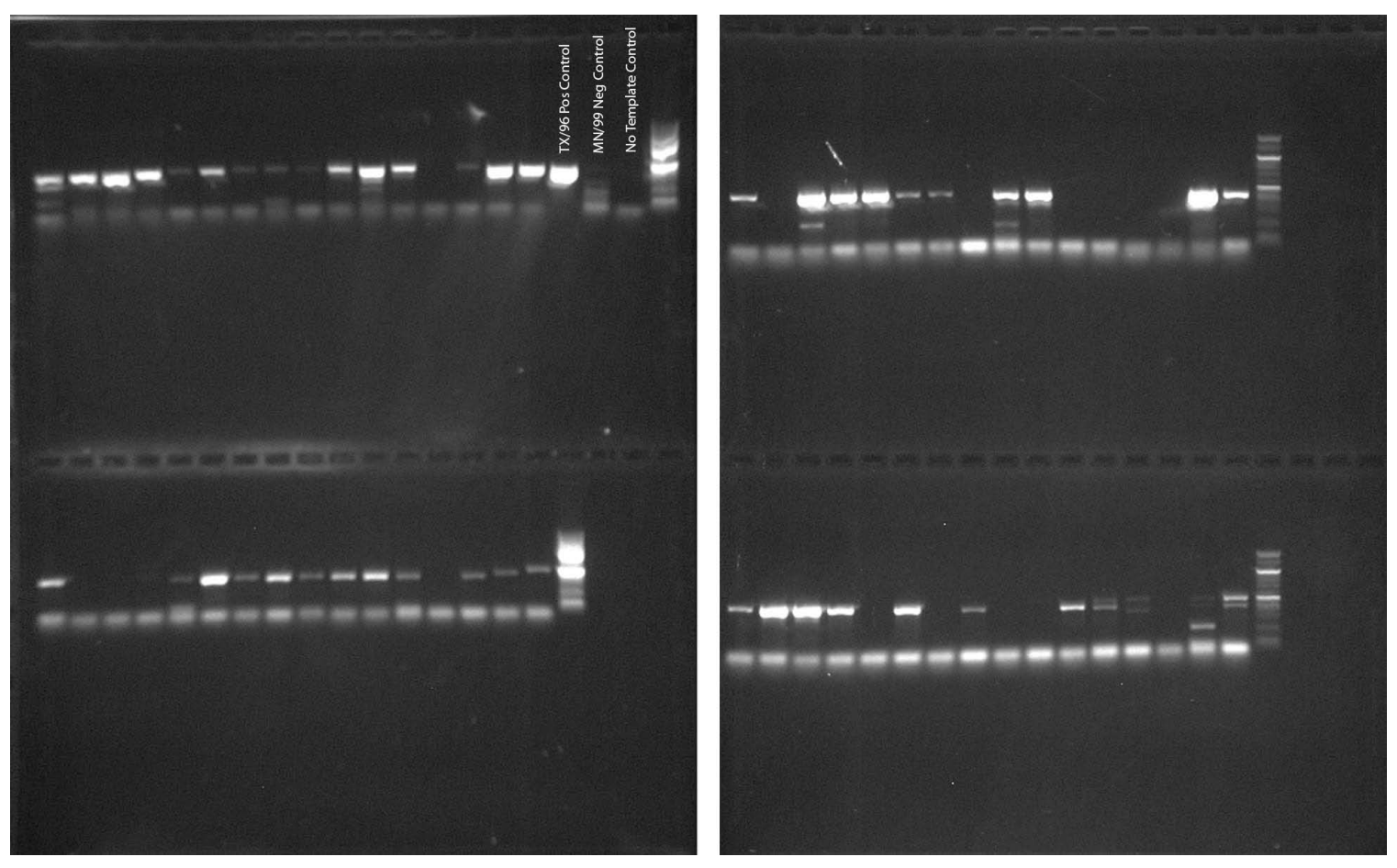

Figure 3-5. H3 Gene PCR on TX/96 + SW/MN/99 Co-infection Supernatants. RNA was extracted from the cell supernatants of co-infected MDCK cells. One-step RT-PCR was performed using $\mathrm{H} 3$ specific primers and products were visualized on a $1 \%$ agarose gel containing Gel Red. 


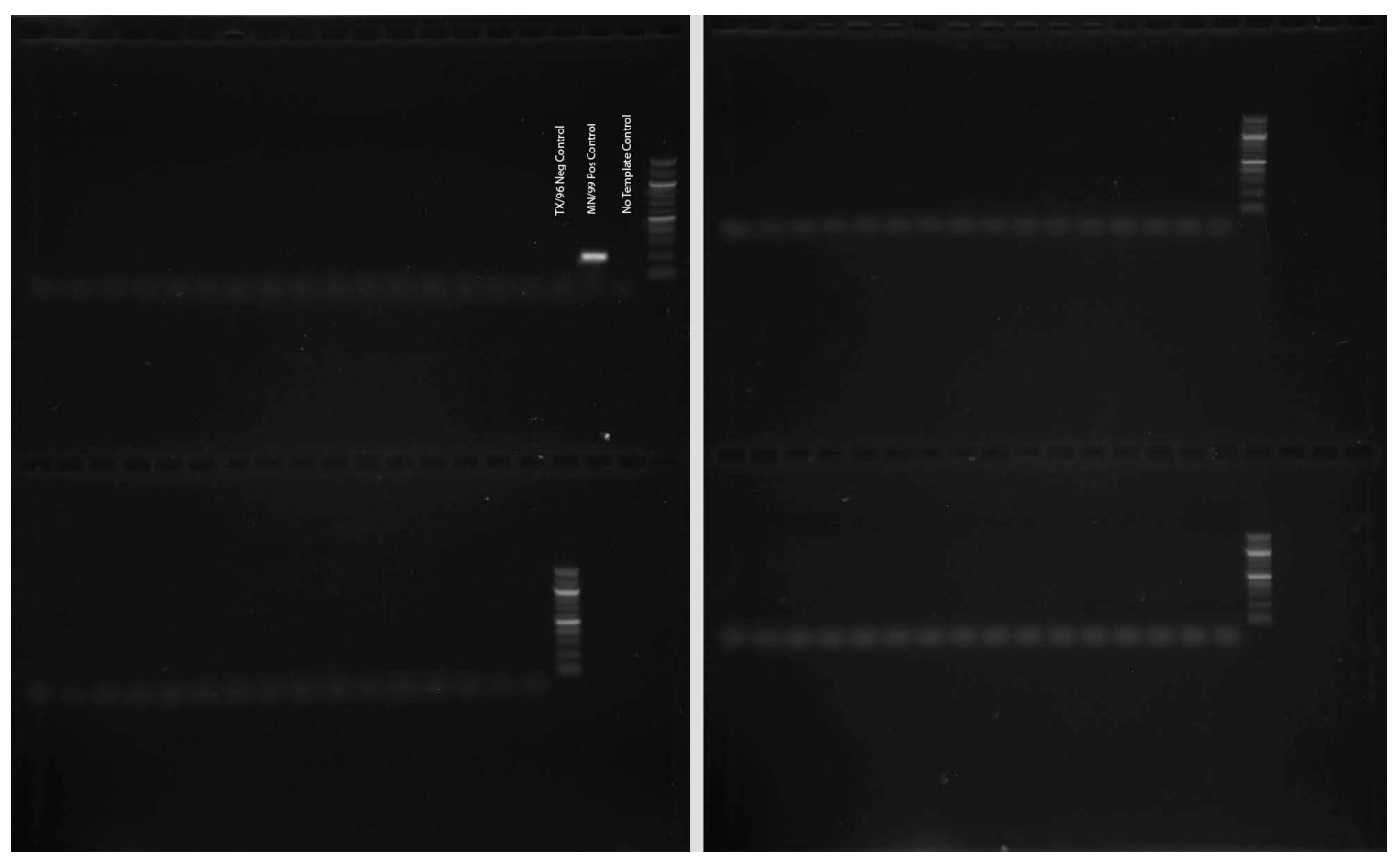

Figure 3-6. PA Gene PCR on TX/96 + SW/MN/99 Co-infection Supernatants. RNA was extracted from the cell supernatants of co-infected MDCK cells. One-step RT-PCR was performed using SW/MN/99 PA specific primers and products were visualized on a $1 \%$ agarose gel containing Gel Red. 


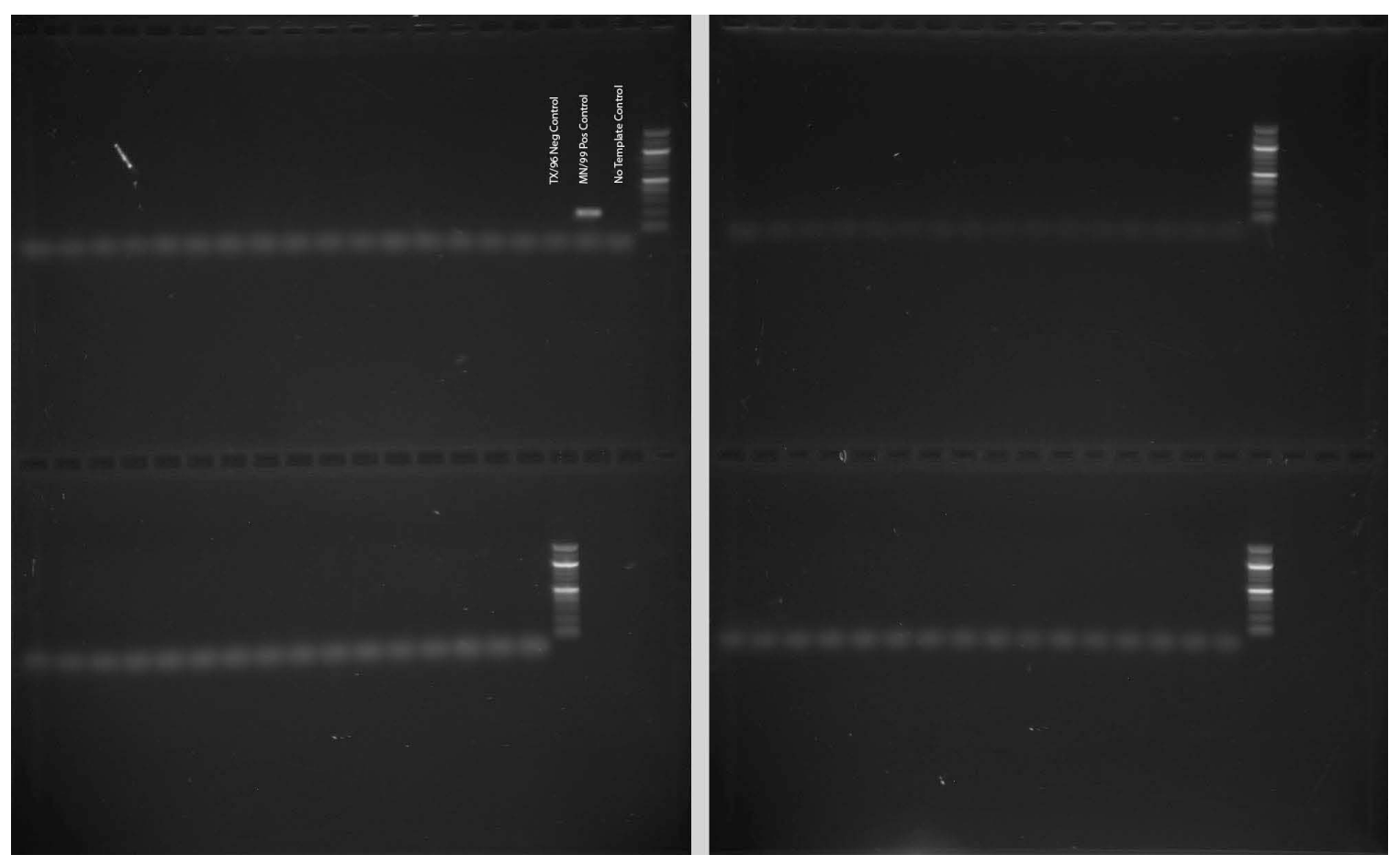

Figure 3-7. PB2 Gene PCR on TX/96 + SW/MN/99 Co-infection Supernatants.

RNA was extracted from the cell supernatants of co-infected MDCK cells. One-step RTPCR was performed using SW/MN/99 PB2 specific primers and products were visualized on a $1 \%$ agarose gel containing Gel Red. 
acquire a human $\mathrm{H} 3$ gene, MDCK cells were co-infected with the reassortant swine virus $\mathrm{SW} / \mathrm{NC} / 02$ and the human influenza virus TX/96. The cells were incubated at $37^{\circ} \mathrm{C}$ or $39^{\circ} \mathrm{C}$ and supernatants were collected 48 hours post-infection. The supernatants were then incubated with swine serum raised against $\mathrm{SW} / \mathrm{NC} / 02$ to neutralize any $\mathrm{H} 1$ viruses and the neutralized supernatants were used to inoculate MDCK cells. The cells were incubated for 48 hours and then RNA was extracted from the cell supernatants. Following RNA extraction, five RT-PCR reactions were performed to detect $\mathrm{M}, \mathrm{H} 1, \mathrm{H} 3$, avian-like swine PA, and avian-like swine PB2. Of the 63 samples collected, 51 were PCR positive for M (Figure 3-8). None of the samples were PCR positive for H1 (Figure 3-9). 31 of the $\mathrm{M}$ positive samples were also positive for $\mathrm{H} 3$ (Figure 3-10), and 7 samples were negative for $\mathrm{M}$ but positive for $\mathrm{H} 3$. Of the 38 samples that were positive for $\mathrm{H} 3,20(53 \%)$ contained both PA and PB2 from SW/NC/02 and 11 (29\%) contained only PA from SW/NC/02 (Figures 3-11 and 3-12). An additional 20 samples were positive for $\mathrm{M}$ but negative for $\mathrm{H} 3$. Nine of these samples contained both PA and PB2 from $\mathrm{SW} / \mathrm{NC} / 02$ and 11 contained $\mathrm{PA}$ from $\mathrm{SW} / \mathrm{NC} / 02$. Although these samples were negative for $\mathrm{H} 1$, without a positive $\mathrm{H} 3 \mathrm{PCR}$, reassortment cannot be confirmed.

Optimal Conditions for Human/Swine Virus Reassortment. Cells were coinfected at a range of MOIs, from 5 to 0.01 , and incubated at two temperatures to determine if there were optimal conditions for the in vitro reassortment of swine influenza viruses. Inoculations with the human and swine viruses were also staggered to determine if this affected reassortment frequency. The conditions under which cells were infected and incubated had varying effects on the frequency of successful reassortment. When cells were co-infected simultaneously and incubated at $37^{\circ} \mathrm{C}, 10$ of the collected samples contained reassortants (Figure 3-13A). More reassortants were detected in samples which were inoculated with TX/96 at an MOI of 1 or 5, but the MOI of $\mathrm{SW} / \mathrm{NC} / 02 \mathrm{did}$ not appear to have an effect. In contrast, when cells were infected with $\mathrm{TX} / 9624$ hours after infection with $\mathrm{SW} / \mathrm{NC} / 02$ and incubated at $37^{\circ} \mathrm{C}$, only four samples contained reassortants (Figure 3-13B). Under these conditions, the MOI of TX/96 did not affect the frequency of reassortment, but three of the four samples where reassortants were detected had been inoculated with $\mathrm{SW} / \mathrm{NC} / 02$ at an $\mathrm{MOI}=0.1$. When cells were coinfected simultaneously and incubated at $39^{\circ} \mathrm{C}$, seven samples contained reassortants (Figure 3-13C). Once again, while the MOI of TX/96 did not appear to affect the frequency of reassortment, five of the seven samples in which reassortants were detected had been inoculated with $\mathrm{SW} / \mathrm{NC} / 02$ at an $\mathrm{MOI}=1$ or 0.1 . When cells were infected with $\mathrm{TX} / 9624$ hours after infection with $\mathrm{SW} / \mathrm{NC} / 02$ and incubated at $39^{\circ} \mathrm{C}$, reassortants were detected in nine samples (Figure 3-13D). In contrast to the other conditions tested, the MOI of both TX/96 and SW/NC/02 affected the frequency with which reassortants were detected, with reassortants most frequently detected in samples with high TX/96 MOIs and low SW/NC/02 MOIs. 

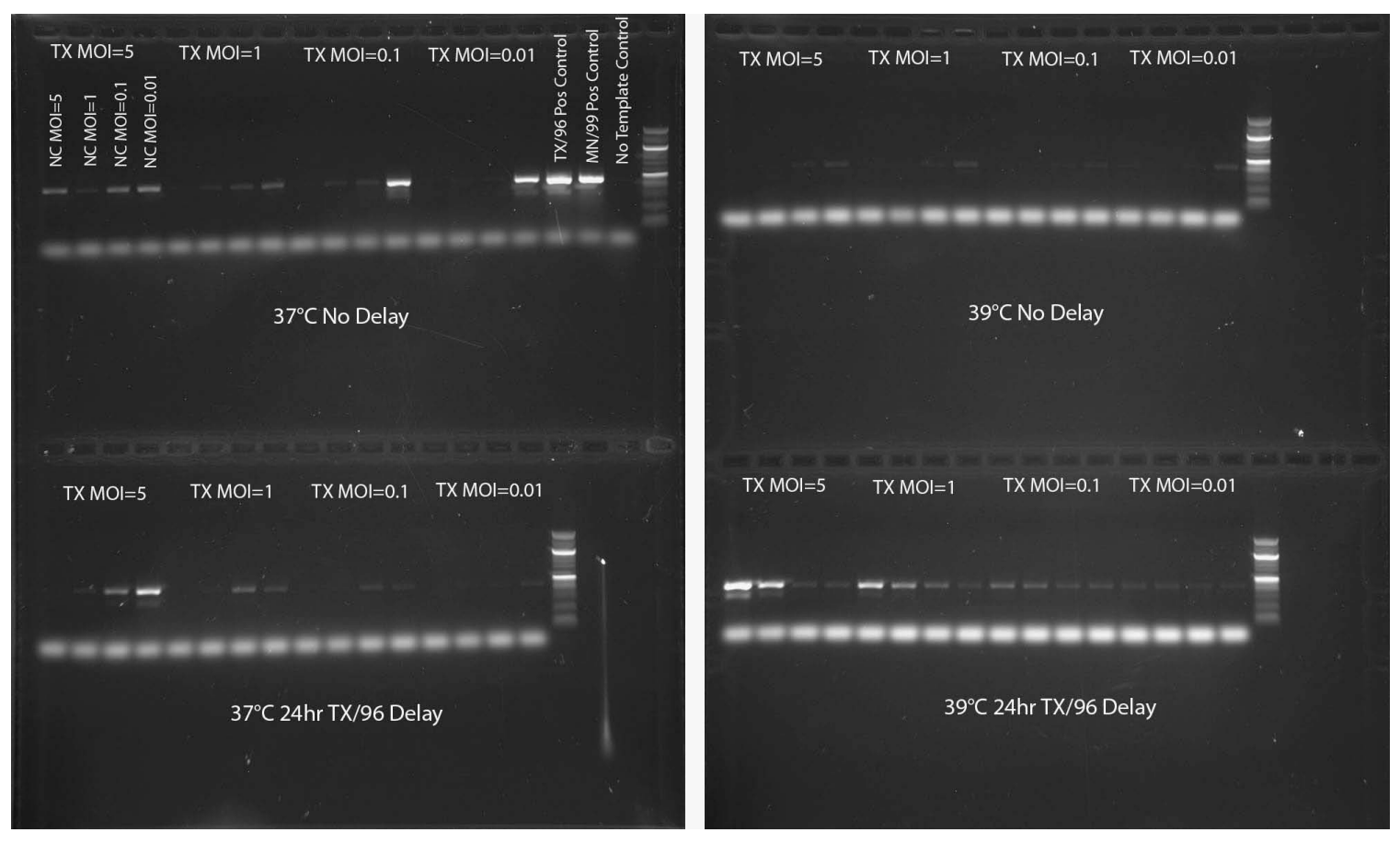

Figure 3-8. M Gene PCR on TX/96 + SW/NC/02 Co-infection Supernatants. MDCK cells were co-infected with TX/96 and SW/MN/99. Forty-eight hours post-infection, the tissue culture media was collected and incubated with swine sera raised against $\mathrm{SW} / \mathrm{NC} / 02$. The neutralized supernatants were then used to infect MDCK cells and the cells were incubated for 48 hours. RNA was extracted from the cell supernatants and one-step RT-PCR was performed using M gene specific primers. All products were run on a $1 \%$ agarose gel containing Gel Red. 


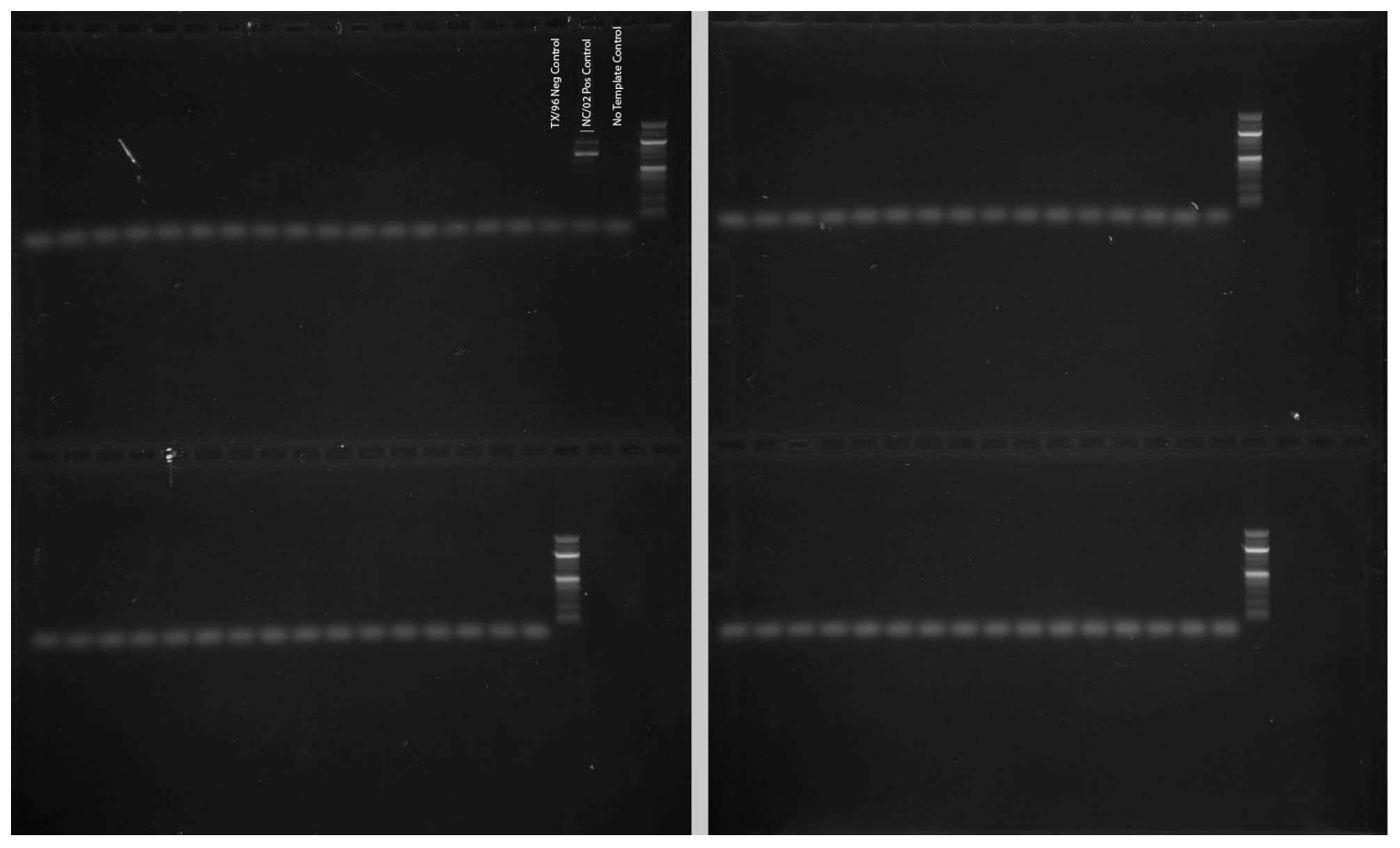

Figure 3-9. H1 Gene PCR on TX/96 + SW/NC/02 Co-infection Supernatants. RNA was extracted from the cell supernatants of co-infected MDCK cells. One-step RT-PCR was performed using $\mathrm{H} 1$ specific primers and products were visualized on a $1 \%$ agarose gel containing Gel Red. 


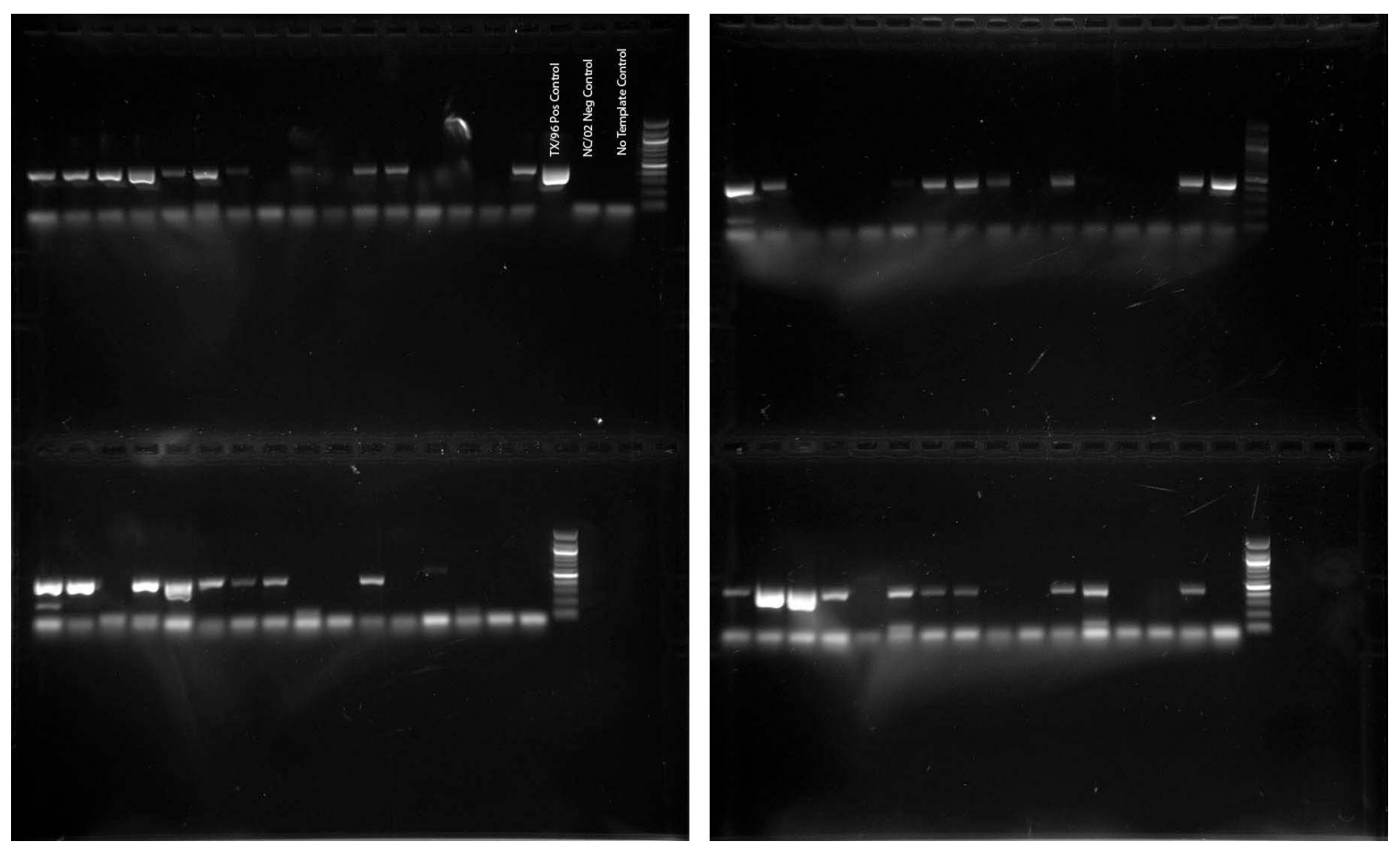

Figure 3-10. H3 Gene PCR on TX/96 + SW/NC/02 Co-infection Supernatants. RNA was extracted from the cell supernatants of co-infected MDCK cells. One-step RT-PCR was performed using $\mathrm{H} 3$ specific primers and products were visualized on a $1 \%$ agarose gel containing Gel Red. 

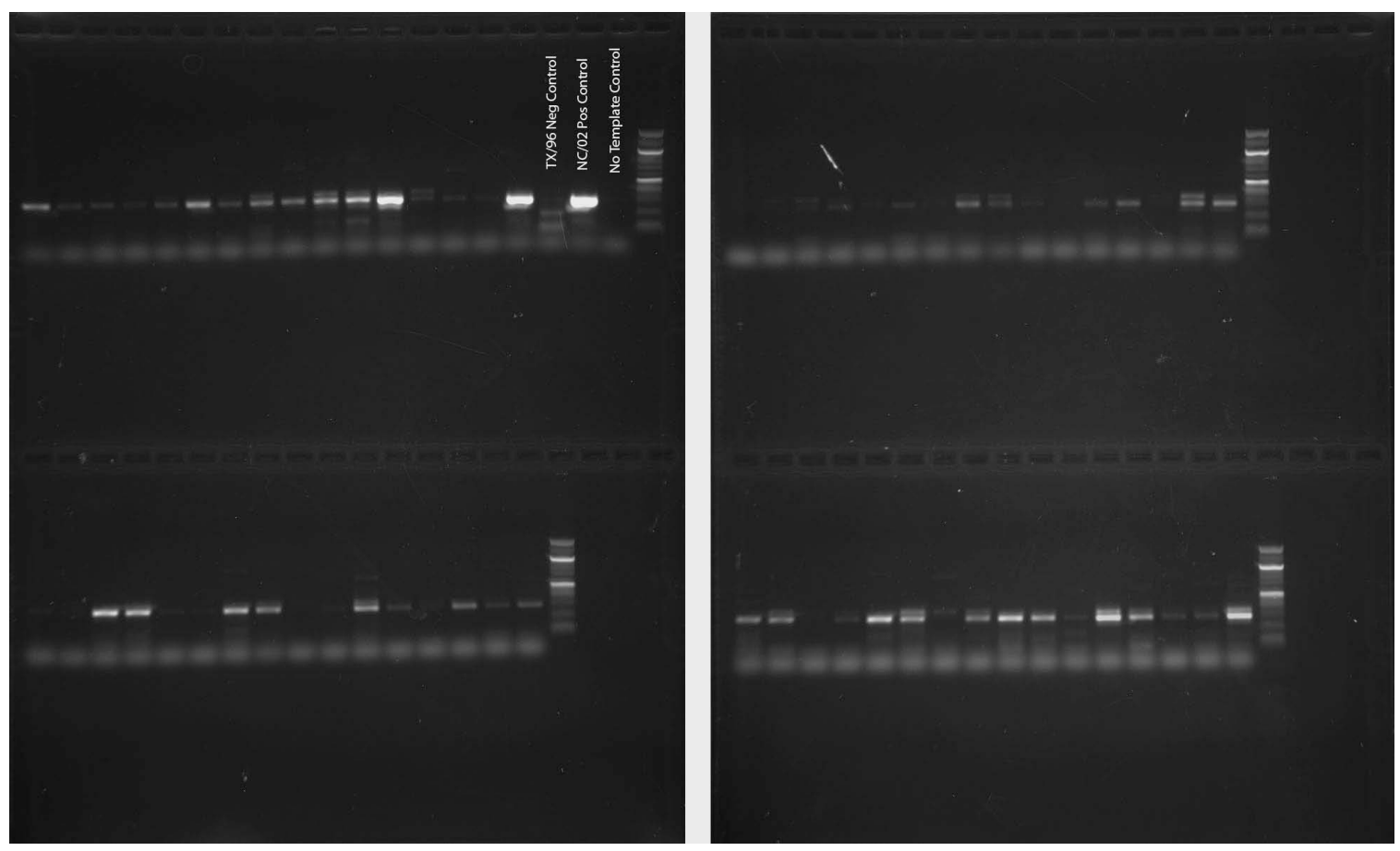

Figure 3-11. PA Gene PCR on TX/96 + SW/NC/02 Co-infection Supernatants. RNA was extracted from the cell supernatants of co-infected MDCK cells. One-step RT-PCR was performed using SW/NC/02 PA specific primers and products were visualized on a $1 \%$ agarose gel containing Gel Red. 

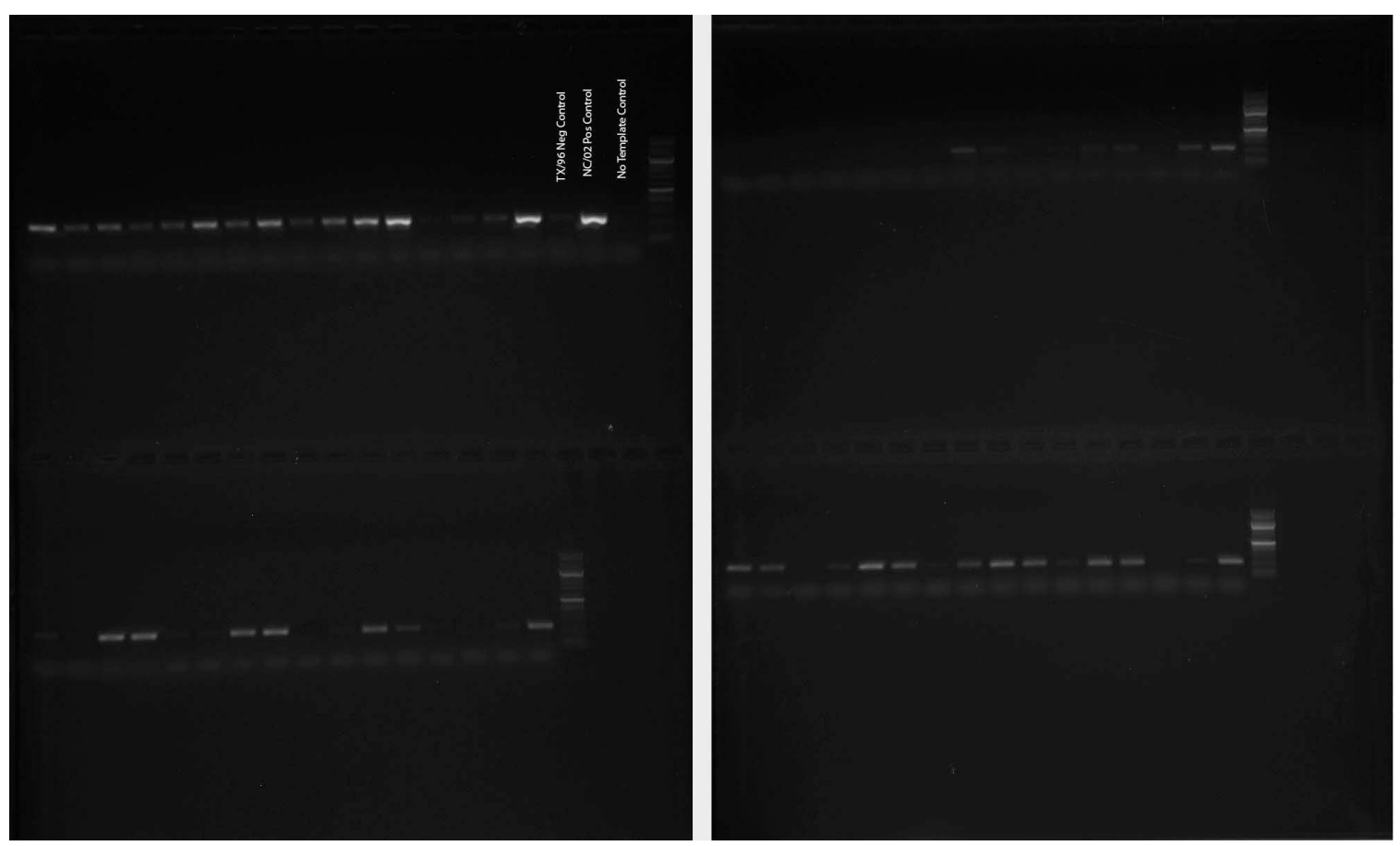

Figure 3-12. PB2 Gene PCR on TX/96 + SW/NC/02 Co-infection Supernatants.

RNA was extracted from the cell supernatants of co-infected MDCK cells. One-step RTPCR was performed using SW/NC/02 PB2 specific primers and products were visualized on a $1 \%$ agarose gel containing Gel Red. 
Figure 3-13. Conditions under Which Reassortant Viruses Were Detected. $37^{\circ} \mathrm{C}$, No delay (A). $37^{\circ} \mathrm{C}$, TX/96 delayed 24 hours (B). $39^{\circ} \mathrm{C}$, No delay (C). $39^{\circ} \mathrm{C}$, TX/96 delayed 24 hours (D). Samples which were positive for $\mathrm{H} 3$ and containing SW/NC/02 $\mathrm{PA}$ and PB2 are shown in green. Samples positive for $\mathrm{H} 3$ and containing SW/NC/ PA are shown in yellow. Samples positive for $\mathrm{H} 3$ but negative for both SW/NC/02 PA and PB2 are shown in blue. Samples that were negative for $\mathrm{H} 3$ are in white. 


\begin{tabular}{|l|c|c|c|}
\hline $\begin{array}{c}\mathrm{TX} / 96 \mathrm{MOI}=5 \\
\mathrm{SW} / \mathrm{NC} / 02 \mathrm{MOI}=5\end{array}$ & $\begin{array}{c}\mathrm{TX} / 96 \mathrm{MOI}=5 \\
\mathrm{SW} / \mathrm{NC} / 02 \mathrm{MOI}=1\end{array}$ & $\begin{array}{c}\mathrm{TX} / 96 \mathrm{MOI}=5 \\
\mathrm{SW} / \mathrm{NC} / 02 \mathrm{MOI}=0.1\end{array}$ & $\begin{array}{c}\mathrm{TX} / 96 \mathrm{MOI}=5 \\
\mathrm{SW} / \mathrm{NC} / 02 \mathrm{MOI}=0.01\end{array}$ \\
\hline $\begin{array}{c}\mathrm{TX} / 96 \mathrm{MOI}=1 \\
\mathrm{SW} / \mathrm{NC} / 02 \mathrm{MOI}=5\end{array}$ & $\begin{array}{c}\mathrm{TX} / 96 \mathrm{MOI}=1 \\
\mathrm{SW} / \mathrm{NC} / 02 \mathrm{MOI}=1\end{array}$ & $\begin{array}{c}\mathrm{TX} / 96 \mathrm{MOI}=1 \\
\mathrm{SW} / \mathrm{NC} / 02 \mathrm{MOI}=0.1\end{array}$ & $\begin{array}{c}\mathrm{TX} / 96 \mathrm{MOI}=1 \\
\mathrm{SW} / \mathrm{NC} / 02 \mathrm{MOI}=0.01\end{array}$ \\
\hline $\begin{array}{c}\mathrm{TX} / 96 \mathrm{MOI}=0.1 \\
\mathrm{SW} / \mathrm{NC} / 02 \mathrm{MOI}=5\end{array}$ & $\begin{array}{c}\mathrm{TX} / 96 \mathrm{MOI}=0.1 \\
\mathrm{SW} / \mathrm{NC} / 02 \mathrm{MOI}=1\end{array}$ & $\begin{array}{c}\mathrm{TX} / 96 \mathrm{MOI}=0.1 \\
\mathrm{SW} / \mathrm{NC} / 02 \mathrm{MOI}=0.1\end{array}$ & $\begin{array}{c}\mathrm{TX} / 96 \mathrm{MOI}=0.1 \\
\mathrm{SW} / \mathrm{NC} / 02 \mathrm{MOI}=0.01\end{array}$ \\
\hline $\begin{array}{c}\mathrm{TX} / 96 \mathrm{MOI}=0.01 \\
\mathrm{SW} / \mathrm{NC} / 02 \mathrm{MOI}=5\end{array}$ & $\begin{array}{c}\mathrm{TX} / 96 \mathrm{MOI}=0.01 \\
\mathrm{SW} / \mathrm{NC} / 02 \mathrm{MOI}=1\end{array}$ & $\begin{array}{c}\mathrm{TX} / 96 \mathrm{MOI}=0.01 \\
\mathrm{SW} / \mathrm{NC} / 02 \mathrm{MOI}=0.1\end{array}$ & $\begin{array}{c}\mathrm{TX} / 96 \mathrm{MOI}=0.01 \\
\mathrm{SW} / \mathrm{NC} / 02 \mathrm{MOI}=0.01\end{array}$ \\
\hline
\end{tabular}

B

\begin{tabular}{|c|c|c|c|}
\hline $\begin{array}{c}\mathrm{TX} / 96 \mathrm{MOI}=5 \\
\mathrm{SW} / \mathrm{NC} / 02 \mathrm{MOI}=5\end{array}$ & $\begin{array}{c}\mathrm{TX} / 96 \mathrm{MOI}=5 \\
\mathrm{SW} / \mathrm{NC} / 02 \mathrm{MOI}=1\end{array}$ & $\begin{array}{c}\text { TX/96 MOI }=5 \\
\text { SW/NC/02 MOI=0.1 }\end{array}$ & $\begin{array}{c}\mathrm{TX} / 96 \mathrm{MOI}=5 \\
\mathrm{SW} / \mathrm{NC} / 02 \mathrm{MOI}=0.01\end{array}$ \\
\hline $\begin{array}{c}\mathrm{TX} / 96 \mathrm{MOI}=1 \\
\mathrm{SW} / \mathrm{NC} / 02 \mathrm{MOI}=5\end{array}$ & $\begin{array}{c}\mathrm{TX} / 96 \mathrm{MOI}=1 \\
\mathrm{SW} / \mathrm{NC} / 02 \mathrm{MOI}=1\end{array}$ & $\begin{array}{c}\text { TX/96 MOI=1 } \\
\text { SW/NC/02 MOI=0.1 }\end{array}$ & $\begin{array}{c}\mathrm{TX} / 96 \mathrm{MOI}=1 \\
\mathrm{SW} / \mathrm{NC} / 02 \mathrm{MOI}=0.01\end{array}$ \\
\hline $\begin{array}{c}\mathrm{TX} / 96 \mathrm{MOI}=0.1 \\
\mathrm{SW} / \mathrm{NC} / 02 \mathrm{MOI}=5\end{array}$ & $\begin{array}{c}\mathrm{TX} / 96 \mathrm{MOI}=0.1 \\
\mathrm{SW} / \mathrm{NC} / 02 \mathrm{MOI}=1\end{array}$ & $\begin{array}{c}\mathrm{TX} / 96 \mathrm{MOI}=0.1 \\
\mathrm{SW} / \mathrm{NC} / 02 \mathrm{MOI}=0.1\end{array}$ & $\begin{array}{c}\mathrm{TX} / 96 \mathrm{MOI}=0.1 \\
\mathrm{SW} / \mathrm{NC} / 02 \mathrm{MOI}=0.01\end{array}$ \\
\hline $\begin{array}{c}\mathrm{TX} / 96 \mathrm{MOI}=0.01 \\
\mathrm{SW} / \mathrm{NC} / 02 \mathrm{MOI}=5\end{array}$ & $\begin{array}{c}\mathrm{TX} / 96 \mathrm{MOI}=0.01 \\
\mathrm{SW} / \mathrm{NC} / 02 \mathrm{MOI}=1\end{array}$ & $\begin{array}{c}\mathrm{TX} / 96 \mathrm{MOI}=0.01 \\
\mathrm{SW} / \mathrm{NC} / 02 \mathrm{MOI}=0.1\end{array}$ & $\begin{array}{c}\mathrm{TX} / 96 \mathrm{MOI}=0.01 \\
\mathrm{SW} / \mathrm{NC} / 02 \mathrm{MOI}=0.01\end{array}$ \\
\hline
\end{tabular}




\begin{tabular}{|c|c|c|c|}
\hline $\begin{array}{c}\mathrm{TX} / 96 \mathrm{MOI}=5 \\
\mathrm{SW} / \mathrm{NC} / 02 \mathrm{MOI}=5\end{array}$ & $\begin{array}{c}\mathrm{TX} / 96 \mathrm{MOI}=5 \\
\mathrm{SW} / \mathrm{NC} / 02 \mathrm{MOI}=1\end{array}$ & $\begin{array}{c}\mathrm{TX} / 96 \mathrm{MOI}=5 \\
\mathrm{SW} / \mathrm{NC} / 02 \mathrm{MOI}=0.1\end{array}$ & $\begin{array}{c}\mathrm{TX} / 96 \mathrm{MOI}=5 \\
\mathrm{SW} / \mathrm{NC} / 02 \mathrm{MOI}=0.01\end{array}$ \\
\hline $\begin{array}{c}\mathrm{TX} / 96 \mathrm{MOI}=1 \\
\mathrm{SW} / \mathrm{NC} / 02 \mathrm{MOI}=5\end{array}$ & $\begin{array}{c}\mathrm{TX} / 96 \mathrm{MOI}=1 \\
\mathrm{SW} / \mathrm{NC} / 02 \mathrm{MOI}=1\end{array}$ & $\begin{array}{c}\mathrm{TX} / 96 \mathrm{MOI}=1 \\
\mathrm{SW} / \mathrm{NC} / 02 \mathrm{MOI}=0.1\end{array}$ & $\begin{array}{c}\text { TX/96 MOI }=1 \\
\text { SW/NC/02 MOI }=0.01\end{array}$ \\
\hline $\begin{array}{c}\mathrm{TX} / 96 \mathrm{MOI}=0.1 \\
\mathrm{SW} / \mathrm{NC} / 02 \mathrm{MOI}=5\end{array}$ & $\begin{array}{c}\mathrm{TX} / 96 \mathrm{MOI}=0.1 \\
\mathrm{SW} / \mathrm{NC} / 02 \mathrm{MOI}=1\end{array}$ & $\begin{array}{c}\mathrm{TX} / 96 \mathrm{MOI}=0.1 \\
\mathrm{SW} / \mathrm{NC} / 02 \mathrm{MOI}=0.1\end{array}$ & $\begin{array}{c}\text { TX/96 MOI }=0.1 \\
\text { SW/NC/02 MOI }=0.01\end{array}$ \\
\hline $\begin{array}{c}\mathrm{TX} / 96 \mathrm{MOI}=0.01 \\
\mathrm{SW} / \mathrm{NC} / 02 \mathrm{MOI}=5\end{array}$ & $\begin{array}{c}\mathrm{TX} / 96 \mathrm{MOI}=0.01 \\
\mathrm{SW} / \mathrm{NC} / 02 \mathrm{MOI}=1\end{array}$ & $\begin{array}{c}\mathrm{TX} / 96 \mathrm{MOI}=0.01 \\
\mathrm{SW} / \mathrm{NC} / 02 \mathrm{MOI}=0.1\end{array}$ & $\begin{array}{c}\mathrm{TX} / 96 \mathrm{MOI}=0.01 \\
\mathrm{SW} / \mathrm{NC} / 02 \mathrm{MOI}=0.01\end{array}$ \\
\hline
\end{tabular}

\begin{tabular}{|c|c|c|c|}
\hline $\begin{array}{c}\mathrm{TX} / 96 \mathrm{MOI}=5 \\
\mathrm{SW} / \mathrm{NC} / 02 \mathrm{MOI}=5\end{array}$ & $\begin{array}{c}\mathrm{TX} / 96 \mathrm{MOI}=5 \\
\mathrm{SW} / \mathrm{NC} / 02 \mathrm{MOI}=1\end{array}$ & $\begin{array}{c}\mathrm{TX} / 96 \mathrm{MOI}=5 \\
\mathrm{SW} / \mathrm{NC} / 02 \mathrm{MOI}=0.1\end{array}$ & $\begin{array}{c}\mathrm{TX} / 96 \mathrm{MOI}=5 \\
\mathrm{SW} / \mathrm{NC} / 02 \mathrm{MOI}=0.01\end{array}$ \\
\hline $\begin{array}{c}\mathrm{TX} / 96 \mathrm{MOI}=1 \\
\mathrm{SW} / \mathrm{NC} / 02 \mathrm{MOI}=5\end{array}$ & $\begin{array}{c}\mathrm{TX} / 96 \mathrm{MOI}=1 \\
\mathrm{SW} / \mathrm{NC} / 02 \mathrm{MOI}=1\end{array}$ & $\begin{array}{c}\mathrm{TX} / 96 \mathrm{MOI}=1 \\
\mathrm{SW} / \mathrm{NC} / 02 \mathrm{MOI}=0.1\end{array}$ & $\begin{array}{c}\mathrm{TX} / 96 \mathrm{MOI}=1 \\
\mathrm{SW} / \mathrm{NC} / 02 \mathrm{MOI}=0.01\end{array}$ \\
\hline $\begin{array}{c}\mathrm{TX} / 96 \mathrm{MOI}=0.1 \\
\mathrm{SW} / \mathrm{NC} / 02 \mathrm{MOI}=5\end{array}$ & $\begin{array}{c}\mathrm{TX} / 96 \mathrm{MOI}=0.1 \\
\mathrm{SW} / \mathrm{NC} / 02 \mathrm{MOI}=1\end{array}$ & $\begin{array}{c}\mathrm{TX} / 96 \mathrm{MOI}=0.1 \\
\mathrm{SW} / \mathrm{NC} / 02 \mathrm{MOI}=0.1\end{array}$ & $\begin{array}{c}\mathrm{TX} / 96 \mathrm{MOI}=0.1 \\
\mathrm{SW} / \mathrm{NC} / 02 \mathrm{MOI}=0.01\end{array}$ \\
\hline $\begin{array}{c}\mathrm{TX} / 96 \mathrm{MOI}=0.01 \\
\mathrm{SW} / \mathrm{NC} / 02 \mathrm{MOI}=5\end{array}$ & $\begin{array}{c}\mathrm{TX} / 96 \mathrm{MOI}=0.01 \\
\mathrm{SW} / \mathrm{NC} / 02 \mathrm{MOI}=1\end{array}$ & $\begin{array}{c}\mathrm{TX} / 96 \mathrm{MOI}=0.01 \\
\mathrm{SW} / \mathrm{NC} / 02 \mathrm{MOI}=0.1\end{array}$ & $\begin{array}{c}\mathrm{TX} / 96 \mathrm{MOI}=0.01 \\
\mathrm{SW} / \mathrm{NC} / 02 \mathrm{MOI}=0.01\end{array}$ \\
\hline
\end{tabular}

Figure 3-13 (continued). 


\section{Discussion}

The ability of reassortant swine influenza A viruses to readily acquire novel HA genes raises the possibility of the introduction of novel HA subtypes into both the swine and human populations. Co-infection of MDCK cells with a human H3N2 virus and a classical swine $\mathrm{H} 1 \mathrm{~N} 1$ virus did not result in any detectable reassortant viruses containing the human $\mathrm{H} 3$ with the swine PA or PB2. There are several possible explanations for this lack of detectable reassortment. The successful reassortment of two influenza A viruses is dependent on infection, replication, packaging, and fitness. While it is assumed that in tissue culture both viruses will be able to enter the same cells, this has not been demonstrated and therefore exclusion of one of the viruses by the other remains a possibility. The detection of $\mathrm{H} 3$ in 48 of the 61 samples suggests that if exclusion did take place, it was exclusion of SW/MN/99 by TX/96. Since this virus has a very similar $\mathrm{HA}$ and $\mathrm{NA}$ to that of $\mathrm{SW} / \mathrm{NC} / 02$, which was readily able to undergo reassortment, this explanation is not likely.

Once both viruses have entered the cell, their genomes must both be replicated. Viruses lacking a functional polymerase complex can be rescued by co-infection with a helper virus, showing that the polymerase from one virus can replicate the genome of another. The genes of TX/96 may be preferentially replicated over those of SW/MN/99, although the amount of each parental virus produced was not determined. Previous studies of co-infection using a classical swine and an avian influenza virus showed that replication of the avian virus interfered with the replication of the swine virus (118). It is also possible that reassortant viruses were created, but were less fit than the parental TX/96 virus and therefore had been overgrown by 48 hours post-infection. Samples taken at earlier timepoints may allow for detection of these populations. The double reassortant $\mathrm{H} 3 \mathrm{~N} 2$ lineage, which contained HA, NA, and PB1 genes from a TX/96-like virus was not able to become established in the swine population, supporting the theory that a reassortant between a classical swine virus and a human virus has no advantage over the parental strains.

In contrast to the lack of detectable reassortment between TX/96 and SW/MN/99, co-infection of MDCK cells with a human H3N2 virus and a triple reassortant swine $\mathrm{H} 1 \mathrm{~N} 1$ virus resulted in a high frequency of reassortant viruses containing human $\mathrm{H} 3$ with avian-origin swine PA or PB2. While fewer samples were positive for the H3 gene, 82\% of the samples which were positive for the human $\mathrm{H} 3$ gene were also positive for $\mathrm{SW} / \mathrm{NC} / 02 \mathrm{PA}$ or PB2. Under a range of conditions, TX/96 and SW/NC/02 were able to enter, replicate, and be packaged in the same cells and the resulting reassortant viruses had an advantage over the parental strains. This is supported by the fact that triple reassortant swine influenza viruses quickly replaced the classical H1N1 lineage in North American swine. Both the 1957 and 1968 pandemic viruses involved the introduction of both HA and PB1 from an avian lineage, and both the double and triple reassortant swine influenza viruses contained HA and PB1 from the same human lineage, suggesting that compatibility between HA and PB1 might also be required for successful reassortment. 
These results correspond well with surveillance data that show the classical swine H1N1 lineage was stable in the North American swine population for close to 80 years, while novel triple reassortant lineage swine viruses continue to emerge $(23,143)$. The presence of avian-origin internal genes appears to be advantageous to swine influenza viruses, as swine influenza viruses in Europe have contained avian-origin internal genes since the introduction of a wholly-avian virus into the swine population in 1979 (108). These viruses have undergone multiple reassortment events resulting in viruses which maintain the avian-origin internal genes but acquire new HA and NA genes $(13,11,88)$.

MDCK cells are derived from canine kidney epithelial cells. While they are a widely used in vitro model for the growth and characterization of influenza A viruses, and contain both $\alpha-2,3$ and $\alpha-2,6$ sialyloligosaccharides on their surface, they are not swine in origin and are not a respiratory cell line. Therefore they may differ from swine respiratory cells in receptors, cytokines, and growth factors. Co-infection of a swine respiratory cell line was attempted, but the viruses did not grow to sufficient titers to analyze. A549 cells, which are a human respiratory epithelial cell line, as well as a recently developed primary swine tracheal culture, may provide more insight into reassortment in the respiratory tract.

The temperature of incubation, amount of virus inoculum, and the timing of coinfection all influenced the successful generation of reassortant viruses in vitro, although no overall pattern was observed. When cells were incubated at $37^{\circ} \mathrm{C}$, delaying infection with TX/96 decreased the number of reassortants detected, possibly due to the viruses not being replicated and packaged at the same time. The samples which did contain reassortants had been infected with $\mathrm{SW} / \mathrm{NC} / 02$ at an $\mathrm{MOI}=0.1$ or 0.01 , which would allow for multiple rounds of replication of $\mathrm{SW} / \mathrm{NC} / 02$ and a higher probability of being replicated in a cell that was also been infected with TX/96. In contrast, when cells were incubated at $39^{\circ} \mathrm{C}$, delaying infection with $\mathrm{TX} / 96$ was not detrimental to the generation of reassortant viruses. The avian-origin polymerase complex has been shown to be more efficient at higher temperatures (8) and therefore viruses which contain the avian PA and $\mathrm{PB} 2$ would be more fit than the wholly $\mathrm{TX} / 96$ virus at $39^{\circ} \mathrm{C}$.

More understanding of the mechanisms controlling influenza reassortment is important because pigs are capable of transmitting influenza to humans, and the dominant viruses circulating in the swine population are able to acquire novel HA genes and potentially introduce novel viruses into the human population. Previous studies on influenza viral reassortment have shown that certain gene segments tend to reassort together $(31,82)$, but that HA and NA are able to reassort independently (112). The independent reassortment of HA and NA possibly evolved as an immune evasion mechanism for the virus. Recent reassortment between a triple reassortant lineage virus and the Eurasian swine H1N1 lineage led to the first human influenza pandemic of the $21^{\text {st }}$ century (33). It is possible that the TRIG cassette is more compatible with a broader range of HA and NA genes than classical swine viruses, therefore allowing increased reassortment, or that increased activity of the polymerase complex of the TRIG cassette causes viruses containing these genes to be more fit that the parental viruses. Further studies, including the reverse genetics generation of single gene reassortant viruses, 
quantitative detection of reassortants, and in vivo co-infections are necessary to elucidate the mechanisms controlling the acquisition of novel HA genes by triple reassortant swine influenza viruses. 


\section{CHAPTER 4: CHARACTERIZATION OF NORTH AMERICAN SWINE INFLUENZA A VIRUSES}

\section{Introduction}

The evolution of swine influenza viruses in North America has been distinct from that in Europe or Asia (10). Prior to 1998, the majority of swine influenza in North America was caused by H1N1 viruses of the classical swine lineage. These viruses were highly stable, both genetically and antigenically, and caused low levels of morbidity and mortality in swine herds. Serological studies performed on pig sera collected between 1988 and 1989 showed that $31 \%$ of samples were positive for antibodies against classical H1N1 swine viruses, but only $1.1 \%$ were positive for antibodies against a contemporary human H3N2 virus (18). These numbers were similar to studies conducted on swine sera from 1976 and 1977 (50). However, when serological studies were performed on sera collected from pigs between 1997 and 1998, the number of samples positive for antibodies against a contemporary human H3N2 virus had risen to 8\% (106). In 1998, two reassortant H3N2 influenza A viruses were isolated from four swine herds in North America. The virus isolated from one of the swine herds was classified as a double reassortant $\mathrm{H} 3 \mathrm{~N} 2$ virus and contained the $\mathrm{HA}$, NA and $\mathrm{PB} 1$ gene segments from a human-origin $\mathrm{H} 3 \mathrm{~N} 2$ virus and the remaining gene segments from the classical swine H1N1 lineage. The virus isolated from the other three swine herds was a triple reassortant virus that contained the HA, NA, and PB1 gene segments from a humanorigin $\mathrm{H} 3 \mathrm{~N} 2$ virus, the $\mathrm{M}$, NP, and NS gene segments from a classical swine-origin H1N1 virus, and the PA and PB2 gene segments from an avian-origin virus (160). This triple reassortant virus quickly became established in the North American swine population (149) and continued to reassort with other circulating viruses $(83,149,142,58)$. The reassortant swine influenza viruses also replaced the previously circulating classical swine H1N1 lineage and these viruses are no longer isolated from North American swine (143).

Once established in the swine population, viruses of the triple reassortant lineage continued to evolve, picking up novel HA genes while maintaining their internal gene constellation $(83,149,142,58)$. As shown in Chapter 3, swine influenza viruses containing the TRIG cassette are more capable of acquiring novel HA genes than classical swine influenza viruses. However, little is known about the reasons for the increased fitness of these triple reassortant viruses in pigs and why they were able to replace the long dominant classical $\mathrm{H} 1 \mathrm{~N} 1$ swine influenza lineage. The rapid appearance of the triple reassortant swine influenza viruses and their high capacity for reassortment indicate that they may pose a pandemic threat to the human population. Furthermore, the high rate of reassortment may indicate unique characteristics of the TRIG cassette in terms of reassortment ability and compatibility with various HA and NA genes.

Several factors have been shown to influence the success of influenza A viruses in different hosts, including the polymerase complex and the surface glycoproteins. The polymerase complex genes PB2, PB1, and PA, none of which are of classical swine 
origin in the TRIG cassette, have been shown to play a role in the generation of reassortant viruses, as well as in replication efficiency, host range restriction, temperature sensitivity, and viral pathogenesis $(42,147,76,90)$. The surface glycoproteins are a major determinant of host range restriction (2) and have also been shown to affect the temperature sensitivity of viral replication(122). The fitness of the triple reassortant swine virus lineage and its ability to continue to reassort compared to that of the double reassortant swine virus, which contains the human-origin PB1, but classical swine origin PA and PB2, suggests a role of the PA and PB2 genes in allowing for successful reassortment and maintenance in pigs. In order to begin to understand these properties, and to determine the influence of PA and PB2 on the replication and temperature sensitivity of swine influenza viruses, the replication kinetics of a classical and several reassortant swine influenza viruses were characterized in vitro through multi-step growth curves at several different temperatures reflecting replication sites of the swine respiratory tract. To determine if the TRIG cassette confers a replicative advantage in vivo, pigs were infected with a classical swine $\mathrm{H} 1 \mathrm{~N} 1$ virus or a triple reassortant $\mathrm{H} 1 \mathrm{~N} 1$ virus, and several triple reassortant swine viruses were characterized in ferrets to determine their pandemic potential in this animal model of human infection.

\section{Materials and Methods}

Viruses Used. Four swine influenza A viruses were characterized in vitro. $\mathrm{SW} / \mathrm{MN} / 37866 / 99$ (SW/MN/99) is a classical swine H1N1 virus (Figure 4-1A). $\mathrm{SW} / \mathrm{NC} / 18161 / 02(\mathrm{SW} / \mathrm{NC} / 02)$ is a triple reassortant swine H1N1 virus with classical swine-origin HA, NA, M, NP, and NS genes, a human-origin PB1 gene, and avian-origin PA and PB2 genes (Figure 4-1B). SW/NC/35922/98 (SW/NC/98) is a double reassortant swine $\mathrm{H} 3 \mathrm{~N} 2$ virus with human-origin $\mathrm{HA}$ and NA genes and classical swine-origin $\mathrm{M}$, NP, NS, PA, and PB2 genes (Figure 4-1C), and SW/TX/4199-2/98 (SW/TX/98) is a triple reassortant swine $\mathrm{H} 3 \mathrm{~N} 2$ virus with human-origin $\mathrm{HA}, \mathrm{NA}$, and $\mathrm{PB} 1$ genes, classical swine-origin M, NP, and NS genes, and avian-origin PA and PB2 genes (Figure 4-1D). $\mathrm{SW} / \mathrm{MN} / 99$ and SW/NC/02 were also characterized in pigs along with A/TX/6/96 (TX/96), a human H3N2 virus that contains an HA and NA similar to those found in the original swine H3N2 reassortant viruses. Three reassortant swine influenza A viruses were characterized in the ferret model, SW/NC/02, SW/TX/98, and SW/NC/38448-2/05 ( $\mathrm{SW} / \mathrm{NC} / 05)$ which is a triple reassortant $\mathrm{H} 1 \mathrm{~N} 1$ swine influenza virus with a humanorigin HA and NA. SW/NC/98, SW/NC/02, and SW/NC/05 were obtained from Dr. Gene Erickson at the Rollins Animal Disease Laboratory and SW/TX/98 and SW/MN/99 were obtained from Dr. Marie Gramer at the University of Minnesota Veterinary Diagnostic Laboratory.

In Vitro Growth Curves. MDCK cells were maintained in MEM supplemented with 5\% fetal calf serum, vitamin solution, and antibiotic/antimycotic solution. One day before infection, cells were trypsinized and seeded into 6-well tissue culture plates. On the day of infection, viruses were diluted to an $\mathrm{MOI}=0.01$ in MEM supplemented with 
A

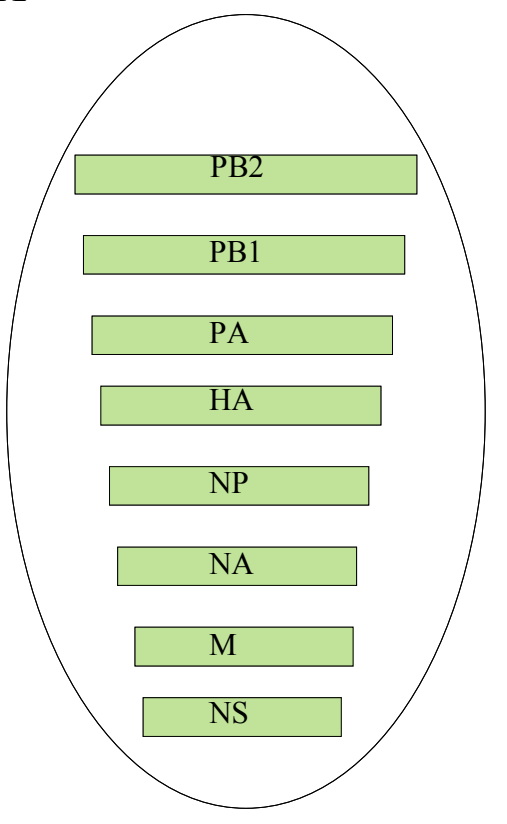

C

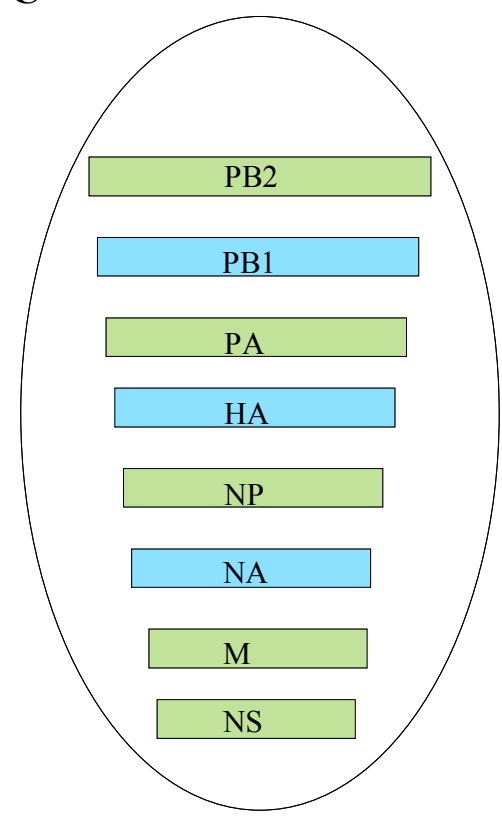

B

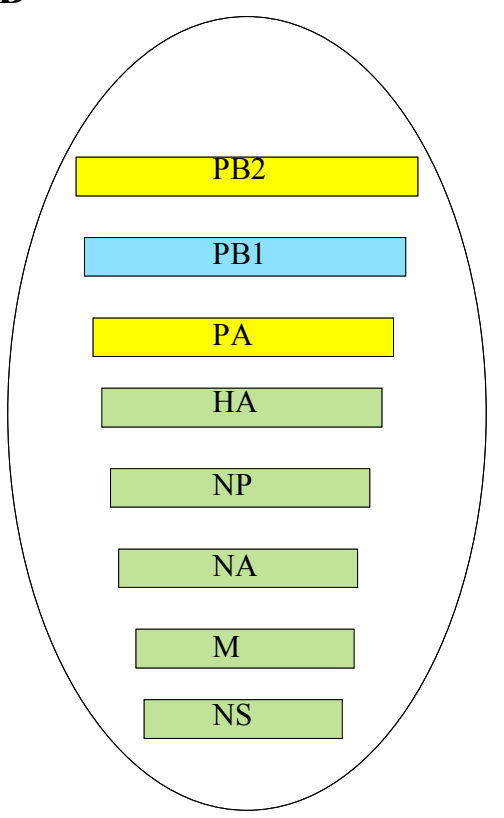

D

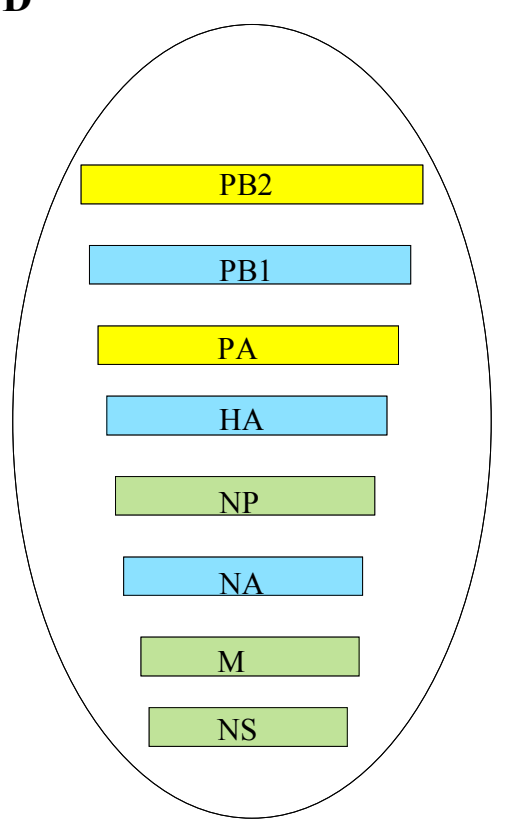

Figure 4-1. Swine Viruses Characterized In Vitro. Gene segments from the classical swine lineage are in green. Gene segments from the human H3N2 lineage are in blue. Gene segments from the avian lineage are in yellow. (A) SW/MN/99. (B) SW/NC/02. (C) SW/NC/98. (D) SW/TX/98. 
bovine serum albumin, vitamin solution, and antibiotic/antimycotic solution. Cells were washed once with infection media and the diluted virus was added. Plates were incubated at $4^{\circ} \mathrm{C}$ for 30 minutes to synchronize the infection, and then were incubated at the appropriate temperature $\left(33^{\circ} \mathrm{C}, 35^{\circ} \mathrm{C}\right.$, or $\left.39^{\circ} \mathrm{C}\right)$ for 1 hour. After incubation, cells were washed twice with $0.9 \% \mathrm{NaCl} \mathrm{pH} 2.2$ and then twice with sterile PBS. Cells were overlayed with MEM containing 2ug/ml L-(tosylamido-2-phenyl) ethyl chloromethyl ketone (TPCK)-trypsin and incubated at $33^{\circ} \mathrm{C}, 35^{\circ} \mathrm{C}$, or $39^{\circ} \mathrm{C}$. Supernatants were collected at 12,24 , and 48 , hours post-infection and viral titers were determined by $\mathrm{TCID}_{50}$. All infections were done in triplicate wells.

Swine Infections. Influenza negative pigs were obtained from Midwest Research Swine (Gibbon, MN). Infectivity and transmissibility of SW/MN/99, SW/NC/02, and TX/96 were tested in four 4 week-old outbred pigs. For each virus, two pigs were anesthetized with ketamine and xylazine and inoculated intranasally with $10^{4}$ plaque forming units (PFU) of virus. Twenty-four hours post-infection, one naïve contact animal was housed with each infected animal. Nasal swabs were taken daily through day 10 post-infection and viral titers were determined by $\mathrm{TCID}_{50}$.

Ferret Infections. Influenza A negative ferrets were obtained from the ferret breeding program at St. Jude Children's Research Hospital (Memphis, TN) or from Triple F Farms (Sayre, PA). Infectivity and transmissibility of each influenza virus were tested in six 3-4 month old ferrets per virus under BSL-2 conditions. Three ferrets were anesthetized with isofluorane and inoculated intranasally with $10^{6} \mathrm{TCID}_{50} \mathrm{SW} / \mathrm{NC} / 02$, $\mathrm{SW} / \mathrm{NC} / 05$, or SW/TX/98 diluted in PBS. Twenty-four hours post-inoculation, one naïve contact animal was housed with each infected animal. At days 1, 4, 7 and 11 postinoculation, animals were anesthetized with ketamine and nasal washes were collected. The nasal washes were titrated in embryonated hen eggs and the EID $_{50}$ was determined.

Hemagglutination Inhibition (HI) Assays. Serum samples were collected from swine and ferrets at 21 days post-infection and treated with Vibrio cholerae receptordestroying enzyme (Denka-Sekien, Tokyo, Japan) followed by heat inactivation at $56^{\circ} \mathrm{C}$ for 30 minutes prior to serological testing. Sera were titrated in round bottom 96-well plates and incubated for 45 minutes at room temperature with four agglutinating doses of homologous virus. A $0.5 \%$ solution of turkey red blood cells was then added and incubated at room temperature for 30 minutes. HI titer was determined based on the highest dilution of sera which caused complete inhibition of red blood cell agglutination.

\section{Results}

Reassortant Swine Viruses Have Improved Growth Kinetics at Early

Timepoints. To determine if viruses containing the TRIG cassette had a replicative 
advantage over double reassortant and classical swine influenza viruses, MDCK cells were infected in triplicate with $0.01 \mathrm{MOI}$ of virus and incubated at $35^{\circ} \mathrm{C}$, the standard temperature used for isolation and growth of influenza A viruses in cell culture.

Supernatants were collected at 12, 24, and 48 hours post-infection and viral titers were determined by TCID $_{50}$. The triple reassortant H3N2 virus, SW/TX/98, had the highest titers at all timepoints $(\mathrm{p}<0.01)$, with an average titer of $10^{5.44} \mathrm{TCID}_{50} / \mathrm{ml}$ at 12 hours post-infection, an average titer of $10^{6.1} \mathrm{TCID}_{50} / \mathrm{ml}$ at 24 hours post-infection, and an average titer of $10^{5.92} \mathrm{TCID}_{50} / \mathrm{ml}$ at 48 hours post-infection (Figure 4-2). The triple reassortant $\mathrm{H} 1 \mathrm{~N} 1$ swine virus, $\mathrm{SW} / \mathrm{NC} / 02$, had an average titer of $10^{3.22} \mathrm{TCID}_{50} / \mathrm{ml}$ at 12 hours post-infection, an average titer of $10^{4.7} \mathrm{TCID}_{50} / \mathrm{ml}$ at 24 hours post-infection, and an average titer of $10^{4.33} \mathrm{TCID}_{50} / \mathrm{ml}$ at 48 hours post-infection. The double reassortant $\mathrm{H} 3 \mathrm{~N} 2$ swine virus, $\mathrm{SW} / \mathrm{NC} / 98$, had an average titer of $10^{4.5} \mathrm{TCID}_{50} / \mathrm{ml}$ at 12 hours postinfection, an average titer of $10^{5} \mathrm{TCID}_{50} / \mathrm{ml}$ at 24 hours post-infection, and an average titer of $10^{4.1} \mathrm{TCID}_{50} / \mathrm{ml}$ at 48 hours post-infection. The classical H1N1 swine virus, $\mathrm{SW} / \mathrm{MN} / 99$, had no detectable titer at 12 hours post-infection, an average titer of $10^{4.1}$ $\mathrm{TCID}_{50} / \mathrm{ml}$ at 24 hours post-infection, and an average titer of $10^{5} \mathrm{TCID}_{50} / \mathrm{ml}$ at 48 hours post-infection.

At 12 hours post-infection, the average titer of each virus was significantly different from all others $(\mathrm{p}<0.01)$, with the triple reassortant $\mathrm{H} 3 \mathrm{~N} 2$ virus attaining the highest titer, followed by the double reassortant H3N2 and the triple reassortant H1N1.

At 24 and 48 hours post-infection, the difference in titers between the classical H1N1 and the triple reassortant $\mathrm{H} 1 \mathrm{~N} 1$, as well as the difference in titers between the triple reassortant $\mathrm{H} 1 \mathrm{~N} 1$ and the double reassortant $\mathrm{H} 3 \mathrm{~N} 2$ were not significantly different from each other, while the difference in titers between the classical H1N1 and the double reassortant $\mathrm{H} 3 \mathrm{~N} 2$ was statistically significant $(\mathrm{p}<0.01)$.

Swine Viruses Differ in Temperature Sensitivity In Vitro. Previously, we found that a triple reassortant $\mathrm{H} 3 \mathrm{~N} 2$ virus grew faster than a classical H1N1 virus at $35^{\circ} \mathrm{C}$. This could lead to a growth advantage in the respiratory tract. To determine if the TRIG cassette altered the temperature sensitivity of swine influenza viruses, multi-step growth curves were performed at $33^{\circ} \mathrm{C}$ or $39^{\circ} \mathrm{C}$, corresponding to the temperatures of the proximal and distal respiratory tract of pigs (73).

At $33^{\circ} \mathrm{C}$, the triple reassortant $\mathrm{H} 1 \mathrm{~N} 1$ and $\mathrm{H} 3 \mathrm{~N} 2$ viruses had similar titers at 12 hours post-infection, $10^{3.83} \mathrm{TCID}_{50} / \mathrm{ml}$ and $10^{4.11} \mathrm{TCID}_{50} / \mathrm{ml}$, respectively, which were higher $(p<0.001)$ than the average titer of the double reassortant virus, which was $10^{2.67}$ $\mathrm{TCID}_{50} / \mathrm{ml}$ (Figure 4-3A). However, by 24 hours post-infection the triple reassortant $\mathrm{H} 3 \mathrm{~N} 2$ virus had an average titer of $10^{6.22} \mathrm{TCID}_{50} / \mathrm{ml}$, which was higher than any of the other viruses $(\mathrm{p}<0.01)$. Although the double reassortant $\mathrm{H} 3 \mathrm{~N} 2 \mathrm{had}$ a lower average titer at 12 hours post-infection, by 24 hours post-infection it had an average titer of $10^{5.53}$ $\mathrm{TCID}_{50} / \mathrm{ml}$, higher than the average titer of the triple reassortant $\mathrm{H} 1 \mathrm{~N} 1$ virus which was $10^{4.44} \mathrm{TCID}_{50} / \mathrm{ml}(\mathrm{p}<0.001)$. At both 24 and 48 hours post-infection, the triple reassortant H3N2 virus had the highest titers, followed by the double reassortant H3N2 virus, the 


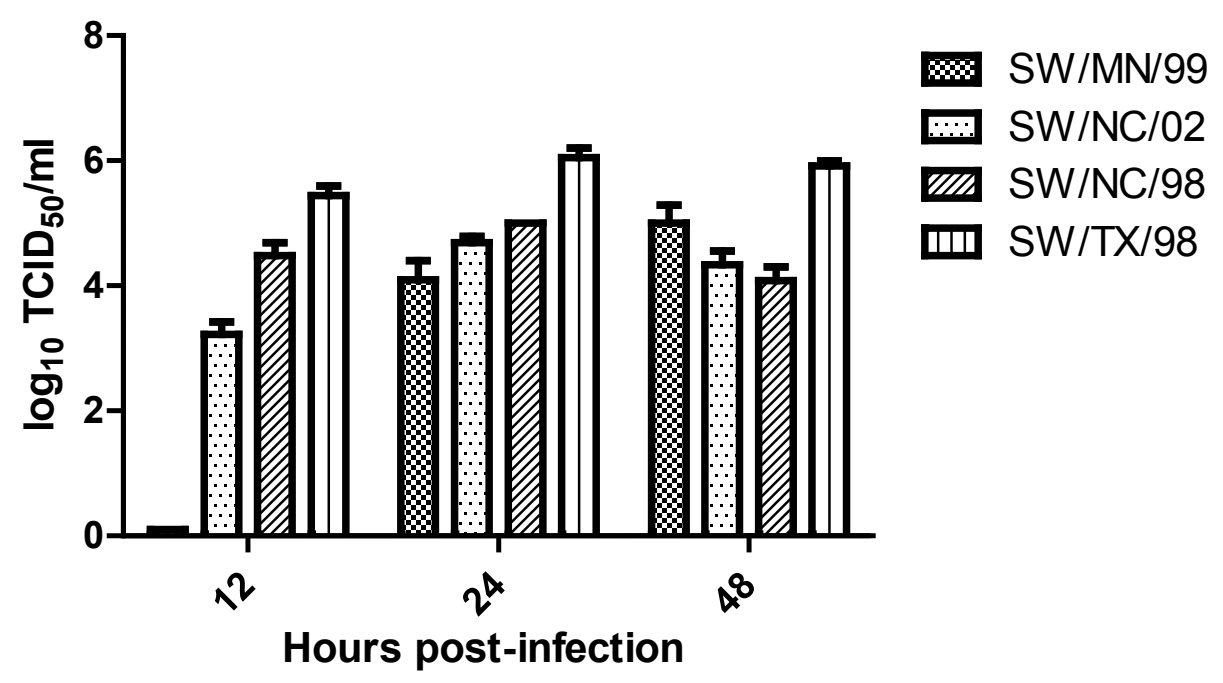

Figure 4-2. Replication of Swine Influenza A Viruses at $35^{\circ} \mathrm{C}$. MDCK cells were infected with $0.01 \mathrm{MOI}$ of virus and incubated at $35^{\circ} \mathrm{C}$. Supernatants were periodically collected and viral titers determined by TCID $_{50}$. All bars represent the mean of 3 wells plus SEM. SW/MN/99 is a classical swine H1N1 virus; SW/NC/02 is a triple reassortant $\mathrm{H} 1 \mathrm{~N} 1$ virus; $\mathrm{SW} / \mathrm{NC} / 98$ is a double reassortant $\mathrm{H} 3 \mathrm{~N} 2$ virus; and $\mathrm{SW} / \mathrm{TX} / 98$ is a triple reassortant $\mathrm{H} 3 \mathrm{~N} 2$ virus. 


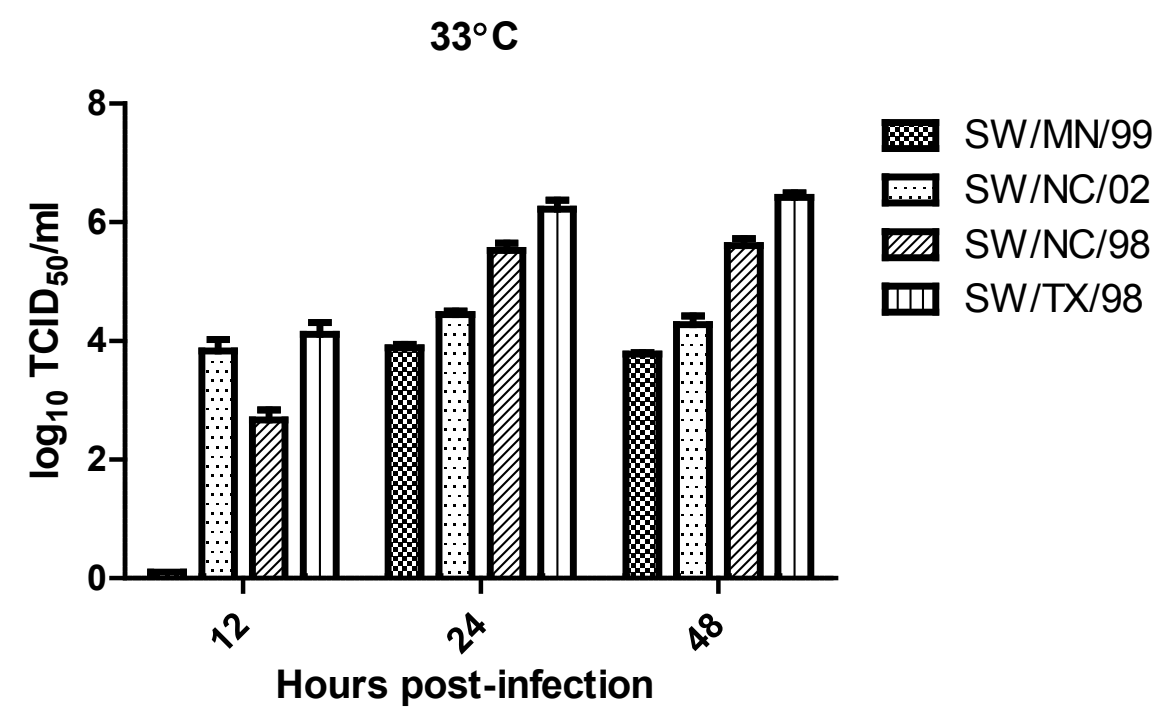

B

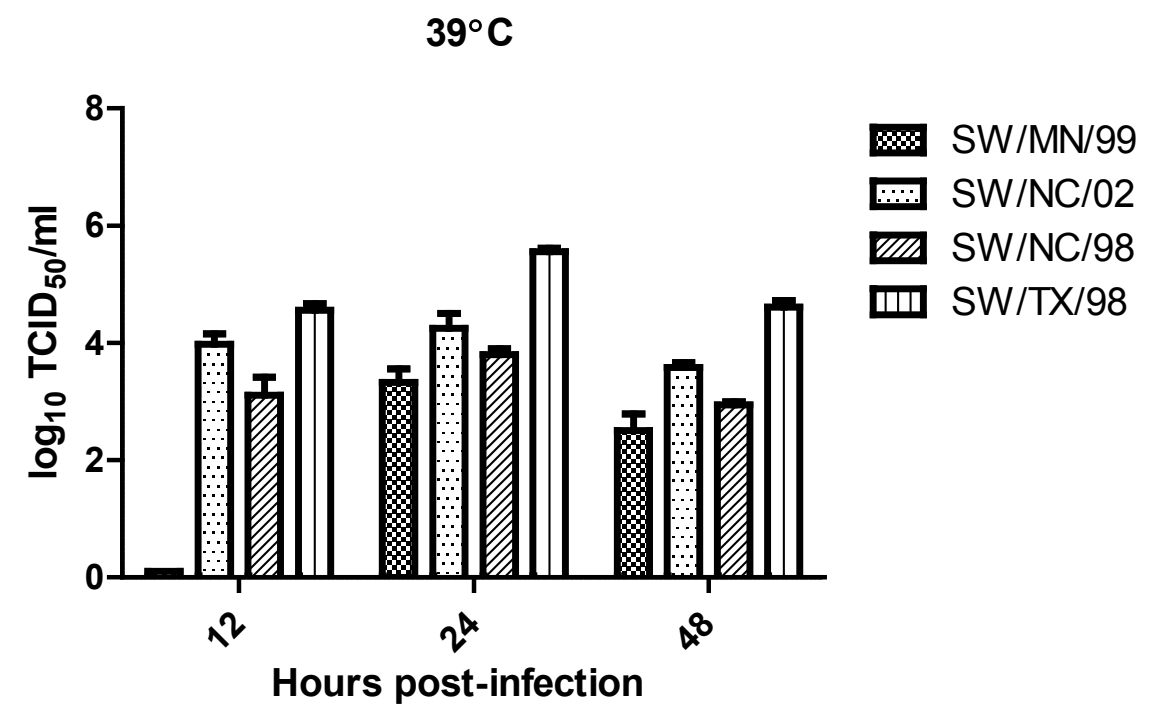

Figure 4-3. Replication of Swine Influenza A Viruses at $33^{\circ} \mathrm{C}$ and $39^{\circ} \mathrm{C}$. MDCK cells were infected with $0.01 \mathrm{MOI}$ of virus and incubated at $33^{\circ} \mathrm{C}(\mathrm{A})$ or $39^{\circ} \mathrm{C}(\mathrm{B})$. Supernatants were collected and viral titers were determined by TCID 50 . All bars represent the mean of triplicate wells plus SEM. 
triple reassortant $\mathrm{H} 1 \mathrm{~N} 1$ virus, and the classical swine H1N1 virus, and all of the titers were significantly different from each other $(\mathrm{p}<0.05)$.

At $39^{\circ} \mathrm{C}$, the triple reassortant $\mathrm{H} 3 \mathrm{~N} 2$ virus had a slightly higher titer $\left(10^{4.6}\right.$ $\left.\mathrm{TCID}_{50} / \mathrm{ml}\right)$ than the triple reassortant $\mathrm{H} 1 \mathrm{~N} 1$ virus $\left(10^{3.97} \mathrm{TCID}_{50} / \mathrm{ml}\right)$ at 12 hours postinfection, although this difference was not statistically significant (Figure 4-3B). The titers of both viruses were significantly higher than that of the double reassortant $\mathrm{H} 3 \mathrm{~N} 2$ $\left(10^{3.1} \mathrm{TCID}_{50} / \mathrm{ml}, \mathrm{p}<0.01\right)$. At 24 hours post-infection, the triple reassortant virus had an average titer of $10^{5.56} \mathrm{TCID}_{50} / \mathrm{ml}$, which was significantly higher than that of the other viruses. The titer of the triple reassortant $\mathrm{H} 1 \mathrm{~N} 1$ virus $\left(10^{4.25} \mathrm{TCID}_{50} / \mathrm{ml}\right)$ was not significantly different from that of the double reassortant $\mathrm{H} 3 \mathrm{~N} 2$ virus $\left(10^{3.81} \mathrm{TCID}_{50} / \mathrm{ml}\right)$, but was significantly higher than the titer of the classical H1N1 virus $\left(10^{3.33} \mathrm{TCID}_{50} / \mathrm{ml}\right.$, $\mathrm{p}<0.01)$. At 48 hours post-infection, all of the titers were significantly different from each other with the exception of the classical swine H1N1 and double reassortant H3N2 viruses. The triple reassortant $\mathrm{H} 3 \mathrm{~N} 2$ virus had the highest average titer, $10^{4.61}$ $\mathrm{TCID}_{50} / \mathrm{ml}$, followed by the triple reassortant $\mathrm{H} 1 \mathrm{~N} 1$ virus with an average titer of $10^{3.58}$ $\mathrm{TCID}_{50} / \mathrm{ml}$, the double reassortant $\mathrm{H} 3 \mathrm{~N} 2$ virus with an average titer of $10^{2.94} \mathrm{TCID}_{50} / \mathrm{ml}$, and the classical $\mathrm{H} 1 \mathrm{~N} 1$ virus with an average titer of $10^{2.5} \mathrm{TCID}_{50} / \mathrm{ml}$.

A 12 hour replication delay was observed for the classical H1N1 virus $\mathrm{SW} / \mathrm{MN} / 99$ at both temperatures (Figure 4-3), similar to what was observed at $35^{\circ} \mathrm{C}$. The lower temperature of $33^{\circ} \mathrm{C}$ did not have a significant effect on SW/MN/99 titers at 24 hours post-infection (Figure 4-4A), but the average titer was $24.5 \%$ lower at 48 hours post-infection $(\mathrm{p}<0.001)$. At $39^{\circ} \mathrm{C}$, viral titers were reduced by $18.7 \%$ at 24 hours postinfection $(\mathrm{p}<0.05)$, and $50 \%$ at 48 hours post-infection $(\mathrm{p}<0.001)$. The double reassortant $\mathrm{H} 3 \mathrm{~N} 2$ and triple reassortant $\mathrm{H} 3 \mathrm{~N} 2$ viruses showed similar patterns of temperature sensitivity that were distinct from that of the triple reassortant H1N1 (Figure 4-4). Both the double and triple reassortant $\mathrm{H} 3 \mathrm{~N} 2$ viruses had lower titers at $39^{\circ} \mathrm{C}$ than at $35^{\circ} \mathrm{C}$ across all timepoints, with an average decrease of $25.7 \%(\mathrm{p}<0.001)$ for the double reassortant $\mathrm{H} 3 \mathrm{~N} 2$ virus, and $15.5 \%(\mathrm{p}<0.05)$ for the triple reassortant $\mathrm{H} 3 \mathrm{~N} 2$ virus. At $39^{\circ} \mathrm{C}$, the double and triple reassortant $\mathrm{H} 3 \mathrm{~N} 2$ viruses each had a decrease at 12 hours post-infection versus $35^{\circ} \mathrm{C}$, but an increase in titer by 48 hours post-infection. The triple reassortant $\mathrm{H} 1 \mathrm{~N} 1$ virus had no significant difference in titers between $33^{\circ} \mathrm{C}$ and $35^{\circ} \mathrm{C}$ at any timepoint, and a $23.4 \%$ increase $(\mathrm{p}<0.05)$ in viral titer at $39^{\circ} \mathrm{C}$ compared to $35^{\circ} \mathrm{C}$ at 12 hours post-infection.

A Human H3N2 Influenza A Virus Inefficiently Infects Swine. To determine if a human $\mathrm{H} 3 \mathrm{~N} 2$ virus was able to infect and transmit between swine and therefore be available for reassortment with circulating swine influenza viruses, two influenza free pigs were inoculated intranasally with $10^{4} \mathrm{PFU}$ of TX/96, which has an HA and NA similar to those found in the original triple reassortant swine viruses. Each inoculated pig had a contact pig housed with it 24 hours post-inoculation and nasal swabs were collected daily to determine viral titers in each pig. Both of the inoculated pigs began to shed virus by day two post-inoculation with an average titer of $10^{3.63} \mathrm{TCID}_{50} / \mathrm{ml}$. They continued to shed virus until day six post-inoculation (Figure 4-5). One of the two contact animals 
A

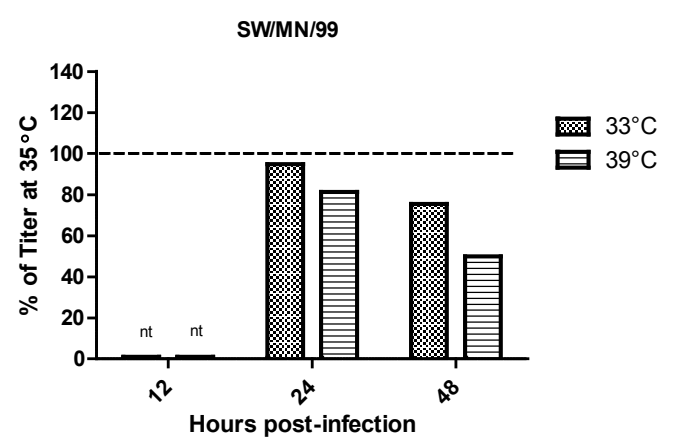

C

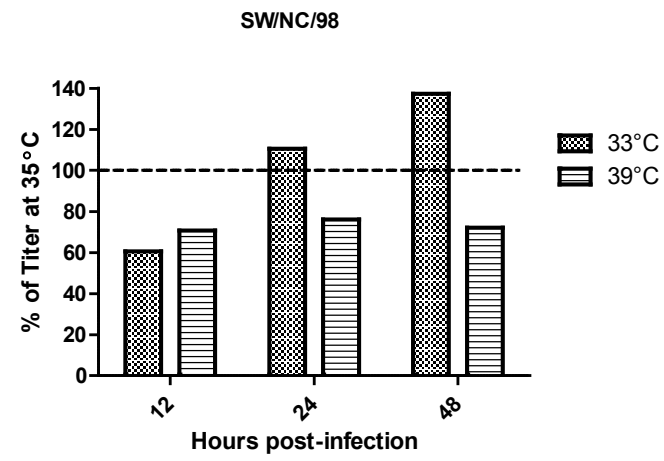

B

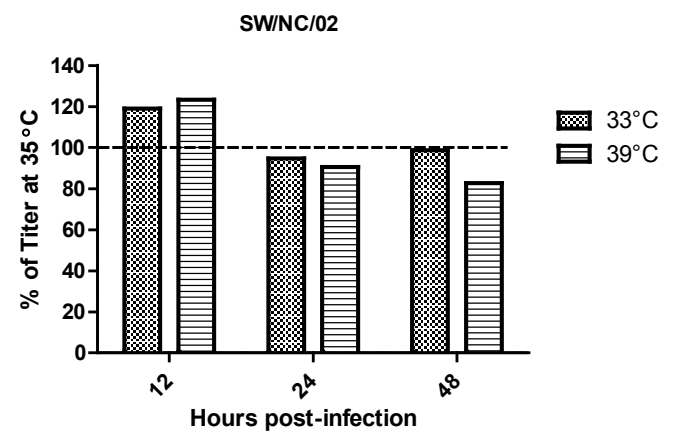

D

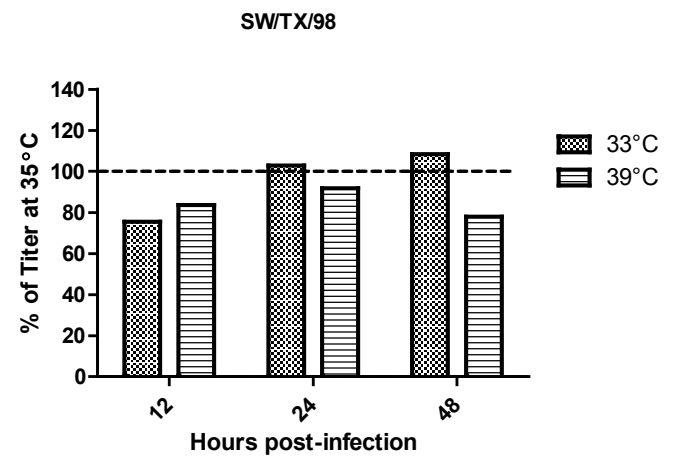

Figure 4-4. Effect of Temperature on Growth of Swine Influenza A Viruses. (A) Classical swine H1N1 virus, SW/MN/99. (B) Triple reassortant swine H1N1 virus, $\mathrm{SW} / \mathrm{NC} / 02$. (C) Double reassortant swine H3N2 virus, SW/NC/98. (D) Triple reassortant swine $\mathrm{H} 3 \mathrm{~N} 2$ virus, $\mathrm{SW} / \mathrm{TX} / 98$. 


\section{TX/96}

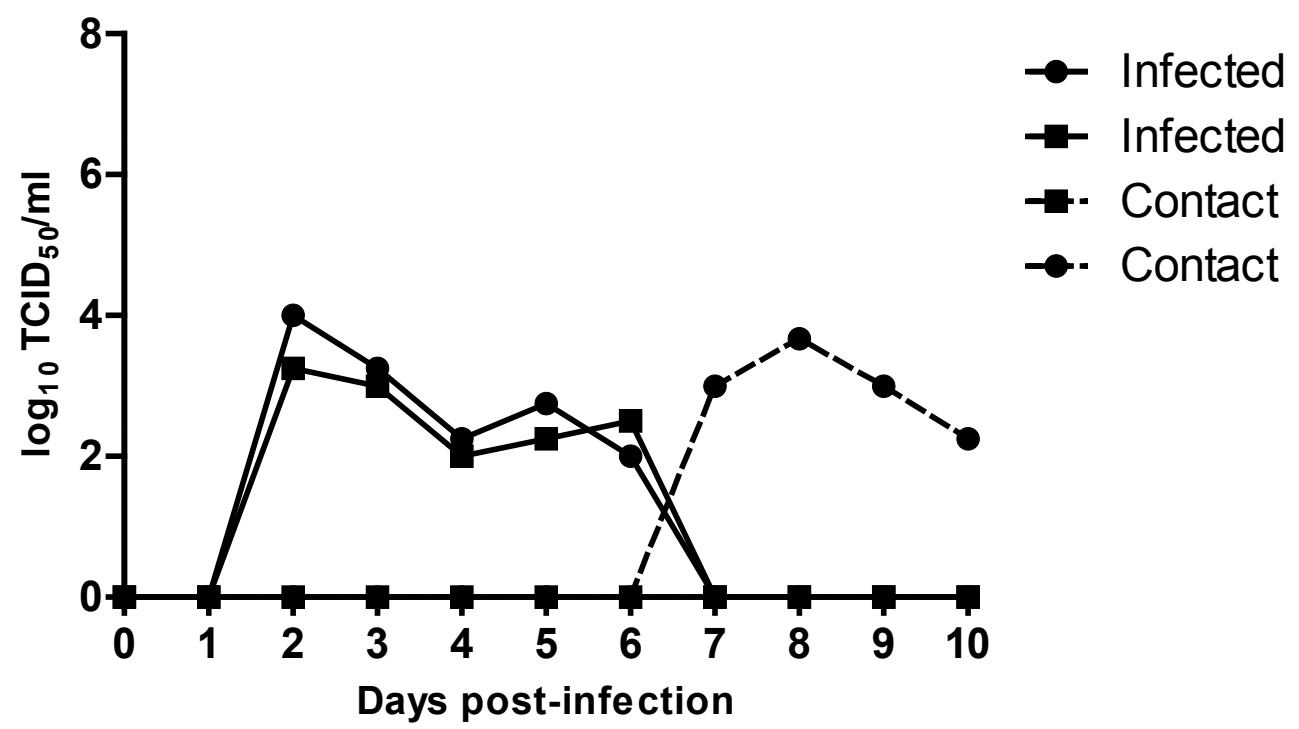

Figure 4-5. Growth and Transmission of a Human H3N2 Virus in Pigs. Two pigs were inoculated intranasally with $10^{4} \mathrm{PFU}$ of TX/96. Twenty-four hours postinoculation, one naïve pig was housed with each infected pig. Nasal swabs were collected daily for ten days post-infection and viral titers were determined by $\mathrm{TCID}_{50}$. 
had a nasal titer of $10^{3} \mathrm{TCID}_{50} / \mathrm{ml}$ at day six post-contact and continued to shed virus through day nine with a peak titer of $10^{3.67} \mathrm{TCID}_{50} / \mathrm{ml}$ at day seven post-contact. The second contact pig did not shed detectable amounts of virus and did not seroconvert. None of the pigs showed any clinical disease symptoms.

A Reassortant H1N1 Swine Virus Does Not Have an Advantage over a Classical H1N1 Swine Virus in the Nasal Cavity of Swine. Following the emergence of triple reassortant swine viruses, classical H1N1 viruses quickly disappeared from the swine population. To determine if the triple reassortant $\mathrm{H} 1 \mathrm{~N} 1$ swine virus had a replication advantage over the classical $\mathrm{H} 1 \mathrm{~N} 1$ swine virus in pigs that would explain its ability to replace the classical H1N1 lineage in the swine population, two pigs were inoculated intranasally with $10^{4} \mathrm{PFU}$ of SW/MN/99 or SW/NC/02. Each infected pig had a contact pig housed with it 24 hours post-inoculation and nasal swabs were collected daily. One of the pigs infected with SW/MN/99 began to shed virus to a titer of $10^{2.25}$ TCID $_{50} / \mathrm{ml}$ at day one post-inoculation, and shed virus until day six, with a peak titer of $10^{4.75} \mathrm{TCID}_{50} / \mathrm{ml}$ at day four (Figure 4-6A). The other inoculated pig did not shed detectable levels of virus until day four post-inoculation with a titer of $10^{2.83} \mathrm{TCID}_{50} / \mathrm{ml}$ and only shed virus for three days. The contact pig housed with the pig that began to shed virus on day one shed virus beginning on day three post-contact and continuing through day seven post-contact, with a peak titer of $10^{5.5} \mathrm{TCID}_{50} / \mathrm{ml}$ at day five postcontact. The other contact pig shed virus from day four through day six post-contact, with a peak titer of $10^{4} \mathrm{TCID}_{50} / \mathrm{ml}$. All four pigs seroconverted and none showed clinical symptoms. Both of the pigs inoculated with $\mathrm{SW} / \mathrm{NC} / 02$ began to shed virus by day two post-inoculation, with an average titer of $10^{3.67} \mathrm{TCID}_{50} / \mathrm{ml}$ and continued to shed virus through day six or day seven with an average peak titer of $10^{4.38} \mathrm{TCID}_{50} / \mathrm{ml}$ (Figure 46B). The two contact pigs began to shed virus at day four post-contact, with an average titer of $10^{3} \mathrm{TCID}_{50} / \mathrm{ml}$. One contact pig shed through day seven post-contact with a peak titer of $10^{4.75} \mathrm{TCID}_{50} / \mathrm{ml}$ and the other shed virus through day nine post-contact with a peak titer of $10^{3.67} \mathrm{TCID}_{50} / \mathrm{ml}$. All four pigs seroconverted but none showed clinical symptoms.

Triple Reassortant Lineage Swine Influenza Viruses Can Replicate and Transmit in Ferrets. The HA protein has been shown to affect replication and transmission of influenza A viruses in several animal models. The replication and transmission of a triple reassortant $\mathrm{H} 3 \mathrm{~N} 2$ swine virus, a triple reassortant $\mathrm{H} 1 \mathrm{~N} 1$ virus with human-origin $\mathrm{HA}$ and NA and a triple reassortant $\mathrm{H} 1 \mathrm{~N} 1$ virus with swine-origin $\mathrm{HA}$ and NA were characterized in ferrets. Three ferrets were inoculated intranasally with $10^{6}$ $\mathrm{TCID}_{50}$ of the triple reassortant H3N2 SW/TX/98, $10^{6} \mathrm{TCID}_{50}$ of SW/NC/02, which has swine-origin HA and NA or $10^{6} \mathrm{TCID}_{50}$ of SW/NC/05, which has human-origin HA and NA. Each inoculated ferret had a contact ferret housed with it and nasal washes were collected on days 1, 4, 7, and 11 post-infection. All three of the ferrets inoculated with $\mathrm{SW} / \mathrm{TX} / 98$ shed detectable levels of virus by day one post-inoculation, with an average titer of $10^{5.17} \mathrm{EID}_{50} / \mathrm{ml}$ (Figure 4-7). The three contact animals all shed virus by day three post-contact, although there was variability in the amount of virus shed between animals, 
A

\section{SW/MN/99}

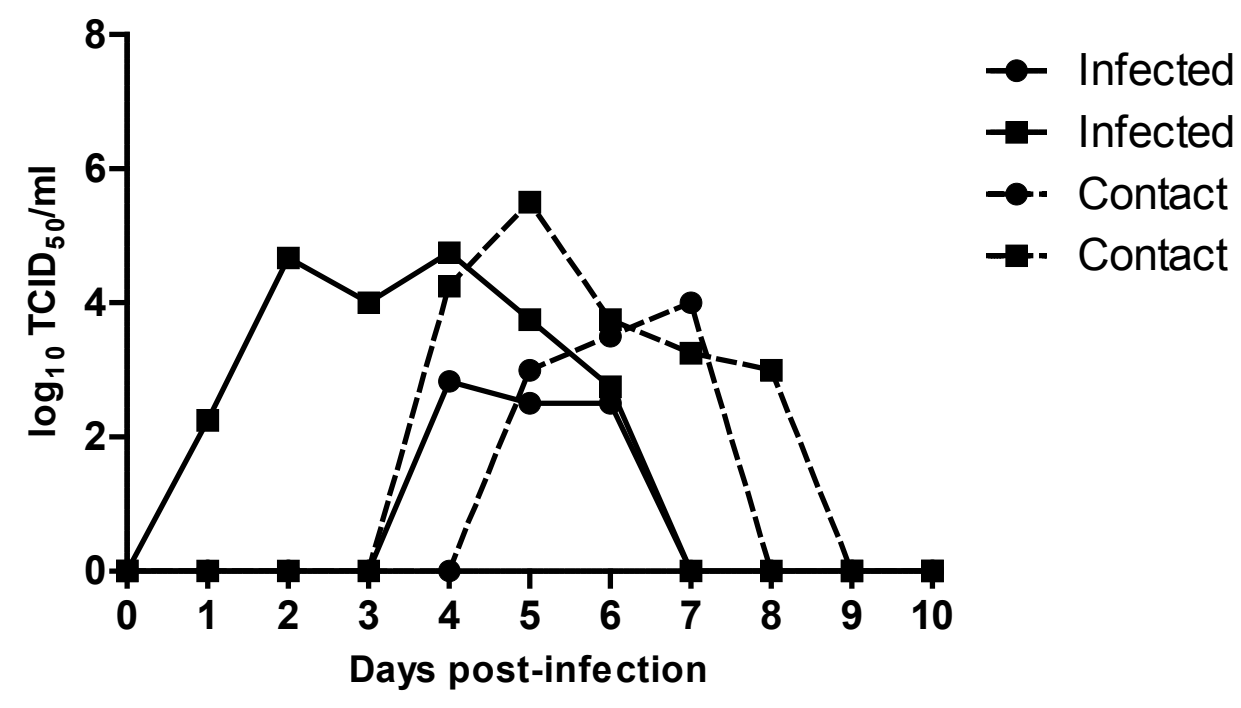

B

SW/NC/02

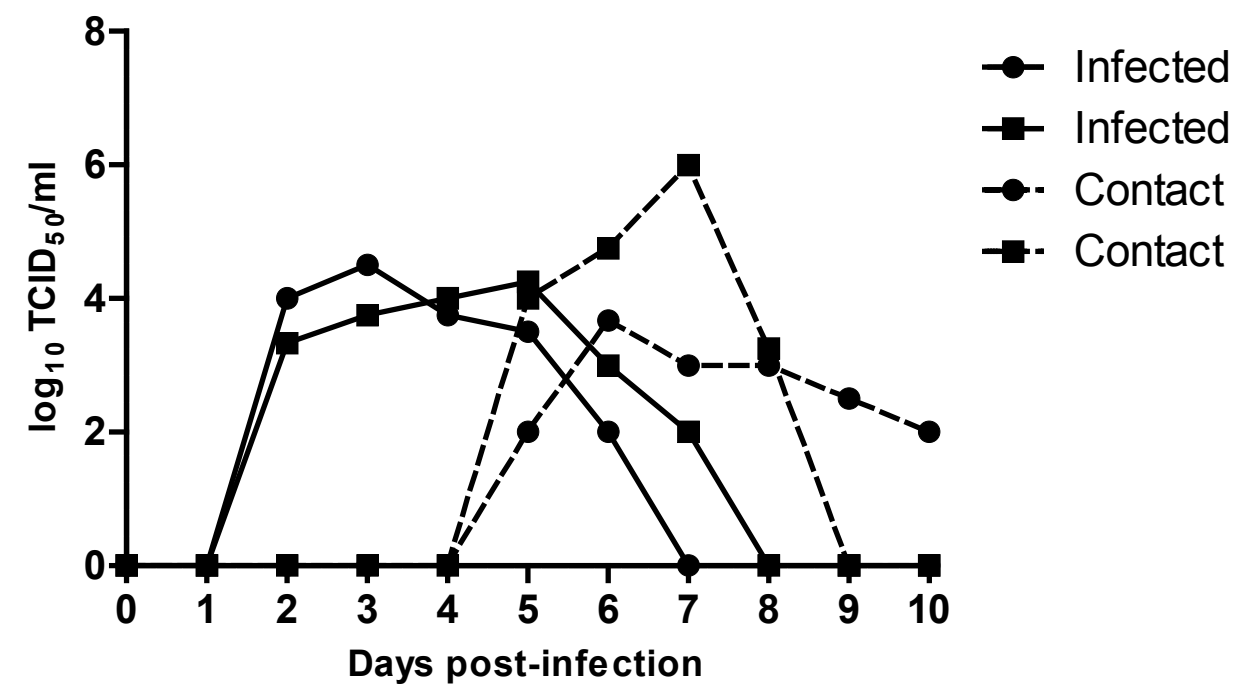

Figure 4-6. Growth and Transmission of Classical and Reassortant Swine H1N1 Viruses in Pigs. Two pigs were infected intranasally with $10^{4} \mathrm{PFU}$ of SW/MN/99 or $\mathrm{SW} / \mathrm{NC} / 02$. Twenty-four hours post-inoculation, one naïve animal was housed with each infected animal. Nasal swabs were collected daily for 10 days post-infection and viral titers were determined by $\mathrm{TCID}_{50}$. 


\section{SW/TX/98}

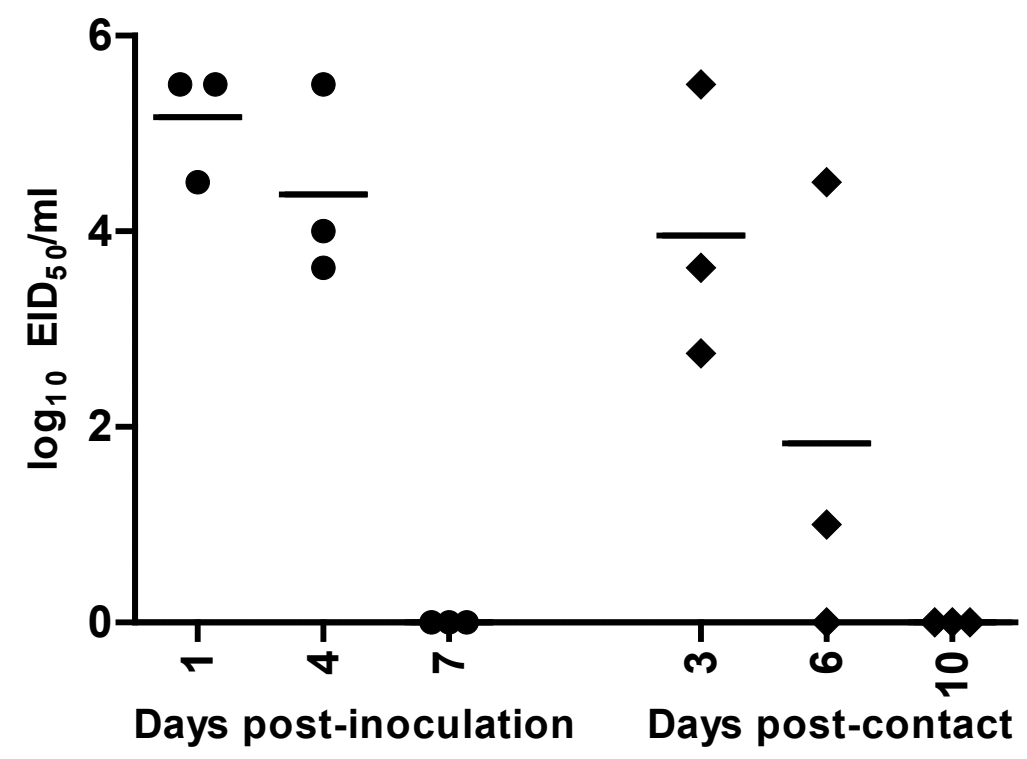

Figure 4-7. Growth and Transmission of a Triple Reassortant Swine H3N2 Virus in Ferrets. Three ferrets were inoculated intranasally with $10^{6} \mathrm{TCID}_{50}$ of SW/TX/98.

Twenty-four hours post-inoculation, one naïve ferret was housed with each infected ferret. Nasal washes were collected 1, 4, 7, and 11 days post-infection and viral titers were determined by EID $_{50}$. 
with titers ranging from $10^{2.75} \mathrm{EID}_{50} / \mathrm{ml}$ to $10^{5.5} \mathrm{EID}_{50} / \mathrm{ml}$. The contact ferret that had the lowest viral titer on day three post-contact did not continue to shed virus, and did not seroconvert. Two of the three ferrets inoculated with $\mathrm{SW} / \mathrm{NC} / 02$ shed low levels of virus at day one post-inoculation, with an average titer of $10^{2.63} \mathrm{EID}_{50} / \mathrm{ml}$, while the third ferret did not shed virus until day four, with a titer of $10^{2.25} \mathrm{EID}_{50} / \mathrm{ml}$ (Figure $4-8 \mathrm{~A}$ ). None of the infected ferrets shed virus at a titer of more than $10^{3} \mathrm{EID}_{50} / \mathrm{ml}$ and all of the ferrets cleared the virus by day seven post-inoculation. None of the three contact animals shed detectable levels of virus, although all three seroconverted, with HI titers similar to infected ferrets. Ferrets inoculated with $\mathrm{SW} / \mathrm{NC} / 05$ shed high levels of virus beginning at day one post-inoculation, with an average titer of $10^{6.25} \mathrm{EID}_{50} / \mathrm{ml}$ (Figure 4-8B). The three contact ferrets shed high levels of virus at day three post-contact, with an average titer of $10^{6.25} \mathrm{EID}_{50} / \mathrm{ml}$, and all seroconverted. Ferrets infected with SW/TX/98 or $\mathrm{SW} / \mathrm{NC} / 05$ lost an average of $8-10 \%$ of their starting body weight but did not show any other clinical symptoms such as sneezing, coughing, or lethargy.

\section{Discussion}

The emergence of the triple reassortant swine influenza virus lineage changed the dynamics of swine flu in North America. Triple reassortant swine influenza viruses are more pathogenic than classical swine influenza viruses (105), and their continued rapid evolution through reassortment and antigenic drift makes vaccination difficult (141). Although double and triple reassortant swine influenza viruses were first isolated at approximately the same time, only the triple reassortant lineage successfully became established in the swine population $(160,149)$. In the years since they were first isolated, viruses of the triple reassortant lineage have supplanted classical swine influenza viruses and have acquired a number of novel HA and NA genes from circulating swine, human, and avian strains while maintaining the specific constellation of internal genes known as the TRIG cassette (143).

Several factors have been shown to contribute to the success of influenza viruses in different hosts, including the surface glycoproteins, HA and NA (122), and the polymerase complex $(78,147,119,42)$. The polymerase complex of reassortant swine viruses appears to be a major determinant of their success. Both the double and triple reassortant viruses are able to initiate replication more quickly than a classical swine influenza virus in MDCK cells, although samples taken at timepoints between 12 and 24 hours post-inoculation are needed to determine the extent of the classical swine virus's replication delay. This advantage of the reassortant viruses in establishing infection may contribute to the success of the triple reassortant lineage in swine. At $33^{\circ}$, which corresponds to the temperature of the nasal cavity of a pig, the two triple reassortant viruses had higher titers than the double reassortant virus at 12 hours post-infection, although this advantage is no longer seen at 24 hours post-infection. At $39^{\circ} \mathrm{C}$, which corresponds to the temperature of the lower respiratory tract of pigs, the triple reassortant viruses grew to higher titers than the double reassortant viruses at all timepoints. 
A

\section{SW/NC/02}

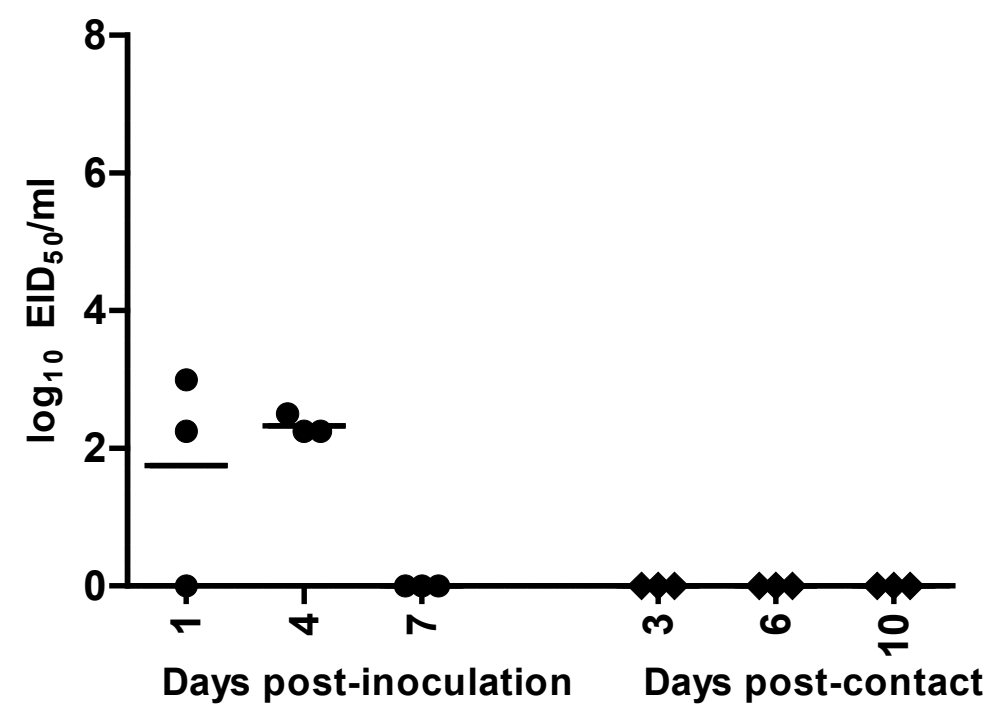

B

SW/NC/05

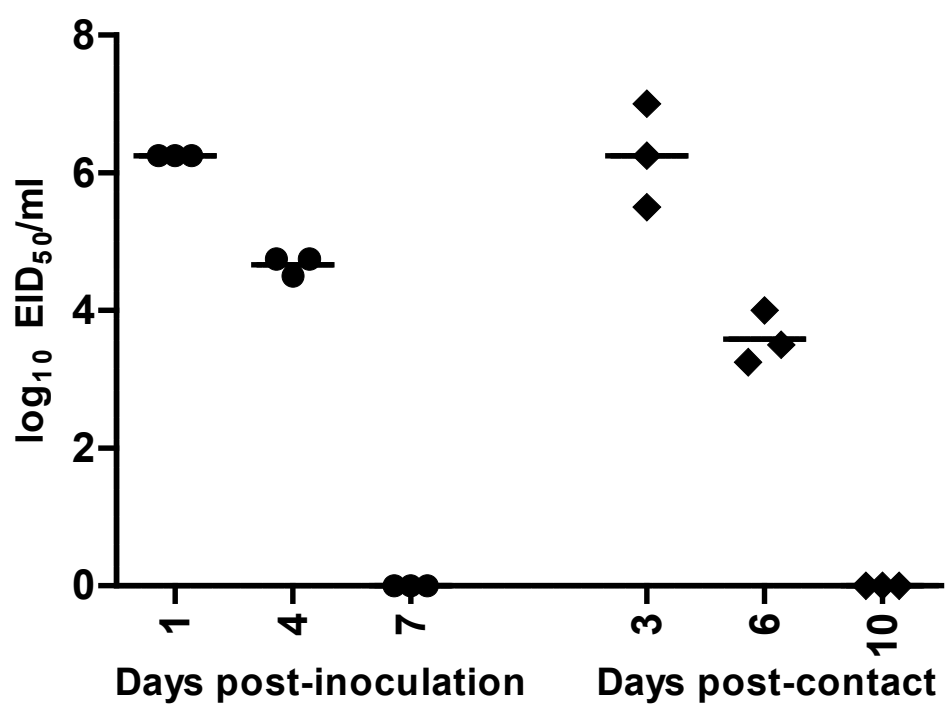

Figure 4-8. Growth and Transmission of Triple Reassortant H1N1 Swine Viruses in Ferrets. Three ferrets were inoculated intranasally with $10^{6} \mathrm{TCID}_{50}$ of SW/NC/02 (A), which contains the HA and NA from the classical swine lineage, or SW/NC/05 (B), which contains the HA and NA from the human lineage. Twenty-four hours postinoculation, one naïve contact animal was housed with each infected animal. Nasal washes were collected 1, 4, 7, and 11 days post-inoculation and viral titers were determined by $\mathrm{EID}_{50}$. 
The polymerase complex of influenza A viruses is heterotrimeric, composed of the PB2, PB1, and PA subunits. PB1 forms the core of the complex, directly interacting with both $\mathrm{PA}$ and PB1. Interestingly, although PA and PB2 are both of avian origin in the TRIG cassette, these two subunits have not been shown to directly interact with each other. Prior studies have highlighted the importance of the PB2 protein in host-range restriction and temperature sensitivity of avian influenza viruses $(87,90,71)$. One amino acid in particular that has been shown to be important is at position 627. In avian viruses, this residue is highly conserved as a glutamic acid (E), but in human viruses, it is a lysine $(\mathrm{K})$.

Position 627 does not reside in an identified functional domain or subunit binding site of the PB2 protein, but it is proposed to be involved in a conformational change which alters the ability of the complex to function in mammalian cells (94). It has been shown that the replication of avian viruses is severely restricted in mammalian cells at lower temperatures when there is an E at position 627 of PB2, but that an E627K mutation abrogates this temperature sensitivity and is considered a necessary mutation for the successful establishment of an avian influenza virus in mammals (87). Avian viruses containing the E627K mutation also have an increased ability to replicate in the nasal turbinates of mice (49). Interestingly, the PB2 of triple reassortant swine viruses is of avian origin, and has retained an $\mathrm{E}$ at position 627 , yet is still able to replicate in mammalian cells across a range of temperatures. This suggests compensatory effects from other changes in the polymerase complex. Chen, et al showed that an avian/human reassortant influenza virus containing an avian PB2 gene with human internal genes had a low rescue efficiency and formed small plaques. However, when the human PA was replaced with an avian PA, the rescue efficiency and growth of the virus was improved (21), indicating that both the PA and PB2 of the triple reassortant lineage of swine influenza may be responsible for the enhanced replication efficiency across all tested temperatures.

At physiological temperatures $\left(33^{\circ} \mathrm{C}\right.$ and $\left.39^{\circ} \mathrm{C}\right)$, triple reassortant swine influenza viruses have an early replicative advantage over other swine influenza viruses, and this advantage may explain their success in the swine population. Reverse genetics studies with triple reassortant viruses containing only the PA or PB2 of avian origin will be necessary to determine if both genes are required for the success of the triple reassortant viruses. Reassortant swine viruses also contain a human-origin PB1 which may play a role in their success. This question could be addressed by replacing the human-origin PB1 gene with a classical swine-origin PB1 gene through reverse genetics.

The replicative advantage of triple reassortant viruses in vitro was not observed in vivo. Although one of the pigs infected with the classical H1N1 virus SW/MN/99 showed a delayed onset of virus shedding and lower viral titers, we believe this to be due to a lack of initial infection and transmission of the virus between cubicles during nasal swabbing. While the number of pigs used is low, this does not appear to represent a disadvantage of classical swine viruses, as the virus was able to establish successful infection in all four pigs. However, experimental intranasal infection with low levels of virus does not mimic natural infection in pigs. Intratracheal infection with high 
inoculums is required to observe clinical symptoms, as much of the pathology is linked to viral titers in the lungs of infected pigs $(105,139)$. Lung pathology was not examined, and virus was not isolated from the trachea or bronchial tissue, so the viruses may differ in their replication in the lower respiratory tract. Differences in viral fitness may only become apparent following the co-infection of pigs with both a classical and reassortant swine influenza virus.

Along with the polymerase complex, the HA of influenza viruses plays an essential role in the success of a virus in a host. Because ferrets show similar patterns of cell receptors and of clinical disease as humans when infected with influenza viruses $(85,140)$, they are a good model to examine the potential threat of a novel influenza virus to the human population. Three triple reassortant swine viruses which were used to inoculate ferrets showed different growth and replication kinetics. SW/TX/98 and $\mathrm{SW} / \mathrm{NC} / 05$, which both have human-origin HA and NA replicated to high titers and transmitted efficiently. SW/NC/02, which has a classical swine lineage HA and NA, did not replicate as well in ferrets and contact ferrets did not shed virus, although they did seroconvert. This contrasts with data from ferrets infected with the pandemic strain of $\mathrm{H} 1 \mathrm{~N} 1$, also a swine-origin reassortant influenza virus. This virus also contains a classical swine-origin HA, yet it replicates and transmits efficiently in ferrets $(86,96)$. Viral titers were determined in eggs and the seroconversion of all contact ferrets with a lack of detectable viral titers, along with the low viral titers observed in infected animals may reflect a defect in the virus's ability to replicate in eggs.

The success of an influenza A virus in a particular host cannot be attributed to a single gene or protein, although the polymerase complex is a major determinant of viral fitness. Through multiple reassortment events, the triple reassortant lineage of swine influenza A viruses obtained an internal gene constellation that has allowed it to become the dominant influenza lineage in North American swine. While the specific mechanisms responsible for the generation and continued success of these viruses remain to be fully determined, it is clear that viruses belonging to this lineage have a replicative advantage over classical swine influenza viruses both in vitro and in vivo and will continue to pose a pandemic threat as they evolve. 


\section{CHAPTER 5: GENERAL DISCUSSION}

Swine are an important host in the ecology of influenza A viruses, as they are susceptible to both mammalian and avian influenza viruses and are able to transmit influenza to humans $(52,64,97)$. They have long been proposed as a mixing vessel for influenza A viruses, providing a host in which avian and mammalian origin viruses can exchange gene segments. While no direct evidence exists to support the emergence of the 1957 and 1968 pandemic viruses from swine, the swine origin of the 2009 H1N1 pandemic virus suggests a critical role for pigs in the generation of pandemic influenza viruses (33).

Swine influenza viruses in North America have evolved rapidly since the introduction of the triple reassortant lineage in 1998, despite their stability for the previous 80 years (143). The introduction of avian-origin gene segments appears to have a significant impact on the dynamics of influenza in swine, a situation observed both in Europe following the introduction of a wholly-avian strain (10), and in North America following the introduction of the triple reassortant lineage containing avian-origin PA and PB2 genes (143). These studies examined the properties of reassortant swine influenza A viruses to better understand why they are able to acquire new HA genes so readily, why they have been so successful in pigs, and if they pose a further pandemic threat to humans.

Influenza A viruses cause yearly epidemics in the human population. Each year during the winter months, influenza infection causes 114,000 hospitalizations (9) and 36,000 deaths (135) in the United States. In the last 100 years, 4 influenza A viruses have emerged which caused worldwide pandemics. A pandemic influenza virus is one that contains an HA to which there is little or no immunity in the population, is capable of sustained human-to-human transmission, and is characterized by higher than average morbidity worldwide $(152,65)$. The first criteria for the emergence of a pandemic influenza virus is an antigenic shift, or the introduction of a virus containing an HA to which the population has little or no immunity (65). This most often occurs through reassortment. Successful reassortment is dependent on four factors: infection, replication, packaging, and fitness.

Reassortant viruses were responsible for human influenza pandemics in 1918, 1957, and 1968, as well as the newly-emerged 2009 H1N1 pandemic (127). The 1957 and 1968 pandemic viruses were created through the reassortment of human and avian viruses, while the 1918 pandemic is now proposed to have been created through multiple reassortments between human, avian, and swine influenza viruses $(127,33)$. The 2009 H1N1 pandemic strain is the result of a reassortment event between a North American triple reassortant swine virus and a Eurasian swine virus, and contains five of the six TRIG cassette segments (33). While North American triple reassortant swine viruses have been sporadically isolated from infected humans (124), this virus was the first with confirmed human-to-human transmission (99). 
One of the main determinants of the ability of an influenza virus to infect a cell is receptor binding. Epithelial cells in the avian intestinal tract contain predominantly $\alpha-2,3$ linked sialyloligosaccharides, and the HAs on the surface of avian lineage influenza viruses preferentially recognize these receptors $(52,53)$. Epithelial cells in the human respiratory tract contain predominantly $\alpha-2,6$ linked sialyloligosaccharides and the HAs on the surface of human lineage influenza viruses preferentially recognize these receptors $(29,30)$. Epithelial cells in the respiratory tract of pigs contain both $\alpha-2,3$ and $\alpha-2,6$ linked sialyloligosaccharides, making them susceptible to infection with both avian and mammalian influenza viruses (52). However, successful reassortment requires not only the dual infection of the same host, but co-infection of the same cell in that host. Although it is known that the swine respiratory tract contains both avian and human influenza receptors, their distribution in the respiratory tract has not been shown, and it is not known if they are present on the same cells. It has been demonstrated that the human respiratory tract does contain cells expressing $\alpha-2,3$ linked receptors, but that these cells are lower in the respiratory tract and are expressed by a different cell type than those that express the more common $\alpha-2,6$ linked receptors (92). The absence of both receptor linkages on the same cell does not preclude co-infection however, as growth in pigs has been shown to be sufficient to change the receptor specificity of an influenza virus HA from $\alpha-2,3$ to $\alpha-2,6(52)$. It is possible that this change must occur before an avian influenza virus could infect the same cell as and reassort with a mammalian-origin virus.

Once two viruses have infected the same cell, their genomes must both be replicated in order for reassortment to occur. These studies showed that human and swine-origin viruses are able to replicate in pigs, and previous studies have supported these findings as well as demonstrating that avian viruses are also able to replicate in pigs (64). While viruses of human, swine, and avian lineage are all able to replicate in pigs individually, it is not known if replication of one virus interferes with the replication of another virus in vivo. In vitro studies showed that co-infection of MDCK cells with an avian virus and a classical swine virus resulted in a lack of replication of the swine influenza virus genome, but this effect was only observed when a very high MOI of the avian virus was used and both viruses were added simultaneously (118). Neither of these conditions is likely to be met in vivo, and the mechanism responsible for this inhibition has not been determined.

Following replication of the viral genomes, one of each of the eight gene segments of an influenza A virus must be packaged into a new virus particle. Newly synthesized vRNA molecules must associate with PB2, PB1, PA, and NP for the formation of new vRNPs and exportation from the nucleus into the cell cytoplasm. These vRNPs then interact with M1 and the cell cytoskeleton to be transported to areas of the membrane containing high concentrations of HA and NA proteins $(103,37,12)$. If any of these interactions are negatively impacted by the origin of the vRNA or vRNP proteins, then reassortment may be impaired. The selective packaging of vRNPs into new virus particles is dependent on short conserved regions in the 3' and 5' coding regions of each segment $(79,146,40,41)$. These regions are thought to interact with each other or with viral proteins to allow for the selection of one copy of each gene segment (89). Changes in secondary structure of the RNA or conformational changes in proteins may lead to 
preferential packaging of gene segments from one parental strain over another, limiting or preventing reassortment. Assuming two viruses of different lineages are able to infect, replicate in, and be packaged together into new viral particles in the same cell, reassortant viruses will still not be detected if the progeny virus is not more fit than the parental strains. Many factors impact viral fitness, including polymerase efficiency and the ability of the HA to evade the host immune system $(117,119,147)$.

Comparison of triple reassortant swine viruses to double reassortant and classical swine viruses revealed that triple reassortant lineage viruses are less temperature sensitive than classical swine viruses and human viruses. This could allow for replication in areas of the respiratory tract inhospitable to other swine influenza viruses and possibly increase the chance of replication in the same tissues as a human or avian virus. Location of replication is not the sole explanation for reassortment, however, as co-infections in tissue culture resulted in no reassortment between classical swine and human viruses. Reassortant swine viruses were more efficient at establishing infection, with increased growth kinetics in MDCK cells at 12 hours post-infection. They are also better able to establish infection in swine. This "jump-start" in replication allows these viruses to outcompete non-reassortant viruses, explaining the disappearance of the classical swine influenza virus, and the lack of detection of wholly-avian $\mathrm{H} 2$ viruses in the swine population. Whether the 2009 pandemic H1N1 strain replaces the currently circulating human epidemic strains is yet to be determined, but during the southern hemisphere flu season, the pandemic strain was dominant (137).

The introduction of an influenza virus containing the TRIG cassette into the human population raises several concerns. Epidemiological data has suggested, and this study has shown, that a swine virus containing the TRIG cassette has a greater reassortment potential than a classical swine influenza virus. When MDCK cells were co-infected with a TRIG virus and a human $\mathrm{H} 3 \mathrm{~N} 2$ virus, reassortant viruses containing the TRIG with human HA were readily detected. This increases the possibility of the introduction of multiple subtypes of HA into the swine population and possibly the human population. While avian influenza viruses do not usually initiate successful infection in humans, they readily infect pigs (64), and the isolation in 2006 of a virus containing avian-origin $\mathrm{H} 2$ and $\mathrm{N} 3$ genes on the TRIG backbone has shown that TRIG viruses are not only able to successfully acquire mammalian-origin surface glycoproteins, but avian-origin HA and NA genes as well (84).

After a virus with a novel HA has been created, it must be able to infect and transmit between humans in order to cause a pandemic. The ability of an influenza A virus to successfully infect a human host is largely dependent on HA receptor specificity and polymerase activity. As mentioned, the epithelial cells of the human respiratory epithelial tract contain predominantly $\alpha-2,6$ linked receptors, so a virus containing an HA which preferentially binds these receptors will be more likely to infect a human than one containing an HA which preferentially binds $\alpha-2,3$ linked receptors. An HA with $\alpha-2,6$ receptor specificity also appears to be necessary for effective aerosol transmission of an influenza virus between humans, but is not sufficient to confer aerosol transmissibility to an avian virus (145). In addition to receptor specificity, the viral polymerase complex 
must be able to efficiently replicate the viral genome in a host cell. PB2 has been shown to be a major host-range determinant. Avian viruses have a conserved glutamic acid reside at position 627, while human viruses have a lysine (130). Human cells have been shown to inhibit the activity of the polymerase complex of avian-origin viruses containing a glutamic acid residue at position 627 (94) and the substitution of lysine for glutamic acid improves the replication of avian viruses in mammalian cells (90) and increases the pathogenicity of highly pathogenic avian H5N1 viruses in mice (48). Because position 627 of PB2 is not located in a known catalytic or subunit interaction site, it is proposed that the mechanism controlling polymerase activity is a conformational change that affects interactions between the polymerase complex and the vRNA molecules (94). Interestingly, the presence of a lysine residue at PB2 627 is not necessary for the efficient replication of avian influenza viruses in pigs, as swine influenza viruses have maintained a glutamic acid residue at position 627 of PB2. Additionally, the $2009 \mathrm{H} 1 \mathrm{~N} 1$ pandemic strain also contains glutamic acid rather than lysine at position 627, indicating that other genes of the TRIG cassette may have compensatory changes that allow for efficient replication of the virus in humans.

This study has shown that TRIG viruses are not only able to successfully acquire avian HA and NA genes, but also to support the adaptation of the HA receptor binding site from an avian-like preference to a human-like preference. A single amino acid change in the receptor binding site of the HA of $\mathrm{H} 2$ appears to be responsible for the virus's ability to transmit through direct contact in ferrets. It is not yet known if $\mathrm{SW} / \mathrm{MO} / 06$ is capable of aerosol transmission, or what changes might be necessary to confer that ability. While an influenza virus needs to be able to transmit by aerosol to be a pandemic threat to the human population (65), direct contact is sufficient to allow the virus to spread through a swine herd, and the adaptations required to make the virus transmit by aerosol is still unknown. In the case of the 1918 pandemic, only two amino acid changes in the HA could abolish aerosol transmission of the virus (136).

The ability of viruses containing the TRIG cassette to acquire avian surface glycoproteins could also lead to the production of a virus containing the HA and NA from a highly pathogenic avian influenza virus. Highly pathogenic H5N1 influenza viruses have not become successfully established in the swine or human populations (80), and serological studies have shown that the infection rate of swine with $\mathrm{H} 5 \mathrm{~N} 1$ viruses is low (24), limiting the opportunity for reassortment with a triple reassortant swine virus. However, now that a virus containing most of the TRIG cassette is widely circulating in the human population, there is the possibility of reassortment with an $\mathrm{H} 5$ virus in humans. However, the TRIG cassette is not the only mechanism responsible for the success of reassortant viruses. In the ferret model, HA greatly influenced the transmissibility of triple reassortant lineage viruses, with viruses containing human-origin HA and NA genes replicating and transmitting more efficiently than one containing swine-origin HA and NA genes.

Although reassortment has been involved in the generation of recent pandemic strains, relatively little is known about the mechanisms controlling reassortment and the successful establishment of a new virus in a population. There are many questions which 
remain to be answered in order to fully understand the success of triple reassortant swine influenza viruses. The TRIG cassette is a constellation of six gene segments of swine, human, and avian origin. Studies are needed to determine if this specific combination of gene segments is required both for successful reassortment and for increased replication efficiency. While viral polymerase activity has been implicated in the adaptation of avian viruses to mammalian hosts (42), the polymerase activity of the avian PA and PB2 in the TRIG cassette has not been compared to that of human or classical swine influenza viruses. Additionally, while viruses containing the TRIG cassette have been shown to have increased fitness in cell culture, it has not been demonstrated that they have increased fitness in pigs, although the disappearance of the classical swine influenza lineage suggests reassortant viruses have an advantage over the classical swine lineage in vivo as well.

Although epidemiological data has shown that TRIG viruses can successfully acquire human $\mathrm{H} 1$ and $\mathrm{H} 3$, swine $\mathrm{H} 1$, and avian $\mathrm{H} 2$ glycoproteins, it has not yet been determined if they are capable of acquiring HAs of other subtypes, including highly pathogenic $\mathrm{H} 5$ and $\mathrm{H} 7$. Also, the virulence of such reassortant viruses could vary greatly, as the polymerase complex of $\mathrm{H} 5 \mathrm{~N} 1$ viruses has been shown to be partially responsible for their high level of pathogenicity in ferrets (119), and H5N1 viruses isolated from pigs have reduced virulence in mice (131). Acquisition of a novel HA is not sufficient for the emergence of a new pandemic strain, as the virus must also be capable of sustained human to human transmission (65). The viral adaptations necessary for aerosol transmission of an influenza virus in humans remain to be determined.

Triple reassortant lineage influenza viruses have several unique characteristics which distinguishes them from other influenza A viruses. They are highly successful at causing infection in swine, they are able to replicate at a broader range of temperatures in vitro, and they have an increased potential for acquisition of HA genes from different influenza viruses. The maintenance of previously circulating human HA genes in the swine population also raises the possibility of the re-introduction of these viruses into the human population after immunity has waned. The ease with which triple reassortant lineage viruses can acquire new HA genes combined with the ability of swine to act as an intermediate host and transmit influenza to humans highlights the need for continued swine influenza surveillance. 


\section{LIST OF REFERENCES}

1. Amaya, J.N. June 25, 2009, A/H1N1 influenza, Argentina. http://www.oie.int/wahis/public.php?page $=$ single_report\&pop=1\&reportid=8227. Accessed October 12, 2009.

2. Baigent, S.J. and J.W. McCauley. 2003. Influenza type A in humans, mammals and birds: determinants of virus virulence, host-range and interspecies transmission. Bioessays. 25:657-671.

3. Bancroft, C.T. and T.G. Parslow. 2002. Evidence for segment-nonspecific packaging of the influenza a virus genome. J. Virol. 76:7133-7139.

4. Barbey-Morel, C.L., T.N. Oeltmann, K.M. Edwards, and P.F. Wright. 1987. Role of respiratory tract proteases in infectivity of influenza A virus. J. Infect. Dis. 155:667-672.

5. Barry, J.M., C. Viboud, and L. Simonsen. 2008. Cross-protection between successive waves of the 1918-1919 influenza pandemic: epidemiological evidence from US Army camps and from Britain. J. Infect. Dis. 198:1427-1434.

6. Bergmann, M., A. Garcia-Sastre, E. Carnero, H. Pehamberger, K. Wolff, P. Palese, and T. Muster. 2000. Influenza virus NS1 protein counteracts PKRmediated inhibition of replication. J. Virol. 74:6203-6206.

7. Braam, J., I. Ulmanen, and R.M. Krug. 1983. Molecular model of a eucaryotic transcription complex: functions and movements of influenza $P$ proteins during capped RNA-primed transcription. Cell. 34:609-618.

8. Bradel-Tretheway, B.G., Z. Kelley, S. Chakraborty-Sett, T. Takimoto, B. Kim, and S. Dewhurst. 2008. The human H5N1 influenza A virus polymerase complex is active in vitro over a broad range of temperatures, in contrast to the WSN complex, and this property can be attributed to the PB2 subunit. J. Gen. Virol. 89:2923-2932.

9. Bridges, C.B., W.W. Thompson, M.I. Meltzer, G.R. Reeve, W.J. Talamonti, N.J. Cox, H.A. Lilac, H. Hall, A. Klimov, and K. Fukuda. 2000. Effectiveness and cost-benefit of influenza vaccination of healthy working adults: A randomized controlled trial. JAMA. 284:1655-1663.

10. Brown, I.H. 2000. The epidemiology and evolution of influenza viruses in pigs. Vet. Microbiol. 74:29-46.

11. Brown, I.H., P.A. Harris, J.W. McCauley, and D.J. Alexander. 1998. Multiple genetic reassortment of avian and human influenza A viruses in European pigs, resulting in the emergence of an H1N2 virus of novel genotype. J. Gen. Virol. 79 (Pt 12):2947-2955. 
12. Bui, M., E.G. Wills, A. Helenius, and G.R. Whittaker. 2000. Role of the influenza virus M1 protein in nuclear export of viral ribonucleoproteins. J. Virol. 74:1781-1786.

13. Campitelli, L., I. Donatelli, E. Foni, M.R. Castrucci, C. Fabiani, Y. Kawaoka, S. Krauss, and R.G. Webster. 1997. Continued evolution of H1N1 and H3N2 influenza viruses in pigs in Italy. Virology. 232:310-318.

14. Carroll, A. July 31, 2009, Influenza A subtype H1, Australia. http://www.oie.int/wahis/public.php?page=single_report\&pop=1\&reportid=8332. Accessed October 12, 2009.

15. Castrucci, M.R., L. Campitelli, A. Ruggieri, G. Barigazzi, L. Sidoli, R. Daniels, J.S. Oxford, and I. Donatelli. 1994. Antigenic and sequence analysis of H3 influenza virus haemagglutinins from pigs in Italy. J. Gen. Virol. 75 ( Pt 2):371379.

16. Castrucci, M.R., I. Donatelli, L. Sidoli, G. Barigazzi, Y. Kawaoka, and R.G. Webster. 1993. Genetic reassortment between avain and human influenza A viruses in Italian pigs. Virology. 193:503-506.

17. CDC. 2009. Update: influenza activity--United States, April-August 2009. MMWR Morb. Mortal. Wkly. Rep. 58:1009-1012.

18. Chambers, T.M., V.S. Hinshaw, Y. Kawaoka, B.C. Easterday, and R.G. Webster. 1991. Influenza viral infection of swine in the United States 1988-1989. Arch. Virol. 116:261-265.

19. Chan, M.C. June 11, 2009, World now at the start of 2009 influenza pandemic. http://www.who.int/mediacentre/news/statements/2009/h1n1 pandemic phase6 20 090611/en/index.html. Accessed September 28, 2009.

20. Chen, J., K.H. Lee, D.A. Steinhauer, D.J. Stevens, J.J. Skehel, and D.C. Wiley. 1998. Structure of the hemagglutinin precursor cleavage site, a determinant of influenza pathogenicity and the origin of the labile conformation. Cell. 95:409-417.

21. Chen, L.M., C.T. Davis, H. Zhou, N.J. Cox, and R.O. Donis. 2008. Genetic compatibility and virulence of reassortants derived from contemporary avian H5N1 and human H3N2 influenza A viruses. PLoS. Pathog. 4:doi:10.1371/journal.ppat.1000072.

22. Chen, W., P.A. Calvo, D. Malide, J. Gibbs, U. Schubert, I. Bacik, S. Basta, R. O'Neill, J. Schickli, P. Palese, P. Henklein, J.R. Bennink, and J.W. Yewdell. 2001. A novel influenza A virus mitochondrial protein that induces cell death. Nat. Med. 7:1306-1312.

23. Choi, Y.K., S.M. Goyal, and H.S. Joo. 2002. Prevalence of swine influenza virus subtypes on swine farms in the United States. Arch. Virol. 147:1209-1220. 
24. Choi, Y.K., T.D. Nguyen, H. Ozaki, R.J. Webby, P. Puthavathana, C. Buranathal, A. Chaisingh, P. Auewarakul, N.T. Hanh, S.K. Ma, P.Y. Hui, Y. Guan, J.S. Peiris, and R.G. Webster. 2005. Studies of H5N1 influenza virus infection of pigs by using viruses isolated in Vietnam and Thailand in 2004. J. Virol. 79:10821-10825.

25. Chutinimitkul, S., N. Thippamom, S. Damrongwatanapokin, S. Payungporn, R. Thanawongnuwech, A. Amonsin, P. Boonsuk, D. Sreta, N. Bunpong, R. Tantilertcharoen, P. Chamnanpood, S. Parchariyanon, A. Theamboonlers, and Y. Poovorawan. 2008. Genetic characterization of H1N1, H1N2 and H3N2 swine influenza virus in Thailand. Arch. Virol. 153:1049-1056.

26. Clifford, J. November 3, 2009, 2009 pandemic A/H1N1 influenza, United States of America.

http://www.oie.int/wahis/public.php?page=single report\&pop=1\&reportid=8613. Accessed November 12, 2009.

27. Compans, R.W., H. Meier-Ewert, and P. Palese. 1974. Assembly of lipidcontaining viruses. J. Supramol. Struct. 2:496-511.

28. Cong, Y.L., J. Pu, Q.F. Liu, S. Wang, G.Z. Zhang, X.L. Zhang, W.X. Fan, E.G. Brown, and J.H. Liu. 2007. Antigenic and genetic characterization of H9N2 swine influenza viruses in China. J. Gen. Virol. 88:2035-2041.

29. Connor, R.J., Y. Kawaoka, R.G. Webster, and J.C. Paulson. 1994. Receptor specificity in human, avian, and equine $\mathrm{H} 2$ and $\mathrm{H} 3$ influenza virus isolates. Virology. 205:17-23.

30. Couceiro, J.N., J.C. Paulson, and L.G. Baum. 1993. Influenza virus strains selectively recognize sialyloligosaccharides on human respiratory epithelium; the role of the host cell in selection of hemagglutinin receptor specificity. Virus Res. 29:155-165.

31. Cox, N.J., H.F. Maassab, and A.P. Kendal. 1979. Comparative studies of wildtype and cold-mutant (temperature-sensitive) influenza viruses: nonrandom reassortment of genes during preparation of live virus vaccine candidates by recombination at 25 degrees between recent $\mathrm{H} 3 \mathrm{~N} 2$ and H1N1 epidemic strains and cold-adapted A/An Arbor/6/60. Virology. 97:190-194.

32. Cross, K.J., W.A. Langley, R.J. Russell, J.J. Skehel, and D.A. Steinhauer. 2009. Composition and functions of the influenza fusion peptide. Protein Pept. Lett. 16:766-778.

33. Dawood, F.S., S. Jain, L. Finelli, M.W. Shaw, S. Lindstrom, R.J. Garten, L.V. Gubareva, X. Xu, C.B. Bridges, and T.M. Uyeki. 2009. Emergence of a novel swine-origin influenza A (H1N1) virus in humans. N. Engl. J. Med. 360:2605-2615. 
34. Desselberger, U., K. Nakajima, P. Alfino, F.S. Pedersen, W.A. Haseltine, C. Hannoun, and P. Palese. 1978. Biochemical evidence that "new" influenza virus strains in nature may arise by recombination (reassortment). Proc. Natl. Acad. Sci. U. S. A. 75:3341-3345.

35. Duhaut, S.D. and J.W. McCauley. 1996. Defective RNAs inhibit the assembly of influenza virus genome segments in a segment-specific manner. Virology. 216:326337.

36. Easterday, B.C. and V.S. Hinshaw. 1992. Swine influenza, p. 349-357. In A.D. Leman, B.E. Straw, W.L. Mengeling, S.D. D'Allaire, and D.J. Taylor (ed.), Diseases of Swine, Iowa State Press, Ames, IA.

37. Elton, D., M. Simpson-Holley, K. Archer, L. Medcalf, R. Hallam, J. McCauley, and P. Digard. 2001. Interaction of the influenza virus nucleoprotein with the cellular CRM1-mediated nuclear export pathway. J. Virol. 75:408-419.

38. Evans, B. 2009, A/H1N1 influenza, Canada. http://www.oie.int/wahis/public.php?page=single_report\&pop=1\&reportid=8065. Accessed October 12, 2009.

39. Fouchier, R.A., V. Munster, A. Wallensten, T.M. Bestebroer, S. Herfst, D. Smith, G.F. Rimmelzwaan, B. Olsen, and A.D. Osterhaus. 2005.

Characterization of a novel influenza A virus hemagglutinin subtype (H16) obtained from black-headed gulls. J. Virol. 79:2814-2822.

40. Fujii, K., Y. Fujii, T. Noda, Y. Muramoto, T. Watanabe, A. Takada, H. Goto, T. Horimoto, and Y. Kawaoka. 2005. Importance of both the coding and the segment-specific noncoding regions of the influenza A virus NS segment for its efficient incorporation into virions. J. Virol. 79:3766-3774.

41. Fujii, Y., H. Goto, T. Watanabe, T. Yoshida, and Y. Kawaoka. 2003. Selective incorporation of influenza virus RNA segments into virions. Proc. Natl. Acad. Sci. U. S. A. 100:2002-2007.

42. Gabriel, G., B. Dauber, T. Wolff, O. Planz, H.D. Klenk, and J. Stech. 2005. The viral polymerase mediates adaptation of an avian influenza virus to a mammalian host. Proc. Natl. Acad. Sci. U. S. A. 102:18590-18595.

43. Garcia-Sastre, A. 2005. Interferon antagonists of influenza viruses, p. 95-114. In P. Palese (ed.), Modulation of Host Gene Expression and Innate Immunity by Viruses, Springer, Dordrecht.

44. Gaydos, J.C., F.H. Top, Jr., R.A. Hodder, and P.K. Russell. 2006. Swine influenza a outbreak, Fort Dix, New Jersey, 1976. Emerg. Infect. Dis. 12:23-28.

45. Gibbens, N. September 18, 2009, Pandemic influenza A H1N1 (2009), United Kingdom. 
http://www.oie.int/wahis/public.php?page=single_report\&pop=1\&reportid=8451. Accessed October 12, 2009.

46. Gray, G.C., T. McCarthy, A.W. Capuano, S.F. Setterquist, C.W. Olsen, and M.C. Alavanja. 2007. Swine workers and swine influenza virus infections. Emerg. Infect. Dis. 13:1871-1878.

47. Harvey, R., A.C. Martin, M. Zambon, and W.S. Barclay. 2004. Restrictions to the adaptation of influenza a virus $\mathrm{H} 5$ hemagglutinin to the human host. J. Virol. 78:502-507.

48. Hatta, M., P. Gao, P. Halfmann, and Y. Kawaoka. 2001. Molecular basis for high virulence of Hong Kong H5N1 influenza A viruses. Science. 293:1840-1842.

49. Hatta, M., Y. Hatta, J.H. Kim, S. Watanabe, K. Shinya, T. Nguyen, P.S. Lien, Q.M. Le, and Y. Kawaoka. 2007. Growth of H5N1 influenza A viruses in the upper respiratory tracts of mice. PLoS. Pathog. 3:1374-1379.

50. Hinshaw, V.S., W.J. Bean, Jr., R.G. Webster, and B.C. Easterday. 1978. The prevalence of influenza viruses in swine and the antigenic and genetic relatedness of influenza viruses from man and swine. Virology. 84:51-62.

51. Hoffmann, E., G. Neumann, Y. Kawaoka, G. Hobom, and R.G. Webster. 2000. A DNA transfection system for generation of influenza A virus from eight plasmids. Proc. Natl. Acad. Sci. U. S. A. 97:6108-6113.

52. Ito, T., J.N. Couceiro, S. Kelm, L.G. Baum, S. Krauss, M.R. Castrucci, I. Donatelli, H. Kida, J.C. Paulson, R.G. Webster, and Y. Kawaoka. 1998. Molecular basis for the generation in pigs of influenza A viruses with pandemic potential. J. Virol. 72:7367-7373.

53. Ito, T., Y. Suzuki, L. Mitnaul, A. Vines, H. Kida, and Y. Kawaoka. 1997. Receptor specificity of influenza A viruses correlates with the agglutination of erythrocytes from different animal species. Virology. 227:493-499.

54. Jung, T., C. Choi, and C. Chae. 2002. Localization of swine influenza virus in naturally infected pigs. Vet. Pathol. 39:10-16.

55. Kalthoff, D., A. Globig, and M. Beer. 2009. (Highly pathogenic) avian influenza as a zoonotic agent. Vet. Microbiol.

56. Karasin, A.I., I.H. Brown, S. Carman, and C.W. Olsen. 2000. Isolation and characterization of H4N6 avian influenza viruses from pigs with pneumonia in Canada. J. Virol. 74:9322-9327.

57. Karasin, A.I., S. Carman, and C.W. Olsen. 2006. Identification of human H1N2 and human-swine reassortant H1N2 and H1N1 influenza A viruses among pigs in Ontario, Canada (2003 to 2005). J. Clin. Microbiol. 44:1123-1126. 
58. Karasin, A.I., C.W. Olsen, and G.A. Anderson. 2000. Genetic characterization of an H1N2 influenza virus isolated from a pig in Indiana. J. Clin. Microbiol. 38:24532456.

59. Karasin, A.I., C.W. Olsen, I.H. Brown, S. Carman, M. Stalker, and G. Josephson. 2000. H4N6 influenza virus isolated from pigs in Ontario. Can. Vet. J. 41:938-939.

60. Karasin, A.I., M.M. Schutten, L.A. Cooper, C.B. Smith, K. Subbarao, G.A. Anderson, S. Carman, and C.W. Olsen. 2000. Genetic characterization of H3N2 influenza viruses isolated from pigs in North America, 1977-1999: evidence for wholly human and reassortant virus genotypes. Virus Res. 68:71-85.

61. Karasin, A.I., K. West, S. Carman, and C.W. Olsen. 2004. Characterization of avian H3N3 and H1N1 influenza A viruses isolated from pigs in Canada. J. Clin. Microbiol. 42:4349-4354.

62. Kawaoka, Y., N. Cox, O. Haller, S. Hongo, N. Kaverin, H.D. Klenk, R.A. Lamb, J. McCauley, P. Palese, E. Rimstad, and R.G. Webster. 2005. Orthomyxoviridae, p. 681-693. In C. Fauquet, M. Mayo, J. Maniloff, U. Desselberger, and L. Ball (ed.), Virus Taxonomy: VIIIth Report of the International Committee on Taxonomy of Viruses., Elsevier Academic Press, London.

63. Kendal, A.P. 1987. Epidemiologic implications of changes in the influenza virus genome. Am. J. Med. 82:4-14.

64. Kida, H., T. Ito, J. Yasuda, Y. Shimizu, C. Itakura, K.F. Shortridge, Y. Kawaoka, and R.G. Webster. 1994. Potential for transmission of avian influenza viruses to pigs. J. Gen. Virol. 75 ( Pt 9):2183-2188.

65. Kilbourne, E.D. 1977. Influenza pandemics in perspective. JAMA. 237:1225-1228.

66. Koen, J.S. 1919. A practical method for field diagnosis of swine diseases. Am. J. Vet. Med. 14:468-470.

67. Komadina, N., V. Roque, P. Thawatsupha, J. Rimando-Magalong, S. Waicharoen, E. Bomasang, P. Sawanpanyalert, M. Rivera, P. Iannello, A.C. Hurt, and I.G. Barr. 2007. Genetic analysis of two influenza A (H1) swine viruses isolated from humans in Thailand and the Philippines. Virus Genes. 35:161-165.

68. Krug, R.M. 1981. Priming of influenza viral RNA transcription by capped heterologous RNAs. Curr. Top. Microbiol. Immunol. 93:125-149.

69. Krug, R.M., F.V. Alonso-Caplen, I. Julkunen, and M. Katze. 1989. Expression and replication of the influenza virus genome, p. 89-152. In R.M. Krug (ed.), The Influenza Viruses, Plenum Press, New York. 
70. Kundin, W.D. 1970. Hong Kong A-2 influenza virus infection among swine during a human epidemic in Taiwan. Nature. 228:857-

71. Labadie, K., A.E. Dos Santos, M.A. Rameix-Welti, S. van der Werf, and N. Naffakh. 2007. Host-range determinants on the PB2 protein of influenza A viruses control the interaction between the viral polymerase and nucleoprotein in human cells. Virology. 362:271-282.

72. Lamb, R.A., L.J. Holsinger, and L.H. Pinto. 1994. The influenza A virus M2 ion channel protein and its role in the influenza virus life cycle, p. 303-321. In E. Wimmer (ed.), Receptor-Mediated Virus Entry into Cells, Cold Spring Harbor Press, Cold Spring Harbor.

73. Landolt, G.A., A.I. Karasin, M.M. Schutten, and C.W. Olsen. 2006. Restricted infectivity of a human-Lineage H3N2 influenza A virus in pigs is hemagglutinin and neuraminidase gene dependent. J. Clin. Microbiol. 44:297-301.

74. Lee, C.S., B.K. Kang, H.K. Kim, S.J. Park, B.K. Park, K. Jung, and D.S. Song. 2008. Phylogenetic analysis of swine influenza viruses recently isolated in Korea. Virus Genes. 37:168-176.

75. Leigh, M.W., R.J. Connor, S. Kelm, L.G. Baum, and J.C. Paulson. 1995. Receptor specificity of influenza virus influences severity of illness in ferrets. Vaccine. 13:1468-1473.

76. Li, C., M. Hatta, S. Watanabe, G. Neumann, and Y. Kawaoka. 2008. Compatibility among polymerase subunit proteins is a restricting factor in reassortment between equine H7N7 and human H3N2 influenza viruses. J. Virol. 82:11880-11888.

77. Li, M.L., B.C. Ramirez, and R.M. Krug. 1998. RNA-dependent activation of primer RNA production by influenza virus polymerase: different regions of the same protein subunit constitute the two required RNA-binding sites. EMBO J. 17:5844-5852.

78. Li, O.T., M.C. Chan, C.S. Leung, R.W. Chan, Y. Guan, J.M. Nicholls, and L.L. Poon. 2009. Full factorial analysis of mammalian and avian influenza polymerase subunits suggests a role of an efficient polymerase for virus adaptation. PLoS ONE. 4:doi:10.1371/journal.pone.0005658.

79. Liang, Y., Y. Hong, and T.G. Parslow. 2005. cis-Acting packaging signals in the influenza virus PB1, PB2, and PA genomic RNA segments. J. Virol. 79:1034810355.

80. Lipatov, A.S., Y.K. Kwon, L.V. Sarmento, K.M. Lager, E. Spackman, D.L. Suarez, and D.E. Swayne. 2008. Domestic pigs have low susceptibility to H5N1 highly pathogenic avian influenza viruses. PLoS Pathog. 4:doi:10.1371/journal.ppat.1000102. 
81. Liu, C., M.C. Eichelberger, R.W. Compans, and G.M. Air. 1995. Influenza type A virus neuraminidase does not play a role in viral entry, replication, assembly, or budding. J. Virol. 69:1099-1106.

82. Lubeck, M.D., P. Palese, and J.L. Schulman. 1979. Nonrandom association of parental genes in influenza A virus recombinants. Virology. 95:269-274.

83. Ma, W., M. Gramer, K. Rossow, and K.J. Yoon. 2006. Isolation and genetic characterization of new reassortant $\mathrm{H} 3 \mathrm{~N} 1$ swine influenza virus from pigs in the midwestern United States. J. Virol. 80:5092-5096.

84. Ma, W., A.L. Vincent, M.R. Gramer, C.B. Brockwell, K.M. Lager, B.H. Janke, P.C. Gauger, D.P. Patnayak, R.J. Webby, and J.A. Richt. 2007. Identification of H2N3 influenza A viruses from swine in the United States. Proc. Natl. Acad. Sci. U. S. A. 104:20949-20954.

85. Maher, J.A. and J. DeStefano. 2004. The ferret: an animal model to study influenza virus. Lab Anim (NY). 33:50-53.

86. Maines, T.R., A. Jayaraman, J.A. Belser, D.A. Wadford, C. Pappas, H. Zeng, K.M. Gustin, M.B. Pearce, K. Viswanathan, Z.H. Shriver, R. Raman, N.J. Cox, R. Sasisekharan, J.M. Katz, and T.M. Tumpey. 2009. Transmission and pathogenesis of swine-origin $2009 \mathrm{~A}(\mathrm{H} 1 \mathrm{~N} 1)$ influenza viruses in ferrets and mice. Science. 325:484-487.

87. Manzoor, R., Y. Sakoda, N. Nomura, Y. Tsuda, H. Ozaki, M. Okamatsu, and H. Kida. 2009. PB2 protein of a highly pathogenic avian influenza virus strain $\mathrm{A} /$ chicken/Yamaguchi/7/2004 (H5N1) determines its replication potential in pigs. J. Virol. 83:1572-1578.

88. Marozin, S., V. Gregory, K. Cameron, M. Bennett, M. Valette, M. Aymard, E. Foni, G. Barigazzi, Y. Lin, and A. Hay. 2002. Antigenic and genetic diversity among swine influenza A H1N1 and H1N2 viruses in Europe. J. Gen. Virol. 83:735-745.

89. Marsh, G.A., R. Rabadan, A.J. Levine, and P. Palese. 2008. Highly conserved regions of influenza a virus polymerase gene segments are critical for efficient viral RNA packaging. J. Virol. 82:2295-2304.

90. Massin, P., W.S. van der, and N. Naffakh. 2001. Residue 627 of PB2 is a determinant of cold sensitivity in RNA replication of avian influenza viruses. J. Virol. 75:5398-5404.

91. Matlin, K.S., H. Reggio, A. Helenius, and K. Simons. 1981. Infectious entry pathway of influenza virus in a canine kidney cell line. J. Cell Biol. 91:601-613. 
92. Matrosovich, M.N., T.Y. Matrosovich, T. Gray, N.A. Roberts, and H.D. Klenk. 2004. Human and avian influenza viruses target different cell types in cultures of human airway epithelium. Proc. Natl. Acad. Sci. U. S. A. 101:4620-4624.

93. McAuley, J.L., F. Hornung, K.L. Boyd, A.M. Smith, R. McKeon, J. Bennink, J.W. Yewdell, and J.A. McCullers. 2007. Expression of the 1918 influenza A virus PB1-F2 enhances the pathogenesis of viral and secondary bacterial pneumonia. Cell Host. Microbe. 2:240-249.

94. Mehle, A. and J.A. Doudna. 2008. An inhibitory activity in human cells restricts the function of an avian-like influenza virus polymerase. Cell Host. Microbe. 4:111122.

95. Mitnaul, L.J., M.N. Matrosovich, M.R. Castrucci, A.B. Tuzikov, N.V. Bovin, D. Kobasa, and Y. Kawaoka. 2000. Balanced hemagglutinin and neuraminidase activities are critical for efficient replication of influenza A virus. J. Virol. 74:60156020 .

96. Munster, V.J., W.E. de, J.M. van den Brand, S. Herfst, E.J. Schrauwen, T.M. Bestebroer, d. van, V, C.A. Boucher, M. Koopmans, G.F. Rimmelzwaan, T. Kuiken, A.D. Osterhaus, and R.A. Fouchier. 2009. Pathogenesis and transmission of swine-origin 2009 A(H1N1) influenza virus in ferrets. Science. 325:481-483.

97. Myers, K.P., C.W. Olsen, and G.C. Gray. 2007. Cases of swine influenza in humans: a review of the literature. Clin. Infect. Dis. 44:1084-1088.

98. Myers, K.P., C.W. Olsen, S.F. Setterquist, A.W. Capuano, K.J. Donham, E.L. Thacker, J.A. Merchant, and G.C. Gray. 2006. Are swine workers in the United States at increased risk of infection with zoonotic influenza virus? Clin. Infect. Dis. 42:14-20.

99. Naffakh, N. and S. van der Werf. 2009. April 2009: an outbreak of swine-origin influenza $\mathrm{A}(\mathrm{H} 1 \mathrm{~N} 1)$ virus with evidence for human-to-human transmission. Microbes. Infect. 11:725-728.

100. Nardelli, L., S. Pascucci, G.L. Gualandi, and P. Loda. 1978. Outbreaks of classical swine influenza in Italy in 1976. Zentralbl. Veterinarmed. B. 25:853-857.

101. National Institute of Allergy and Infectious Diseases. May 4, 2009, Timeline of human flu pandemics. http://www3.niaid.nih.gov/topics/Flu/Research/Pandemic/TimelineHumanPandemi cs.htm. Accessed October 21, 2009.

102. Nemeroff, M.E., X.Y. Qian, and R.M. Krug. 1995. The influenza virus NS1 protein forms multimers in vitro and in vivo. Virology. 212:422-428. 
103. Neumann, G., M.T. Hughes, and Y. Kawaoka. 2000. Influenza A virus NS2 protein mediates vRNP nuclear export through NES-independent interaction with hCRM1. EMBO J. 19:6751-6758.

104. Olsen, C.W. 2002. The emergence of novel swine influenza viruses in North America. Virus Res. 85:199-210.

105. Olsen, C.W., I.H. Brown, B.C. Easterday, and K. Van Reeth. 2006. Swine influenza, p. 469-482. In B.E. Straw, J.J. Zimmermann, S.D. D'Allaire, and D.J. Taylor (ed.), Diseases of Swine, 9th ed. Blackwell Publishing, Ames, IA.

106. Olsen, C.W., S. Carey, L. Hinshaw, and A.I. Karasin. 2000. Virologic and serologic surveillance for human, swine and avian influenza virus infections among pigs in the north-central United States. Arch. Virol. 145:1399-1419.

107. Peiris, J.S., Y. Guan, D. Markwell, P. Ghose, R.G. Webster, and K.F. Shortridge. 2001. Cocirculation of avian H9N2 and contemporary "human" H3N2 influenza A viruses in pigs in southeastern China: potential for genetic reassortment? J. Virol. 75:9679-9686.

108. Pensaert, M., K. Ottis, J. Vandeputte, M.M. Kaplan, and P.A. Bachmann. 1981. Evidence for the natural transmission of influenza A virus from wild ducts to swine and its potential importance for man. Bull. World Health Organ. 59:75-78.

109. Pinto, L.H., L.J. Holsinger, and R.A. Lamb. 1992. Influenza virus M2 protein has ion channel activity. Cell. 69:517-528.

110. Poole, E., D. Elton, L. Medcalf, and P. Digard. 2004. Functional domains of the influenza A virus PB2 protein: identification of NP- and PB1-binding sites. Virology. 321:120-133.

111. Poon, L.L., D.C. Pritlove, E. Fodor, and G.G. Brownlee. 1999. Direct evidence that the poly(A) tail of influenza A virus mRNA is synthesized by reiterative copying of a $U$ track in the virion RNA template. J. Virol. 73:3473-3476.

112. Rabadan, R., A.J. Levine, and M. Krasnitz. 2008. Non-random reassortment in human influenza A viruses. Influenza. Other Respi. Viruses. 2:9-22.

113. Reed, L.J. and H. Muench. 1938. A simple method of estimating fifty percent endpoint. Am. J. Hyg. 27:493-497.

114. Reid, A.H. and J.K. Taubenberger. 2003. The origin of the 1918 pandemic influenza virus: a continuing enigma. J. Gen. Virol. 84:2285-2292.

115. Rogan, P.J. September 29, 2009, Pandemic A/H1N1 2009 virus, Ireland. http://www.oie.int/wahis/public.php?page $=$ single report\&pop $=1 \&$ reportid $=8473$. Accessed October 12, 2009. 
116. Rogers, G.N. and J.C. Paulson. 1983. Receptor determinants of human and animal influenza virus isolates: differences in receptor specificity of the $\mathrm{H} 3$ hemagglutinin based on species of origin. Virology. 127:361-373.

117. Rolling, T., I. Koerner, P. Zimmermann, K. Holz, O. Haller, P. Staeheli, and G. Kochs. 2009. Adaptive mutations resulting in enhanced polymerase activity contribute to high virulence of influenza A virus in mice. J. Virol. 83:6673-6680.

118. Rott, R., M. Orlich, and C. Scholtissek. 1981. Intrinsic interference between swine influenza and fowl plague virus. Arch. Virol. 69:25-32.

119. Salomon, R., J. Franks, E.A. Govorkova, N.A. Ilyushina, H.L. Yen, D.J. HulsePost, J. Humberd, M. Trichet, J.E. Rehg, R.J. Webby, R.G. Webster, and E. Hoffmann. 2006. The polymerase complex genes contribute to the high virulence of the human H5N1 influenza virus isolate A/Vietnam/1203/04. J. Exp. Med. 203:689-697.

120. Scholtissek, C. 1990. Pigs as the "mixing vessel" for the creation of new pandemic influenza A viruses. Med. Principles Pract. 2:65-71.

121. Scholtissek, C., W. Rohde, H. Von, V, and R. Rott. 1978. On the origin of the human influenza virus subtypes H2N2 and H3N2. Virology. 87:13-20.

122. Scull, M.A., L. Gillim-Ross, C. Santos, K.L. Roberts, E. Bordonali, K. Subbarao, W.S. Barclay, and R.J. Pickles. 2009. Avian influenza virus glycoproteins restrict virus replication and spread through human airway epithelium at temperatures of the proximal airways. PLoS. Pathog.

5:doi:10.1371/journal.ppat.1000424.

123. Shapiro, G.I. and R.M. Krug. 1988. Influenza virus RNA replication in vitro: synthesis of viral template RNAs and virion RNAs in the absence of an added primer. J. Virol. 62:2285-2290.

124. Shinde, V., C.B. Bridges, T.M. Uyeki, B. Shu, A. Balish, X. Xu, S. Lindstrom, L.V. Gubareva, V. Deyde, R.J. Garten, M. Harris, S. Gerber, S. Vagoski, F. Smith, N. Pascoe, K. Martin, D. Dufficy, K. Ritger, C. Conover, P. Quinlisk, A. Klimov, J.S. Bresee, and L. Finelli. 2009. Triple-reassortant swine influenza A (H1) in humans in the United States, 2005-2009. N. Engl. J. Med. 360:2616-2625.

125. Shope, R.E. 1931. Swine influenza. III. Filtration experiments and aetiology. J. Exp. Med. 54:373-385.

126. Shortridge, K.F., R.G. Webster, W.K. Butterfield, and C.H. Campbell. 1977. Persistence of Hong Kong influenza virus variants in pigs. Science. 196:1454-1455.

127. Smith, G.J., J. Bahl, D. Vijaykrishna, J. Zhang, L.L. Poon, H. Chen, R.G. Webster, J.S. Peiris, and Y. Guan. 2009. Dating the emergence of pandemic influenza viruses. Proc. Natl. Acad. Sci. U. S. A. 106:11709-11712. 
128. Smith, G.J., D. Vijaykrishna, J. Bahl, S.J. Lycett, M. Worobey, O.G. Pybus, S.K. Ma, C.L. Cheung, J. Raghwani, S. Bhatt, J.S. Peiris, Y. Guan, and A. Rambaut. 2009. Origins and evolutionary genomics of the 2009 swine-origin H1N1 influenza A epidemic. Nature. 459:1122-1125.

129. Smith, H. and C. Sweet. 1988. Lessons for human influenza from pathogenicity studies with ferrets. Rev. Infect. Dis. 10:56-75.

130. Subbarao, E.K., W. London, and B.R. Murphy. 1993. A single amino acid in the PB2 gene of influenza A virus is a determinant of host range. J. Virol. 67:17611764 .

131. Takano, R., C.A. Nidom, M. Kiso, Y. Muramoto, S. Yamada, K. Shinya, Y. Sakai-Tagawa, and Y. Kawaoka. 2009. A comparison of the pathogenicity of avian and swine H5N1 influenza viruses in Indonesia. Arch. Virol. 154:677-681.

132. Takemae, N., S. Parchariyanon, S. Damrongwatanapokin, Y. Uchida, R. Ruttanapumma, C. Watanabe, S. Yamaguchi, and T. Saito. 2008. Genetic diversity of swine influenza viruses isolated from pigs during 2000 to 2005 in Thailand. Influenza. Other Respi. Viruses. 2:181-189.

133. Taubenberger, J.K., A.H. Reid, and T.G. Fanning. 2000. The 1918 influenza virus: a killer comes into view. Virology. 274:241-245.

134. Taubenberger, J.K., A.H. Reid, R.M. Lourens, R. Wang, G. Jin, and T.G. Fanning. 2005. Characterization of the 1918 influenza virus polymerase genes. Nature. 437:889-893.

135. Thompson, W.W., D.K. Shay, E. Weintraub, L. Brammer, N. Cox, L.J. Anderson, and K. Fukuda. 2003. Mortality associated with influenza and respiratory syncytial virus in the United States. JAMA. 289:179-186.

136. Tumpey, T.M., T.R. Maines, H.N. Van, L. Glaser, A. Solorzano, C. Pappas, N.J. Cox, D.E. Swayne, P. Palese, J.M. Katz, and A. Garcia-Sastre. 2007. A two-amino acid change in the hemagglutinin of the 1918 influenza virus abolishes transmission. Science. 315:655-659.

137. U.S.Department of Health and Human Services. August 26, 2009, Assessment of the 2009 influenza A (H1N1) pandemic on selected countries in the southern hemisphere: Argentina, Australia, Chile, New Zealand and Uruguay. http://www.flu.gov/professional/global/final.pdf. Accessed October 22, 2009.

138. Van Reeth, K. 2007. Avian and swine influenza viruses: our current understanding of the zoonotic risk. Vet. Res. 38:243-260.

139. Van Reeth, K., H. Nauwynck, and M. Pensaert. 1998. Bronchoalveolar interferon-alpha, tumor necrosis factor-alpha, interleukin-1, and inflammation 
during acute influenza in pigs: a possible model for humans? J. Infect. Dis. 177:1076-1079.

140. Van Riel, D., V.J. Munster, W.E. de, G.F. Rimmelzwaan, R.A. Fouchier, A.D. Osterhaus, and T. Kuiken. 2007. Human and avian influenza viruses target different cells in the lower respiratory tract of humans and other mammals. Am. J. Pathol. 171:1215-1223.

141. Vincent, A.L., K.M. Lager, B.H. Janke, M.R. Gramer, and J.A. Richt. 2008. Failure of protection and enhanced pneumonia with a US H1N2 swine influenza virus in pigs vaccinated with an inactivated classical swine $\mathrm{H} 1 \mathrm{~N} 1$ vaccine. Vet. Microbiol. 126:310-323.

142. Vincent, A.L., W. Ma, K.M. Lager, M.R. Gramer, J.A. Richt, and B.H. Janke. 2009. Characterization of a newly emerged genetic cluster of H1N1 and H1N2 swine influenza virus in the United States. Virus Genes. doi:10.1007/s11262-0090386-6.

143. Vincent, A.L., W. Ma, K.M. Lager, B.H. Janke, and J.A. Richt. 2008. Swine influenza viruses a North American perspective. Adv. Virus Res. 72:127-154.

144. Vreede, F.T., T.E. Jung, and G.G. Brownlee. 2004. Model suggesting that replication of influenza virus is regulated by stabilization of replicative intermediates. J. Virol. 78:9568-9572.

145. Wan, H., E.M. Sorrell, H. Song, M.J. Hossain, G. Ramirez-Nieto, I. Monne, J. Stevens, G. Cattoli, I. Capua, L.M. Chen, R.O. Donis, J. Busch, J.C. Paulson, C. Brockwell, R. Webby, J. Blanco, M.Q. Al-Natour, and D.R. Perez. 2008. Replication and transmission of H9N2 influenza viruses in ferrets: evaluation of pandemic potential. PLoS. ONE. 3:doi:10.1371/journal.pone.0002923.

146. Watanabe, T., S. Watanabe, T. Noda, Y. Fujii, and Y. Kawaoka. 2003. Exploitation of nucleic acid packaging signals to generate a novel influenza virusbased vector stably expressing two foreign genes. J. Virol. 77:10575-10583.

147. Watanabe, T., S. Watanabe, K. Shinya, J.H. Kim, M. Hatta, and Y. Kawaoka. 2009. Viral RNA polymerase complex promotes optimal growth of 1918 virus in the lower respiratory tract of ferrets. Proc. Natl. Acad. Sci. U. S. A. 106:588-592.

148. Webby, R.J., K. Rossow, G. Erickson, Y. Sims, and R. Webster. 2004. Multiple lineages of antigenically and genetically diverse influenza A virus co-circulate in the United States swine population. Virus Res. 103:67-73.

149. Webby, R.J., S.L. Swenson, S.L. Krauss, P.J. Gerrish, S.M. Goyal, and R.G. Webster. 2000. Evolution of swine H3N2 influenza viruses in the United States. J. Virol. 74:8243-8251. 
150. Webster, R.G. 1999. Influenza viruses (orthomyxoviridae): general features, p. 824-829. In R.G. Webster and A. Granoff (ed.), Encyclopedia of Virology, 2nd ed. Academic Press, New York.

151. Webster, R.G., W.J. Bean, O.T. Gorman, T.M. Chambers, and Y. Kawaoka. 1992. Evolution and ecology of influenza A viruses. Microbiol. Rev. 56:152-179.

152. World Health Organization. December 5, 2005, Avian influenza frequently asked questions. http://www.who.int/csr/disease/avian_influenza/avian_faqs/en/. Accessed October 22, 2009.

153. World Health Organization. May 3, 2009, Influenza A (H1N1) - update 11. http://www.who.int/csr/don/2009 05 03/en/index.html. Accessed May 22, 2009.

154. World Health Organization. June 24, 2009, Influenza A (H1N1) - update 53. http://www.who.int/csr/don/2009 06 24/en/index.html. Accessed September 25, 2009.

155. Wright, P.F., G. Neumann, and Y. Kawaoka. 2007. Orthomyxoviruses, p. 16921736. In D.M. Knipe and P.M. Howley (ed.), Field's Virology, 5th ed. Lippincott Williams and Wilkins, Philadelphia, PA.

156. Yu, H., R.H. Hua, T.C. Wei, Y.J. Zhou, Z.J. Tian, G.X. Li, T.Q. Liu, and G.Z. Tong. 2008. Isolation and genetic characterization of avian origin H9N2 influenza viruses from pigs in China. Vet. Microbiol. 131:82-92.

157. Yu, H., G.H. Zhang, R.H. Hua, Q. Zhang, T.Q. Liu, M. Liao, and G.Z. Tong. 2007. Isolation and genetic analysis of human origin $\mathrm{H} 1 \mathrm{~N} 1$ and $\mathrm{H} 3 \mathrm{~N} 2$ influenza viruses from pigs in China. Biochem. Biophys. Res. Commun. 356:91-96.

158. Zell, R., S. Motzke, A. Krumbholz, P. Wutzler, V. Herwig, and R. Durrwald. 2008. Novel reassortant of swine influenza H1N2 virus in Germany. J. Gen. Virol. 89:271-276.

159. Zhou, N.N., D.A. Senne, J.S. Landgraf, S.L. Swenson, G. Erickson, K. Rossow, L. Liu, K.J. Yoon, S. Krauss, and R.G. Webster. 2000. Emergence of H3N2 reassortant influenza A viruses in North American pigs. Vet. Microbiol. 74:47-58.

160. Zhou, N.N., D.A. Senne, J.S. Landgraf, S.L. Swenson, G. Erickson, K. Rossow, L. Liu, K. Yoon, S. Krauss, and R.G. Webster. 1999. Genetic reassortment of avian, swine, and human influenza A viruses in american pigs. J. Virol. 73:88518856.

161. Zhu, Q., H. Yang, W. Chen, W. Cao, G. Zhong, P. Jiao, G. Deng, K. Yu, C. Yang, Z. Bu, Y. Kawaoka, and H. Chen. 2008. A naturally occurring deletion in its NS gene contributes to the attenuation of an $\mathrm{H} 5 \mathrm{~N} 1$ swine influenza virus in chickens. J. Virol. 82:220-228. 


\section{VITA}

Christy Brockwell Staats was born in East Meadow, NY on February 3, 1983. She graduated from Bleckley County High School and Middle Georgia College in Cochran, GA in the spring of 2001. Following graduation, she enrolled at the University of Georgia and received her Bachelor of Science degree in Biochemistry and Molecular Biology in May 2003. She began her studies in the Interdisciplinary Program at the University of Tennessee Health Science Center in August 2003 and performed her dissertation research under the supervision of Dr. Richard Webby at St. Jude Children's Research Hospital. She received her PhD with a concentration in Molecular Sciences in December 2009. 